DIEGO BOGADO TOMASIELLO

\title{
Modelagem dinâmica espacial das \\ desigualdades de acessibilidade aos empregos
}

São Paulo 


\section{Modelagem dinâmica espacial das desigualdades de acessibilidade aos empregos}

\section{Versão Corrigida}

Tese apresentada à Escola Politécnica da Universidade de São Paulo para obtenção do título de Doutor em Ciências.

Área de concentração: Engenharia de Transportes

Subárea: Informações Espaciais

Orientadora: Profa. Dra. Mariana Abrantes Giannotti

São Paulo 
Autorizo a reprodução e divulgação total ou parcial deste trabalho, por qualquer meio convencional ou eletrônico, para fins de estudo e pesquisa, desde que citada a fonte.

Este exemplar foi revisado e corrigido em relação à versão original, sob responsabilidade única do autor e com a anuência de seu orientador.

São Paulo, de de

Assinatura do autor:

Assinatura do orientador:

\section{Catalogação-na-publicação}

Tomasiello, Diego Bogado

Modelagem dinâmica espacial das desigualdades de acessibilidade aos empregos / D. B. Tomasiello -- versão corr. -- São Paulo, 2020.

$111 \mathrm{p}$.

Tese (Doutorado) - Escola Politécnica da Universidade de São Paulo. Departamento de Engenharia de Transportes.

1.Acessibilidade aos empregos 2.Desigualdades 3.Modelagem baseada em agentes 4.Coeficiente Gini I.Universidade de São Paulo. Escola Politécnica. Departamento de Engenharia de Transportes II.t. 
À minha família e à minha companheira, que me apoiaram incondicionalmente ao longo do meu doutorado. 


\section{Agradecimentos}

À minha orientadora Profa. Dra. Mariana Abrantes Giannotti pela confiança em meu trabalho, inestimável apoio, motivação e por ser um modelo de profissional que vou buscar ser ao longo de minha carreira acadêmica;

À minha mãe Maria Bernadette, aos meu irmãos Rafael, Miguel e Marina e a minha companheira Clarice por terem me apoiado ao longo dos anos de doutorado;

À minha supervisora na Universidade de Melbourne, Profa. Dra. Patrícia Sauri Lavieri por todos os ensinamentos e orientações ao longo de meu período sanduíche;

À equipe do projeto RESOLUTION, em especial aos Professores Flávia Feitosa, Antônio Miguel Monteiro, Joana Barros e Pedro Andrade pelo aprendizado ao longo do projeto;

Ao Professor Karst Geurs e John Pritchard pelos ensinamentos e parceria acadêmica;

Às Professoras integrantes do projeto ASTRID, Adelaide Nardocci, Anne Slovic e Maria de Fátima Andrade pelos ensinamentos e parceria ao longo dos trabalhos acadêmicos;

Aos professores do Programa de Pós-Graduação em Engenharia de Transportes da Escola Politécnica da USP pelos ensinamentos;

Aos colegas do Laboratório de Geoprocessamento (LABGEO), em especial Beatriz Moura, Bruna Pizzol, Juliana Siqueira, Tainá Bittencourt, Mateus Humberto, Nuno Graça e Renato Arbex pelo convívio, apoio e aprendizado;

Aos colegas do programa de Engenharia de Infraestrutura da Universidade de Melbourne, em especial ao colega Yu-Tong Cheng pela rica troca de experiências;

Aos colaboradores do Programa de Pós-Graduação em Engenharia de Transportes da Escola Politécnica da USP, em especial à Luciane Watanabe e Leonardo Godoy;

À Coordenação de Aperfeiçoamento de Pessoal de Nível Superior (CAPES) pelo financiamento de minha pesquisa de doutorado. 
"If you didn't grow it, you didn't explain it."

-- Josh Epstein 


\section{Resumo}

O acesso ao emprego é objeto de estudo de grande importância na área de transportes. A investigação de como o sistema de transporte pode influenciar o processo de escolha residencial e, consequentemente, como a acessibilidade aos empregos é distribuída para os diversos grupos que compõem a sociedade, é algo que deve ser melhor explorado. Com a evolução da capacidade de processamento de computadores, metodologias de modelagem têm mostrado capacidade de emular sistemas urbanos complexos, envolvendo uso do solo e transportes. Neste contexto, a presente tese visa investigar a dinâmica das desigualdades de acessibilidade aos empregos. Para investigar os processos que levam as desigualdades de acessibilidade aos empregos, foi proposto um modelo baseado em agentes, implementado em plataforma aberta, para representar, de forma simplificada, o comportamento humano na escolha residencial através de variáveis de status da vizinhança e acessibilidade aos empregos. Foram realizados estudos de caso em São Paulo e Curitiba, municípios localizados em um país em desenvolvimento, e em Melbourne (Austrália), localizado em um país desenvolvido, para avaliar a robustez do modelo na representação da realidade de diferentes áreas de estudo. Os resultados mostram que o modelo permitiu representar a realidade das diferentes áreas de estudo, sendo as áreas localizadas no Brasil retratadas com maior fidedignidade. O modelo também possibilitou simular diferentes cenários de oferta de transporte, emprego e habitação para o município de São Paulo. Foi observado que o cenário de maior redução das desigualdades de acessibilidade foi o que envolveu um aumento da oferta de transporte público, empregos e habitações de interesse social em áreas de alta acessibilidade aos empregos. O modelo também permitiu retratar pequenas alterações temporais ocorridas em São Paulo no período de 2007 a 2017, refletidas na parametrização do modelo. O presente trabalho busca alimentar o debate sobre as desigualdades de acessibilidade aos empregos e gerar ideias sobre políticas públicas para reduzí-las.

Palavras-chave: Acessibilidade aos empregos, Desigualdades, Modelagem baseada em agentes, Coeficiente Gini. 


\section{Abstract}

Access to employment is an important object of study in the area of transport. An investigation on how the transport system can influence the residential location choice process and, consequently, how job accessibility is distributed according to different social groups should be better explored. The evolution in computer processing capacity allowed modeling methodologies to simulate complex urban systems, including land use and transport systems. In this context, this thesis aims to investigate the dynamics of the job accessibility inequalities. In order to investigate the processes that lead to job accessibility inequalities, an agent-based model was proposed to reproduce, in a simplified way using open source platform, the residential location choice process considering neighborhood status and job accessibility variables. Case studies were carried out in São Paulo and Curitiba, located in a developing country, and in Melbourne (Australia), located in a developed country, to evaluate the robustness of the model in representing the reality of the different areas of study. The results show that the model allowed to represent the reality of the different areas of study, with the areas located in Brazil represented with greater reliability. The model also made it possible to simulate different scenarios of transport, employment and housing supply for the municipality of São Paulo. It was observed that the scenario of greater reduction in job accessibility inequalities was the one that involved an increase in the supply of public transport, employment and social housing in areas with high job accessibility. The model also allowed to represent minor temporal changes that occurred in São Paulo in the period from 2007 to 2017, reflected in the parameterization of the model. The present work seeks to create insights into inequalities in access to jobs and to feed the debate on how public policies can alleviate inequalities.

Keywords: Job accessibility, Inequalities, Agent-based modeling, Gini coefficient. 


\section{Lista de ilustrações}

Figura 1 - Ciclo do uso do solo e transportes (traduzido e adaptado de Paquette et al., 1972). . . . . . . . . . . . . . . . . . . . . 22

Figura 2 - Modelo conceitual e fatores experimentais. . . . . . . . . . . . 41

Figura 3 - Fluxograma do Modelo. . . . . . . . . . . . . . . . . 45

Figura 4 - Fluxograma geral do trabalho. . . . . . . . . . . . 48

Figura 5 - Município de São Paulo. . . . . . . . . . . . . . . . . 49

Figura 6 - Distribuição dos grupos socio-ocupacionais no município de São Paulo. 51

Figura 7 - Localização das linhas perimetral, radial, habitações de interesse social e empregos simulados. . . . . . . . . . . . . . . . 5 55

Figura 8 - Situação observada, cenário base e saídas das simulações dos experimentos. 56

Figura 9 - Cenários de localização das habitações de interesse social. . . . . . . . 60

Figura 10 - Quarto Experimento - Localização residencial resultante. . . . . . . . . 60

Figura 11 - Quarto Experimento - Distribuição resultante das acessibilidades ao emprego por grupo socio-ocupacional. . . . . . . . . . . . . . 61

Figura 12 - Quarto Experimento - Curvas de Lorenz e coeficiente de Gini resultantes. 61

Figura 13 - Oferta de habitações de interesse social. . . . . . . . . . . . . . 63

Figura 14 - Localização residencial resultante. . . . . . . . . . . . . . . . . 63

Figura 15 - Quinto experimento - Distribuição das acessibilidades aos empregos por modo de transporte . . . . . . . . . . . . . . . . . 63

Figura 16 - Localização residencial dos grupos de renda para 2007. . . . . . . . . . 67

Figura 17 - Localização residencial dos grupos de renda para 2017. . . . . . . . . . 68

Figura 18 - Localização dos empregos em 2007 e 2017. . . . . . . . . . . . . . . . . 69

Figura 19 - Resultados do modelo de 2007. . . . . . . . . . . . . . . 71

Figura 20 - Resultados do modelo de 2017. . . . . . . . . . . . . . . . . . . 72

Figura 21 - Distribuição dos grupos sociais no município de Curitiba. . . . . . . . . 75

Figura 22 - Resultados do modelo de Curitiba. . . . . . . . . . . . . . . 77

Figura 23 - Área de interesse - zona central da região metropolitana de Melbourne. 80

Figura 24 - Distribuição dos grupos sociais na zona central da região metropolitana de Melbourne. . . . . . . . . . . . . . . . . . . . 81

Figura 25 - Distribuição de empregos na zona central da região metropolitana de Melbourne. . . . . . . . . . . . . . . . . 82

Figura 26 - Distribuição de habitações de interesse social na zona central da região metropolitana de Melbourne. . . . . . . . . . . . . . . . . 83

Figura 27 - Distribuição da acessibilidade aos empregos no modelo de Melbourne. . 86

Figura 28 - Distribuição dos grupos de renda em Melbourne. . . . . . . . . . . . 86

Figura 29 - Visão geral dos processos do modelo. . . . . . . . . . . . . . . . 105 


\section{Lista de tabelas}

Tabela 1 - Distribuição dos Grupos de Renda em São Paulo em 2007 e 2017. . . . 67

Tabela 2 - Distribuição dos Grupos de Renda em Melbourne e Curitiba. . . . . . 80

Tabela 3 - Estrutura do protocolo ODD (GRIMM et al., 2006). . . . . . . . . . . 103

Tabela 4 - Nome e descrição das variáveis dos agentes. . . . . . . . . . . . . 104

Tabela 5 - Nome e descrição das variáveis das células do ambiente de simulação. . 104 


\section{Sumário}

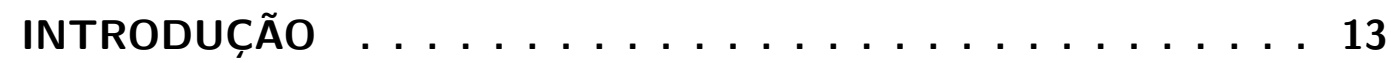

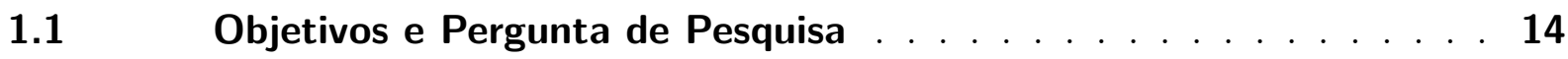

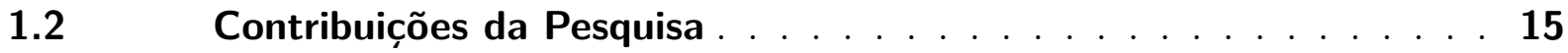

$1.3 \quad$ Organização da Tese . . . . . . . . . . . . . . . . 15

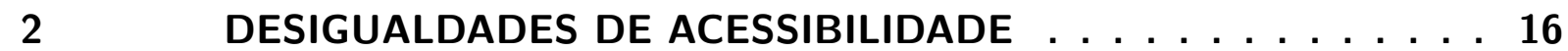

2.1 Exclusão Social Relacionada ao Transporte . . . . . . . . . . . 16

2.2 Medidas de Desigualdade de Acessibilidade . . . . . . . . . . 23

$2.3 \quad$ Medidas de Acessibilidade . . . . . . . . . . . . . . . . . . . 24

3 MODELAGEM BASEADA EM AGENTES . . . . . . . . . 29

3.1 Acessibilidade e Escolha Residencial em Modelos Baseados em Agen-

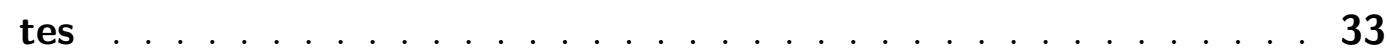

3.2 Verificação, Calibração e Validação de Modelos . . . . . . . . . 36

3.2.1 Verificação . . . . . . . . . . . . . . . . . . 37

3.2.2 Calibração. . . . . . . . . . . . . . . . . . . . . 37

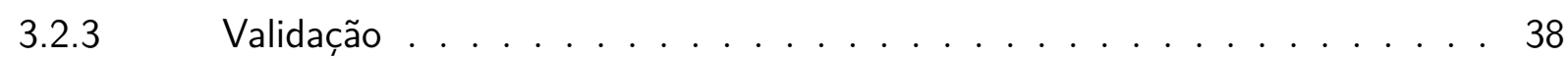

4 MODELO PARA ANÁLISE DAS DESIGUALDADES DE ACESSI-

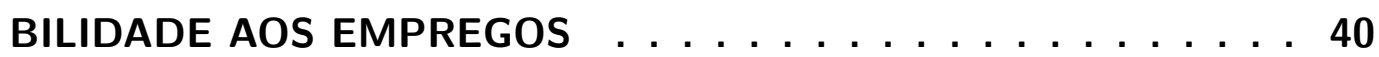

4.1 Submodelo Ambiente . . . . . . . . . . . . . . . . . 40

4.2 Submodelo Trabalhadores . . . . . . . . . . . . . . . . . 42

$4.3 \quad$ Fatores Experimentais . . . . . . . . . . . . . . . . . . 44

$4.4 \quad$ Plataforma de Implementação do Modelo . . . . . . . . . . . . 46

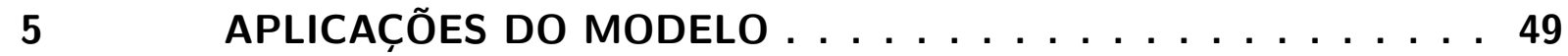

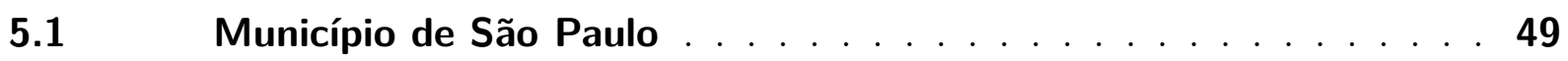

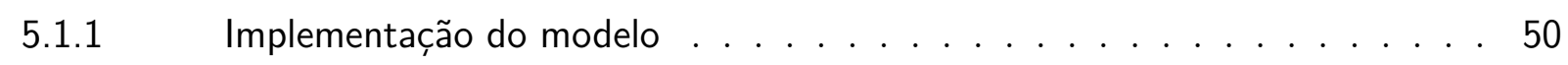

$5.1 .2 \quad$ Calibração do modelo . . . . . . . . . . . . . . . . . 53

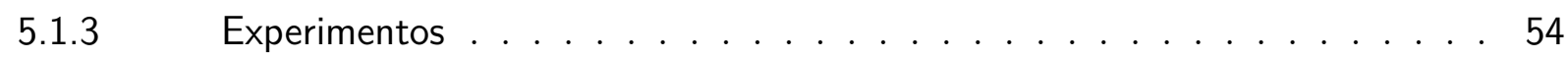

5.1.3.1 Primeiro experimento - linhas perimetral e radial . . . . . . . . . . 54

5.1.3.2 Segundo experimento - linhas perimetral, radial e habitações de interesse social . 57

5.1.3.3 Terceiro experimento - linhas perimetral, radial e novos empregos . . . . . . . 58

5.1.3.4 Quarto experimento - linhas perimetral, radial, novos empregos e habitações de interesse social . . . . . . . . . . . . . . . . . . . . . . . 59 
5.1.3.5 Quinto experimento - Programa de habitação Minha Casa Minha Vida (MCMV) e zonas especiais de interesse social (ZEIS) . . . . . . . . . . . . . 62

5.1 .4 Discussões e conclusões . . . . . . . . . . . . . . . . 64

$5.2 \quad$ Município de São Paulo 2007 e 2017 . . . . . . . . . . . . . . . . 66

5.2.1 Implementação dos modelos de São Paulo 2007 e 2017 . . . . . . . . . . . 66

5.2.2 Calibração dos modelos de São Paulo 2007 e 2017 . . . . . . . . . . . . . 70

5.2.3 Resultados dos modelos de São Paulo 2007 e 2017 . . . . . . . . . . . . . . 71

5.2.4 Discussões e conclusões sobre os modelos de São Paulo 2007 e 2017 . . . . 72

5.3 Avaliação Empírica do Modelo em Contextos Urbanos Distintos do de São Paulo . . . . . . . . . . . . . . . . . . . . . . . 73

5.3.1 Município de Curitiba . . . . . . . . . . . . . . . . . 74

5.3.1.1 Implementação do modelo de Curitiba . . . . . . . . . . . . . 74

5.3.1.2 Calibração do modelo de Curitiba . . . . . . . . . . . . . 76

5.3.1.3 Resultados do modelo de Curitiba . . . . . . . . . . . . . . . . 77

5.3.1.4 Discussões e conclusões sobre o modelo de Curitiba . . . . . . . . . . . . . 78

5.3.2 Zona Central da Região Metropolitana de Melbourne . . . . . . . . . . . . 79

5.3.2.1 Implementação do modelo de Melbourne . . . . . . . . . . . . . . . 79

5.3.2.2 Calibração do modelo de Melbourne . . . . . . . . . . . . . . . . 84

5.3.2.3 Resultados do modelo de Melbourne . . . . . . . . . . . . . . . . 85

5.3.2.4 Discussões e conclusões sobre o modelo de Melbourne . . . . . . . . . . . . 87

6 CONCLUSÕES E DISCUSSÕES . . . . . . . . . . . . . 89

6.1 Síntese do trabalho . . . . . . . . . . . . . 89

6.2 Conclusões, contribuições e limitações metodológicas . . . . . . . 91

$6.3 \quad$ Sugestões para trabalhos futuros . . . . . . . . . . . . . 92

REFERÊNCIAS ....................... 93

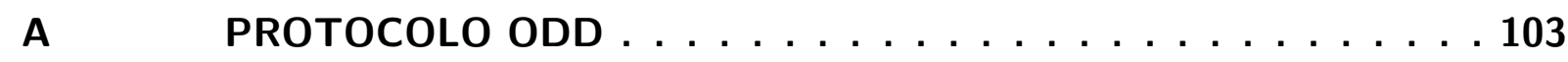

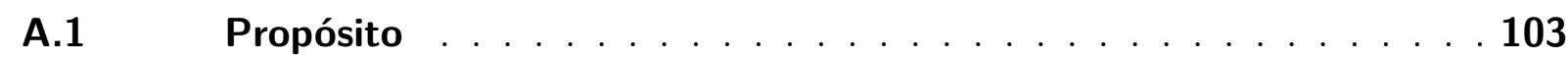

A.2 Variáveis de estado e escalas . . . . . . . . . . . . . . 103

A.3 Visão de processo e escalonamento . . . . . . . . . . . . 104

A.4 Conceitos do projeto . . . . . . . . . . . . 106

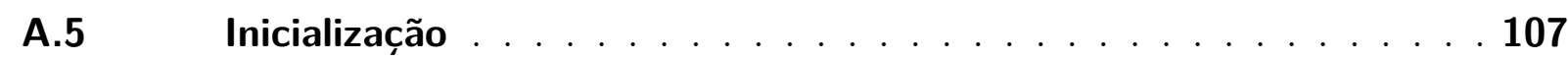

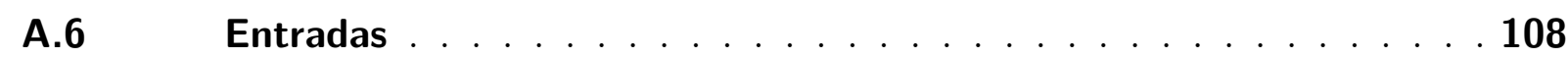

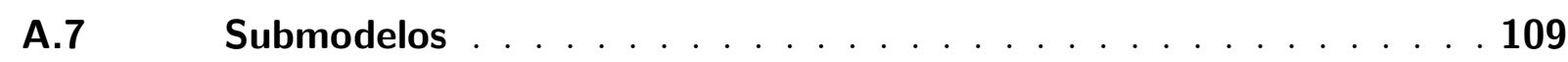




\section{Prólogo}

A motivação técnica para o desenvolvimento do trabalho foi me aprofundar nos estudos de desigualdades de acessibilidade e simulação através de modelagem baseada em agentes. Ao longo de meu mestrado, me dediquei no mapeamento das desigualdades de acessibilidade entre os modos de transporte público e privado em São Paulo. Após identificar uma desigualdade de acessibilidade expressiva, um passo natural foi me aprofundar nos estudos de desigualdades de acessibilidade no meu doutorado, mas dessa vez, utilizando ferramental computacional para simular medidas que atenuassem as desigualdades entre diferentes grupos sociais. O desafio de aprender mais sobre modelagem baseada em agentes também foi bastante motivador, pois é uma técnica empregada com sucesso em estudos urbanos.

A motivação de cunho pessoal é a minha convicção de que o transporte possui um papel essencial na integração da sociedade brasileira e diminuição das desigualdades. $\mathrm{O}$ transporte deve ser planejado de forma a conectar pessoas aos diversos serviços ofertados em uma cidade, incluindo oportunidades de crescimento pessoal e profissional de forma eficiente. Somente com pessoas mais integradas à sociedade, seu potencial pode ser desenvolvido e retornar em forma de benefícios para a sociedade. 


\section{Introdução}

A acessibilidade, que pode ser entendida como o produto do sistema de transporte e do uso e ocupação do solo, é uma medida raramente empregada na avaliação de políticas ou projetos de transporte (WEE; GEURS, 2011). O entendimento de sua dinâmica é de fundamental importância para a percepção de como ela é distribuída entre os diversos grupos que compõem a sociedade e identificação de desigualdades.

As relações entre o sistema de transporte e o uso e ocupação do solo causam impactos no ambiente que são de fundamental importância na gestão do crescimento urbano (WADDELL, 2002). Mudanças no uso e ocupação do solo podem modificar a demanda por transporte, induzindo o sistema de transporte a mudar e, de maneira inversa, alterações no sistema de transporte podem modificar os níveis de acessibilidade e incentivar mudanças no uso e ocupação do solo (PAQUETTE; ASHFORD; WRIGHT, 1972; SHAW; XIN, 2003). A modelagem das relações entre o uso e ocupação do solo e transportes não é elementar, em vista da diversidade de atores que influenciam as decisões de investimentos e desenvolvimento do ambiente urbano.

Os modelos espaciais que envolvem uso do solo e transportes pressupõem a hipótese de que o aumento da acessibilidade tende a ser seguido por um aumento no valor da terra (PAQUETTE; ASHFORD; WRIGHT, 1972). Esse processo pode tornar um local previamente ocupado por uma população de menor renda inacessível a essa mesma população, fazendo com que se desloquem para locais com valor de terra mais baixo, que são, tradicionalmente, no contexto brasileiro, regiões mais afastadas do centro ou áreas degradadas.

Diversos autores abordam as desigualdades de acessibilidade em diferentes contextos (VASCONCELLOS, 2005; WEE; GEURS, 2011; JARAMILLO; LIZÁRRAGA; GRINDLAY, 2012; LUCAS; WEE; MAAT, 2016; PEREIRA et al., 2017; MARTÍNEZ et al., 2018; MORENO-MONROY; LOVELACE; RAMOS, 2018), enquanto outros autores tratam de modelos de escolha residencial sem um enfoque em desigualdades de acessibilidade (WADDELL, 2002; ZHOU; KOCKELMAN, 2008; FONTAINE; ROUNSEVELL, 2009; LEE et al., 2010; JORDAN; BIRKIN; EVANS, 2014; BABAKAN; TALEAI, 2015; BABAKAN; ALIMOHAMMADI, 2016; ZHUGE et al., 2016; GUO; BUCHMANN; SCHWARZ, 2019). O presente trabalho busca preencher essa lacuna ao apresentar um modelo de escolha residencial para explorar desigualdades de acessibilidade, o que não foi encontrado na literatura até o momento. 
A criação de um modelo de escolha residencial, utilizando abordagem bottom-up, para investigar desigualdades de acessibilidade permitirá explorar, dinamicamente, as relações entre a acessibilidade e o uso e ocupação do solo. Dessa forma, podem ser avaliados aumentos de oferta de transporte e seus impactos no uso e ocupação do solo, permitindo o melhor entendimento dos mecanismos e etapas envolvidas nesse processo.

\subsection{Objetivos e Pergunta de Pesquisa}

O objetivo geral da pesquisa é investigar os processos de desigualdades de acessibilidade aos empregos dos diferentes grupos sociais. A partir da investigação, avaliar impactos potenciais de políticas públicas em transporte, habitação e emprego nas desigualdades de acessibilidade.

Os objetivos específicos da pesquisa são:

- Simular, para o município de São Paulo, cenários alternativos com diferentes políticas públicas de ofertas de emprego, habitação e transporte público, analisando seus impactos nas desigualdades de acessibilidade aos empregos;

- Simular a dinâmica do processo de localização residencial para os municípios de São Paulo e Curitiba, localizados em um país em desenvolvimento, e para a zona central da região metropolitana de Melbourne, localizada em um país desenvolvido;

- Simular dois cenários para o município de São Paulo, sendo um do ano de 2007 e outro do ano de 2017, para avaliar a adaptabilidade do modelo na representação dos dois períodos.

A pergunta que a pesquisa visa responder é: "Quais são os processos associados às desigualdades de acessibilidade aos empregos, em especial com relação à influencia exercida por políticas de transporte, habitação e empregos?"

A hipótese da pesquisa é que: "A redução das desigualdades de acessibilidade aos empregos depende da ação integrada de políticas de transporte e habitação." 


\subsection{Contribuições da Pesquisa}

A maior contribuição da pesquisa é o desenvolvimento de um modelo híbrido baseado em agentes e automatos celulares que permite simular a localização residencial da população e avaliar como ocorrem as desigualdades de acessibilidade aos empregos.

Outra contribuição é a abordagem das desigualdades de acessibilidade, através da simulação de novas configurações de oferta de habitação, empregos e transporte público. A possibilidade de alterar os padrões de acessibilidade e investigar os impactos nas desigualdades é de grande contribuição para a análise fenomenológica.

\subsection{Organização da Tese}

A tese é composta por quatro capítulos, além da introdução. O segundo capítulo apresenta uma revisão sobre desigualdades de acessibilidade onde é explorada a exclusão social relacionada ao transporte, medidas de desigualdade de acessibilidade e medidas de acessibilidade.

O terceiro capítulo apresenta uma revisão conceitual sobre modelagem baseada em agentes (ABM). O quarto capítulo apresenta o modelo proposto para estudo das desigualdades de acessibilidade aos empregos.

O quinto capítulo apresenta as aplicações do modelo, bem como seus resultados e conclusões e o sexto capítulo apresenta as conclusões gerais dos estudos e discussões. 


\section{Desigualdades de Acessibilidade}

\subsection{Exclusão Social Relacionada ao Transporte}

Na metade da década de 1990, os conceitos, teorias e metodologias de exclusão social foram estabelecidos e posteriormente explorados por pesquisadores da área de transportes, sendo um dos principais temas de estudo na literatura (LUCAS, 2012; WEE; GEURS, 2011). Embora o termo exclusão social esteja bastante relacionado com renda, também considera barreiras que dificultam o acesso de pessoas a empregos, educação, transporte, sistema de saúde e demais atividades em sociedade (KAMRUZZAMAN et al., 2016; STANLEY; LUCAS, 2008; MACKETT; ACHUTHAN; TITHERIDGE, 2009; KENYON; LYONS; RAFFERTY, 2002).

Apesar dos vários estudos sobre exclusão social, ainda não existe um consenso sobre o seu significado (PRESTON; RAJÉ, 2007). Para Daly e Silver (2008), o termo exclusão social apresenta várias raízes, sendo ambíguo, multidimensional, elástico e, por isso, pode ser definido de diversas formas. De acordo com Fragonard, Strohl e Leprince (1993), as tentativas de identificar indivíduos e grupos socialmente excluídos são inevitavelmente reducionistas, pois são vários e interativos os fatores que contribuem para a exclusão social, podendo ser originada a partir de circunstâncias individuais, familiares ou socioeconômicas. Segundo Currie e Delbosc (2010), em muitos estudos a delimitação da população socialmente excluída é associada a grupos como idosos, desempregados e minorias étnicas, sendo raramente definida e medida. Church, Frost e Sullivan (2000), complementam ao afirmar que os excluídos não são somente os pobres, mas também aqueles que perderam capacidades essenciais para a sua qualidade de vida, como a capacidade de conseguir um emprego.

A exclusão social envolve a falta ou a privação de recursos, bens, serviços e a inabilidade de participar de atividades, disponíveis para a maioria das pessoas em uma sociedade, com relação a área econômica, social, cultural e política (WALKER; WALKER, 1997; GINER; ESPINOSA; TORRES, 1998; PEACE, 2001; LEVITAS et al., 2007). Levitas et al. (2007) acrescentam que a exclusão social afeta a qualidade de vida dos indivíduos e a equidade/coesão da sociedade como um todo. Para Burchardt, Grand e Piachaud (2002), um indivíduo é socialmente excluído se: ele(a) é geograficamente residente em uma sociedade, mas por razões além de seu controle, ele(a) não pode participar das atividades normais dos cidadãos daquela sociedade, e ele(a) gostaria de participar dessas atividades. 
Uma das características dos estudos de exclusão social é a incorporação de sua dimensão espacial (DONALDSON, 2006). Madanipour, Cars e Allen (1998) enfatiza a dimensão espacial da exclusão social e como ela pode se manifestar em locais específicos, definindo exclusão social como um processo multidimensional em que diversas formas de exclusão são combinadas: participação nos processos de tomada de decisão, políticos, acesso a empregos, recursos materiais e integração cultural. Quando combinados, criam formas agudas de exclusão que são manifestadas espacialmente em bairros específicos.

Hodgson e Turner (2003) afirmam que a manifestação espacial da exclusão social é de fundamental importância para entender a formação de locais com múltiplas privações, a identificação de pessoas e grupos socialmente excluídos e as relações entre transporte e exclusão social. Um exemplo de manifestação espacial da exclusão social decorre dos preços mais acessíveis de moradias nas periferias das cidades, que faz com que as camadas mais pobres da população venham a habitá-los, porém é pouco provável que esses locais sejam bem servidos de transporte, levando a uma população já excluída do mercado de habitação de alta qualidade e do mercado de trabalho de alto valor agregado a ser privada de bom acesso a serviços públicos (DONALDSON, 2006).

Para Lucas (2012), a lógica de adotar o conceito de exclusão social no transporte ajuda os tomadores de decisão a reconhecerem que:

a) O problema é multidimensional, por exemplo, pode ser dado um enfoque no indivíduo que é afetado ou nos processos, instituições e estruturas da sociedade;

b) Ele é relativo, ou seja, a desvantagem é vista em comparação às relações e atividades normais do resto da população; e

c) Possui uma natureza dinâmica, por exemplo, ela muda com o tempo e espaço, assim como durante a vida da pessoa que é afetada.

No estudo da exclusão social relacionada ao transporte, é fundamental reconhecer a interação entre os fatores relacionados ao indivíduo, como idade, gênero, etnia e deficiências físicas, os fatores relacionados à infraestrutura do local, como a falta ou insuficiência de serviços de transporte público, e os fatores relacionados à economia nacional ou global, como a reestruturação do mercado de trabalho, alterações de legislação, mudanças culturais e migrações (LUCAS, 2012).

Uma parte significativa da exclusão social está associada à superação de barreiras espaciais em determinados momentos de maneira a acessar redes de trabalho, lazer, família e amigos (CASS; SHOVE; URRY, 2005). De acordo com Cass, Shove e Urry (2005), foram identificadas quatro dimensões chave relativas ao acesso: 
- Financeira: partindo do pressuposto de que todo o tipo de transporte tem um custo financeiro, são necessários recursos mínimos para a inclusão social. A disponibilidade de recursos financeiros para a realização de viagens intermitentes de longa distância através de diversos modos de transporte (carro, ônibus, trem, avião e barco) é um dos pré-requisitos para uma pessoa ser incluída socialmente. A dimensão financeira é reconhecidamente importante para a inclusão social, tanto que políticas públicas de subsídio ao transporte de grupos de risco são frequentemente adotadas por governos locais;

- Física: trata das barreiras físicas ocasionadas por inabilidades de pessoas em dirigir, andar, ler instruções ou horários, falta de segurança, dificuldades em acessar locais privados ou ainda ocasionada pelo projeto de cidades, casas ou veículos. Políticas públicas são aplicadas para minimizar barreiras no ambiente físico como, por exemplo, a oferta de veículos especiais para atender a pessoas com inabilidades físicas;

- Organizacional: enfatiza como o acesso a serviços é dependente não somente da disponibilidade de transporte, mas também da forma como ele é organizado. A organização do transporte público é fundamental quando o automóvel não está à disposição, sendo tão importante quanto à proximidade ao transporte a sua cobertura, qualidade, condições de espera e transferência, frequência, confiabilidade e pontualidade;

- Temporal: trata da disponibilidade temporal do acesso como, por exemplo, a baixa oferta de transporte público fora das horas pico e suas consequências para diversas atividades como lazer. Além da oferta temporal do transporte, a disponibilidade de tempo, por parte dos diversos grupos de usuários, também é considerada, sendo que alguns grupos possuem maior flexibilidade de horário do que outros. Como o tempo é visto com valor por usuários dos sistemas de transporte, estes valorizam mais os modos que garantam acesso mais rápido aos locais e serviços de interesse.

A exclusão social pode não ser causada pela falta de oportunidades, mas sim pela falta de acessibilidade decorrente da insuficiência de transporte e/ou infraestrutura precária para acessá-lo (ACHUTHAN; TITHERIDGE; MACKETT, 2010; PRESTON; RAJÉ, 2007). Church, Frost e Sullivan (2000), apresentam sete características do sistema de transporte que contribuem ou estão relacionadas com a exclusão social de certos grupos da população:

a) Exclusão física: onde a barreira física, como o design do veículo, falta de infraestrutura para deficientes ou de informação de horário do transporte, inibe o acesso ao sistema de transporte; 
b) Exclusão geográfica: onde uma pessoa vive pode impedí-la de acessar serviços de transporte, como nas áreas rurais ou periferias das cidades;

c) Exclusão de instalações: a distância do local onde uma pessoa vive em relação a instalações chave como lojas, escolas, centros de saúde ou serviços de lazer pode impedir seu acesso;

d) Exclusão econômica: o alto custo monetário da viagem pode impedir ou limitar o acesso de uma pessoa a instalações ou empregos e, com isso, impactar em sua renda;

e) Exclusão baseada no tempo: a combinação de atividades que demandam tempo como, por exemplo, trabalho, afazeres domésticos e cuidado de crianças reduz o tempo disponível para viajar;

f) Exclusão baseada no medo: onde o temor pela segurança pessoal inibe o uso do espaço público e/ou os serviços de transporte;

g) Exclusão do espaço: onde a segurança ou a gestão do espaço impede que certos grupos acessem espaços públicos como, por exemplo, condomínios fechados.

Para Wee e Geurs (2011), a garantia de opções de acesso e participação em atividades é considerada uma questão ética, porém a combinação de forças do livre mercado em conjunto com políticas de transporte pode resultar em situações em que indivíduos possuam um nível de acesso considerado injusto. Para Litman (2002), a análise da equidade nos transportes deve considerar duas categorias:

- Equidade horizontal: as pessoas devem ser tratadas de forma igual, a não ser que seja justificável a diferenciação de tratamento. Parte dos seguintes pressupostos: políticas e regulações são aplicadas de forma igual para todos os usuários; os gastos públicos per capita e custos são igualmente distribuídos para diferentes grupos populacionais; a qualidade dos serviços é comparável para diferentes grupos e locais; os modos de transporte recebem investimentos públicos na mesma proporção que utilizados; e todos os grupos populacionais têm a oportunidade de participar do processo de decisão relacionado ao transporte.

- Equidade vertical: as pessoas são tratadas de maneira diferente de acordo com sua renda, ou seja, famílias com menor renda pagam menos ou recebem a maior parte dos benefícios em relação às famílias de maior renda. Partem dos seguintes pressupostos: modos com preços mais acessíveis como caminhada, transporte público e bicicleta, recebem maior atenção e são planejados de forma a criar um sistema integrado; são oferecidos descontos especiais para os serviços de transporte de acordo com a renda ou necessidades econômicas; os investimentos em transportes são feitos de 
maneira a favorecer áreas e grupos carentes; e apoiam políticas de moradia com preços acessíveis em locais com alta oferta de transporte multimodal.

Lucas, Wee e Maat (2016) discutem como princípios éticos devem suportar políticas públicas e demonstram como duas teorias distintas de percepção de justiça (igualitarianismo e suficientarianismo), quando aplicadas na área de transportes resultam em políticas de acessibilidade diferentes. Enquanto as teorias igualitárias consideram que a sociedade deva tratar todas as pessoas igualmente, as teorias do suficientarianismo assumem que existem diferenças entre as pessoas e que deva existir um limite mínimo suficiente para atender às suas necessidades básicas e bem-estar (LUCAS; WEE; MAAT, 2016). As políticas de acessibilidade, quando apoiadas em teorias igualitárias, buscarão o acesso de forma igual para cada um dos estratos da população, já quando apoiadas em teorias de suficiência, buscarão um valor mínimo suficiente de acessibilidade para que os indivíduos possam acessar as oportunidades consideradas essenciais (LUCAS; WEE; MAAT, 2016).

No Reino Unido, o planejamento da acessibilidade a serviços essenciais, como emprego, educação, saúde, áreas de lazer e demais serviços, tem sido empregado como uma forma de relacionar a exclusão social e transportes (Social Exclusion Unit, 2003). Para Cebollada (2009), uma das primeiras publicações a relacionar a exclusão social ao transporte público foi o relatório DETR (TRaC, 2000), onde foi diagnosticado que o transporte público, da forma em que está organizado, é incapaz de fornecer acesso adequado às instalações de saúde, educação, compras e empregos para as porções mais pobres da população britânica.

Outros estudos relacionaram a qualidade do transporte público às necessidades sociais no Reino Unido, e se referem aos gastos com a acessibilidade por transporte público rural e seus subsídios (CURRIE, 2010). Segundo Lucas, Grosvenor e Simpson (2001), o aumento da posse de automóvel tornou-o um item indispensável para acessar os mais diversos equipamentos. Dessa forma, os indivíduos ou famílias que não o possuem se encontram em desvantagem devido ao serviço insatisfatório do sistema de transporte público. Mais do que em desvantagem, um estudo conduzido pelo departamento de transporte do Reino Unido (DTLR, 2000), concluiu que famílias sem acesso a carro, em locais periféricos ou rurais, são socialmente excluídas, já que elas não conseguem participar ou se comportar como a maioria das famílias da sociedade.

Em países em desenvolvimento, um dos fatores que causam a exclusão social é a falta de acesso e mobilidade, principalmente para grupos da população que se estabelecem nas periferias dos grandes centros urbanos (JARAMILLO; LIZÁRRAGA; GRINDLAY, 2012). Na América Latina, que é uma região que vem se urbanizando rapidamente, o cenário urbano é caracterizado por fortes desigualdades sociais, segregação espacial e uma 
dinâmica marcada pela formação de assentamentos precários (BLANCO et al., 2018). O acelerado crescimento urbano das grandes cidades da América Latina, particularmente durante os períodos de 1960 a 1970, com a concentração dos empregos nas regiões centrais, levou a segregação da população de baixa renda (COHEN, 2004). Como consequência dessas diferenças marcantes, as populações pobres e ricas acessam de maneira distinta bens e serviços, pois a população pobre tem que lutar para superar obstáculos de mobilidade (HERNANDEZ, 2018).

Martínez et al. (2018) investigaram as políticas de distribuição do transporte e moradias populares na cidade de Santiago do Chile com o objetivo de investigar a limitada conectividade provida pelo sistema de transporte público atualmente. Como resultado, os autores identificaram que as políticas de habitação popular aumentaram as distâncias entre as pessoas e as oportunidades oferecidas na cidade.

Jaramillo, Lizárraga e Grindlay (2012) estudaram as relações entre a exclusão social e a oferta de transporte na cidade de Cali na Colômbia. Os autores exploraram a implementação do sistema de BRT em Santiago de Cali e demonstraram que podem ser realizadas melhorias em sua cobertura considerando índices de necessidade social de transporte e índices de oferta de transporte. O cruzamento de ambos os índices identificou lacunas espaciais de oferta e demanda por transporte.

Hernandez e Titheridge (2016) exploraram as estratégias de viagem adotadas pela população de baixa renda de Soacha (Colômbia) através de uma perspectiva de exclusão social relacionada ao transporte. O cenário de escassez de oferta de transporte, renda e segregação permitiu examinar elementos críticos no acesso à cidade.

Na Região Metropolitana de São Paulo, Vasconcellos (2005) estudou a produção de externalidades negativas do transporte, como, por exemplo, acidentes, poluição e congestionamentos, por diferentes grupos sociais através dos dados da pesquisa origemdestino de 1997. Um dos principais resultados encontrados foi que, apesar da população de classe social mais baixa gastar grande parte do seu orçamento no transporte, ela possui baixa mobilidade e contribui pouco para a produção de externalidades negativas. Já os grupos mais ricos da população, que se utilizam majoritariamente de carros para se movimentarem, investem mais tempo e dinheiro em suas viagens, gerando até quinze vezes mais externalidades do que a população de menor renda.

Moreno-Monroy, Lovelace e Ramos (2018) desenvolveram um estudo sobre a desigualdade no transporte público para acesso às escolas na Região Metropolitana de São Paulo. Os autores desenvolveram índices de acessibilidade considerando a distribuição espacial dos adolescentes, das escolas e da oferta de transporte, simulando impactos de 
cenários com maior centralização da oferta de educação secundária na acessibilidade. Como resultado, foi identificado que a centralização da oferta de educação secundária afeta negativamente os estudantes com menores níveis de acessibilidade.

É um consenso que o aumento da acessibilidade de um local, devido à melhoria da infraestrutura e serviço de transporte, aumentará o valor da terra, ocasionando o deslocamento de pessoas mais pobres, especialmente do interior das cidades (FOX, 2000). Paquette, Ashford e Wright (1972) retratam essa influência recíproca entre o uso do solo e transporte apresentando o ciclo do uso do solo e transportes (Figura 1).

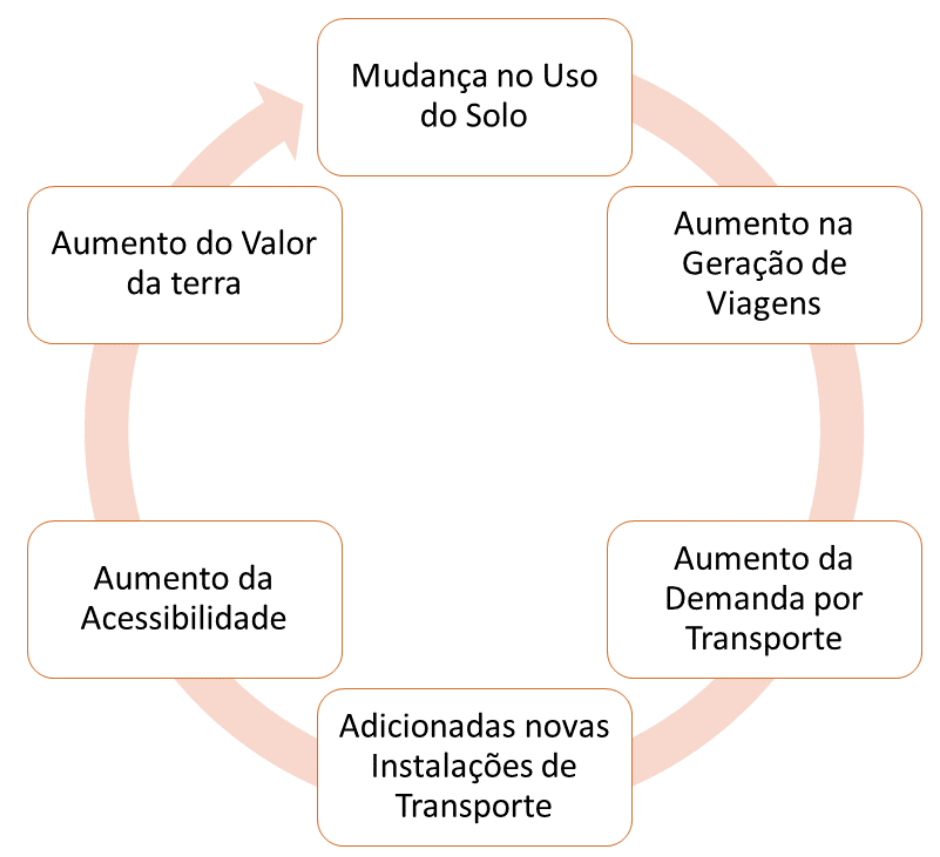

Figura 1 - Ciclo do uso do solo e transportes (traduzido e adaptado de Paquette et al., 1972).

De acordo com Revington (2015), o sistema de transporte pode levar à gentrificação, pois ele altera a distribuição espacial e social do benefício da acessibilidade, influenciando como o espaço urbano é utilizado e por quem. A gentrificação é um processo de reordenamento das áreas urbanas, que envolve o movimento de pessoas de alta renda e do mercado de trabalho de alto valor agregado para áreas urbanas previamente decadentes, resultando no aumento do preço das habitações que levam ao deslocamento dos moradores de menor renda (SMITH, 1996). 


\subsection{Medidas de Desigualdade de Acessibilidade}

Para Xia et al. (2016) foram desenvolvidas três correntes de pesquisa para a mensuração da exclusão social relacionada ao transporte. A primeira se apoiou na fundamentação teórica da exclusão social para, através de conceitos como capital social (CIOMMO et al., 2014), bem-estar (DIENER, 2000), risco de exclusão social (Social Exclusion Unit, 2001) e senso de comunidade (STANLEY et al., 2011), mensurar a exclusão social relacionada ao transporte. A segunda corrente se utiliza de análises espaciais para explorar a incompatibilidade espacial entre a oferta e a demanda por transportes (CURRIE, 2010) assim como a sua infraestrutura, conectividade, mobilidade e acessibilidade (WELCH, 2013). Por fim, a terceira corrente é o estudo comparativo da exclusão social relacionada ao transporte em regiões geográficas e grupos sociais distintos. No presente trabalho é utilizada a segunda abordagem.

Muitos desses estudos consideraram variáveis de frequência de viagens, velocidade, distância, capacidade, quantidades de transferências, tempo de viagem, acessibilidade e custo (XIA et al., 2016). Parte desses estudos abordaram também outros fatores e processos que afetam a igualdade de transportes como o espraiamento urbano, capital social, segregação residencial, densidade residencial, divisão modal, distribuição dos empregos e moradias e a facilidade na compra de habitações (XIA et al., 2016).

Segundo Currie e Delbosc (2010) são encontrados diversos métodos na literatura para identificar a relação entre a desvantagem no transporte e exclusão social, sendo os dois métodos mais comuns: a análise espacial comparativa para identificar grupos com desvantagem de transporte através da distância ou tempo de viagem para acessar empregos, escolas, lojas e hospitais por transporte individual e coletivo; e a análise espacial de variáveis de posse de veículos, habilitação ou nível de serviço do sistema de transporte público.

Donaldson (2006) apresenta três abordagens utilizadas para investigar a relação entre exclusão social e transporte:

- Modelagem: é a abordagem formada pela formulação complexa de equações matemáticas para estimar padrões de tráfego e seus efeitos em cenários futuros de planejamento de transporte. Através de modelos gravitacionais clássicos, associados ao modelo de quatro etapas, e mais recentemente através dos modelos de atividades, podem ser identificados grupos com desvantagens de transportes e falta de oferta de transporte público para zonas com características sociais distintas; 
- Análise socioespacial: abordagem que considera análises espaciais através do uso de Sistemas de Informações Geográficas (SIG) para estabelecer relações e entender como se dá a acessibilidade e as desvantagens de transporte. Através do SIG, a implementação de métricas espaciais e a identificação de locais com serviços de transporte indisponíveis são relativamente simples desde que disponíveis os dados necessários. Análises de proximidade de pontos de acesso ao transporte público, quantidade de conexões da rede, área de acesso e nível de serviço em diferentes horas do dia, em conjunto com dados sociais, permitem a identificação de como diversos grupos são atendidos pelo sistema de transporte público;

- Análise qualitativa: é a abordagem que permite, principalmente através de entrevistas, identificar experiências pessoais no uso do transporte público e compará-las às necessidades de grupos específicos. Essa abordagem permite a identificação tanto de barreiras físicas locais para acessar os serviços de transporte, relacionadas à infraestrutura de transporte, quanto de barreiras sociais, como os altos preços das tarifas e problemas de violência, especialmente em horários noturnos.

No presente trabalho, além de ser utilizado o enfoque em análises espaciais para explorar as diferenças de acessibilidade aos empregos no município de São Paulo, é utilizada uma modelagem para investigar os processos que geram essas desigualdades.

\subsection{Medidas de Acessibilidade}

A acessibilidade é um conceito que tem ganhado importância no planejamento urbano ao longo das últimas cinco décadas (BATTY, 2009a). Hansen (1959) foi o primeiro a trabalhar com o conceito de acessibilidade aplicado ao potencial de interação com oportunidades, tendo definido acessibilidade como "uma medida da intensidade de possibilidades para interação". Ingram (1971) define acessibilidade como "uma característica ou vantagem inerente de um local em relação à facilidade de superar uma forma espacial de impedância (distância ou tempo de viagem)". Para Páez, Scott e Morency (2012) a acessibilidade é definida como o potencial de acesso a oportunidades, espacialmente distribuídas, e pode ser considerada um dos principais resultados do desenvolvimento espacial, sendo consequência da distribuição geográfica da oferta de transporte e de oportunidades. De uma forma geral, a acessibilidade pode ser definida como uma medida de esforço para transpor uma distância, caracterizada pelo desejo de indivíduos em participar de atividades espacialmente distribuídas, considerando seu deslocamento através de um sistema de transporte (JUNIOR, 2000). 
As relações entre uso e ocupação do solo e transportes são historicamente evidenciadas pelo desenvolvimento e integração de diversas cidades a partir de vias fluviais, ferroviárias e rodoviárias (ZONDAG; PIETERS, 2005; ZHUGE et al., 2016). Recentemente, a análise de viagens diárias, em especial viagens a trabalho, mostra a profunda relação entre a localização de empregos, residências e escolas (BEIGE; AXHAUSEN, 2017). Apesar disso, o planejamento de transporte tradicionalmente considera o uso e ocupação do solo como fator exógeno, desconsiderando a resposta do modelo integrado no processo de planejamento (WADDELL et al., 2007).

Para Lucas, Wee e Maat (2016) a exclusão social é um dos resultados da oferta desigual de transporte. O planejamento de transportes deve visar a redução da exclusão social, que pode ser causada ou exacerbada por problemas de acessibilidade como, por exemplo, altos custos, baixa disponibilidade, problemas na localização da infraestrutura e oferta de serviços, assim como na facilidade de acesso por grupos desfavorecidos (DfT, 2005). Schönfelder e Axhausen (2003) ressaltam a importância de políticas de uso e ocupação do solo e transportes, que podem reforçar a exclusão social, uma vez que indivíduos que se encontram diante de circunstâncias onde a localização de sua residência em relação aos serviços de transporte e suas opções de mobilidade inibem a sua participação na sociedade.

Lucas (2012) afirma que está ocorrendo uma transição nas políticas de transporte, passando do modelo tradicional, que se preocupa com a oferta de transporte, para um novo modelo com políticas focadas nas pessoas e suas necessidades, buscando a igualdade no acesso a serviços básicos e redistribuição dos recursos. A ideia por trás das políticas de igualdade é que um certo nível de opções de atividades consideradas importantes na sociedade esteja disponível para todas as pessoas independentemente de sua idade, renda ou posse/disponibilidade de automóvel (WEE; GEURS, 2011).

Para Wachs e Kumagai (1973) a acessibilidade é um componente importante na política de igualdade de oportunidades, estando relacionada não só com a localização, mas também com o status socioeconômico das comunidades em uma região. O conceito de acessibilidade está fortemente relacionado com a exclusão social, podendo seus quatro componentes ser utilizados para derivar causas para a exclusão social (WEE; GEURS, 2011):

a) Sistema de transporte: A exclusão social pode se relacionar com o sistema de transporte através de sua infraestrutura (falta de vias, terminais, linhas de metrô, trem, ônibus, estações e etc.), informação disponível ao usuário (falta de informações do itinerário das linhas de transporte público), custo (tarifas do transporte público, combustível, estacionamento e custos de veículos), barreiras de acesso ao transporte (instalações inadequadas para deficientes físicos) e segurança; 
b) Uso e ocupação do solo: O planejamento do uso e ocupação do solo pode levar ao aumento da exclusão social devido, por exemplo, ao desaparecimento de pequenos estabelecimentos, ocasionado pelo aumento escalar da demanda por produtos;

c) Componente individual: A mudança de necessidades, vontades e habilidades dos indivíduos pode impactar diretamente em seu nível de exclusão. O envelhecimento ou incapacidade ocasionada por algum acidente pode, por exemplo, impedí-lo de conduzir um automóvel. De forma inversa, o aumento de renda e de idade (para jovens) podem permitir a um indivíduo adquirir um veículo e se habilitar a conduzí-lo;

d) Componente temporal: O nível de exclusão social varia de acordo com mudanças temporais nos desejos e necessidades dos indivíduos. Mudanças, por exemplo, no horário de funcionamento de estabelecimentos comerciais e na oferta de transporte podem levar indivíduos com restrições de tempo específicas a acessarem tais estabelecimentos.

No trabalho de Lucas (2012), a autora propõe a adição de um quinto componente (componente cognitivo) ao estudo de Wee e Geurs (2011):

e) Componente cognitivo: na avaliação da exclusão social relacionada ao transporte, é importante considerar a habilidade das pessoas em interagir com o sistema de transporte. A habilidade de interação está relacionada com a familiaridade do indivíduo com o sistema de transporte e outros aspectos culturais, considerando necessidades especiais de grupos de minorias étnicas, deficientes mentais e analfabetos.

Apesar das relações inerentes entre a exclusão social e a acessibilidade, principalmente quando consideradas medidas de acessibilidade baseadas na teoria igualitária, existem outras dimensões não captadas pelas medidas que precisam ser consideradas (LUCAS; WEE; MAAT, 2016):

- As causas da exclusão social não se limitam à falta de acesso, mas também a outros fatores que não são considerados nas medidas de acessibilidade;

- Nem todas as oportunidades apontadas como acessíveis a uma pessoa são adequadas a ela, pois dependem de interesses pessoais, nível de instrução e diversos outros fatores;

- Não necessariamente as oportunidades disponíveis serão acessadas por motivos de restrição de tempo ou falta de interesse. 
Lucas, Wee e Maat (2016) exploram o uso de medidas de acessibilidade em conjunto com o coeficiente Gini para mensurar a equidade no acesso a oportunidades. No estudo, os autores comparam o acesso a oportunidades em três cidades na Holanda através de medidas de acessibilidade cumulativas com diferentes parâmetros de distância. Nos resultados, são apresentadas curvas de Lorenz e coeficientes Gini para cada uma das cidades, indicando quais apresentam maior igualdade no acesso às oportunidades consideradas.

No estudo realizado por Delmelle e Casas (2012) foi avaliado o impacto da implantação do BRT em Cali (Colômbia), em relação ao aumento da acessibilidade para cada um dos estratos da população. Foram criadas redes de transporte público considerando as estações de acesso e linhas do BRT, calculadas as acessibilidades para diversas atividades e geradas áreas de serviço de 5, 10, 15 e 20 minutos a partir das estações. As autoras concluíram que cerca de $80 \%$ da população de Cali consegue acessar o BRT em menos de 15 minutos de caminhada e que grande parte dessa população está situada nos estratos intermediários de renda.

Além das medidas de acessibilidade, existem outras medidas que permitem capturar as distribuições do acesso e oferta de transporte público. Welch (2013) desenvolveu um trabalho com o objetivo de mensurar a distribuição do acesso ao sistema de transporte, considerando sua conectividade, identificando como ela se dá para os diversos grupos populacionais. O cálculo da conectividade inclui variáveis de frequência para cada linha, capacidade, horário de operação e a quantidade de oportunidades acessíveis a partir de cada nó da rede. O autor ainda considerou, em seus cálculos, a distância do centroide das unidades habitacionais até os pontos de acesso ao sistema de transporte como uma forma de ponderar o fato de existirem habitações ocupadas por um certo grupo populacional com maior vantagem locacional. Através do índice calculado para cada uma das habitações, foram feitas análises de equidade para todo o território através do coeficiente Gini e curvas de Lorenz.

Em um estudo realizado por Stanley et al. (2011), foi criado um modelo para indicar o risco de uma pessoa se tornar socialmente excluída. No modelo, são consideradas variáveis como taxa de viagem, renda familiar e diversas outras variáveis qualitativas coletadas através de entrevistas. Os resultados do modelo indicaram que maiores taxas de mobilidade (viagens e atividades) reduzem o risco de exclusão social, permitindo o aumento do capital social.

No estudo de Xia et al. (2016), o método utilizado para calcular a exclusão social, relacionada ao transporte, consistiu em calcular a oferta de transporte público para a cidade de interesse, identificando áreas de alta e de baixa demanda por transporte público e posterior identificação de áreas com baixa oferta e alta demanda por transporte público. O 
cálculo da oferta de transporte público foi feito através da comparação das áreas de buffer dos pontos de acesso ao sistema de transporte público em relação às áreas dos setores censitários correspondentes. Para identificar áreas com alta demanda por transporte público, foram analisadas variáveis contendo o percentual de famílias com baixa renda, sem posse de automóveis e dentro do grupo de interesse. A partir dos resultados, foram identificadas as áreas menos favorecidas pelo sistema de transporte público e sua população residente, sendo as inequidades mostradas através de curvas de Lorenz e coeficiente Gini.

Em um estudo realizado por Preston e Rajé (2007), em Bristol, Nottingham e Oxfordshire na Inglaterra, foram identificados três critérios para medição do grau de exclusão social relacionada ao transporte:

a) O nível de viagem dentro da área de interesse (mobilidade da área);

b) O nível de viagem realizada por grupos ou indivíduos específicos (mobilidade individual);

c) A acessibilidade geral da área de interesse.

A partir dos critérios utilizados por Preston e Rajé (2007), são geradas oito categorias formadas por áreas com alto ou baixo nível de viagens dentro da área de interesse, alto ou baixo nível de viagens, realizadas por grupos ou indivíduos, e alta ou baixa acessibilidade geral da área de interesse. Os autores ressaltaram que o método empregado pode ajudar na identificação de diferenças chave entre regiões da área de interesse, apoiando respostas políticas apropriadas.

No presente trabalho, foram utilizadas medidas de acessibilidade em conjunto com dados de oferta de empregos, transporte, variáveis socioeconômicas e demográficas para a geração de modelos, para o município de São Paulo, Curitiba e zona central da região metropolitana de Melbourne, que auxiliaram no entendimento do processo de desigualdades de acessibilidade aos empregos. A visualização das desigualdades será apoiada graficamente através de curvas de Lorenz e coeficiente Gini. No próximo capítulo é apresentada uma revisão sobre modelos baseados em agentes, técnica que foi utilizada na criação dos modelos. 


\section{Modelagem Baseada em Agentes}

A modelagem baseada em agentes consiste em um método de modelagem onde objetos, também chamados de agentes, são programados para agir e reagir a estímulos de outros agentes ou do ambiente virtual de modo a satisfazer seus objetivos (GILBERT, 2004). De acordo com Batty (2009b), a modelagem baseada em agentes começou a ser desenvolvida na década de 80 e busca representar, ao longo do tempo e espaço, o comportamento de objetos e/ou populações em seu nível mais elementar. Apesar de ser um modelo desagregado, sua abordagem bottom-up permite a identificação de padrões espaçotemporais mais agregados através da interação entre agentes nas simulações (BONABEAU, 2002; BATTY, 2009b).

A possibilidade dos agentes representarem indivíduos com diferentes características torna o ambiente de simulação complexo, permitindo que a heterogeneidade, adaptabilidade e interação dos agentes crie cenários parametrizáveis (BROWN; ROBINSON, 2006; ANDRADE, 2010). Existem diversos tipos de agentes, porém todos eles compartilham da mesma característica que é serem objetos autodirigidos, ou seja, tomam decisões visando atender a um conjunto de regras previamente definidas (IGLESIAS; GARIJO; GONZÁLEZ, 1998).

Para Macy e Willer (2002), a modelagem baseada em agentes impõe quatro elementos chave:

a) Os agentes são autônomos. O sistema não é modelado diretamente como uma entidade globalmente integrada, mas sim através de uma abordagem bottom-up em que a interação local entre objetos autônomos permite observar padrões globais. Macal e North (2010) complementam ao afirmar que a autonomia dos agentes também inclui a sua independência em relação à interferência externa para situações encontradas ao longo da simulação, devido à existência de um identificador único para cada agente, permitindo que se localizem, se comuniquem e que tenham um limite/geometria. Para Castle et al. (2018), a autonomia permite o desenvolvimento de indivíduos autônomos com percepções distintas do ambiente (heterogeneidade) e que podem integrar grupos de acordo com suas similaridades;

b) Os agentes são interdependentes. A interdependência envolve a influência que um agente exerce sobre outros, considerando que ele já foi influenciado através de processos de persuasão, sanção e imitação. A interdependência também pode ser exercida indiretamente através da mudança do comportamento dos agentes de 
acordo com o ambiente de simulação, ou seja, o ambiente altera o comportamento de agentes, que influenciam os demais agentes. Macal e North (2010) destacam que o processo de influência é exercido pelos agentes através de protocolos de comunicação, movimentação e contenção do espaço;

c) Os agentes seguem regras simples. O fato de nós (seres humanos), seguirmos regras em forma de normas, convenções, protocolos, heurísticas, protocolos morais e hábitos sociais permite a reprodução de um cenário global complexo sem, necessariamente, refletir a complexidade do processo cognitivo de indivíduos. Através de regras simples, modelos baseados em agentes permitem a produção de padrões pouco evidentes e de alta complexidade que podem apoiar a análise exploratória de interesse;

d) Os agentes são adaptativos e possuem memória. A adaptação dos agentes se dá através de seu movimento, imitação, replicação ou ainda aprendizagem. A adaptação pode afetar individualmente agentes ou grupos de agentes (população), respectivamente, através da alteração da distribuição de probabilidade de comportamento de cada agente ou de processos de seleção e influência social que afetam populações. Macal e North (2010) afirmam que os agentes devem ter um estado que muda ao longo do tempo, ou seja, um conjunto de atributos que varia ao longo da simulação. De acordo com Castle et al. (2018), as adaptações são geradas a partir da memória e do aprendizado dos agentes, não passando, necessariamente, para o estado mais eficiente possível.

De acordo com Macal e North (2010), uma típica modelagem baseada em agentes é estruturada da seguinte forma:

a) Criação dos agentes, seus atributos e comportamentos: considerando que os agentes devem ser autônomos, seguir regras simples fornecidas previamente, ser adaptativos e interdependentes;

b) Definição das relações entre os agentes e seus métodos de interação:

a) Deve ser definida a topologia do modelo, ou seja, quais agentes estarão conectados e compartilharão informações. Dentro desse conceito estão as denominadas vizinhanças, que são locais de troca de informações entre agentes;

b) Devem ser definidos os métodos de interação que, além da vizinhança, pode envolver os "espaços sociais", ou seja, encontros entre agentes em locais que não sejam necessariamente a vizinhança.

c) Definição do ambiente em que os agentes estão inseridos: O ambiente pode ser utilizado apenas como contexto de localização dos agentes ou fornecer informações 
cruciais para a modelagem, como valor da terra em simulações econômicas ou de infraestrutura de transporte no caso de simulações de tráfego.

Castle et al. (2018) complementam Macy e Willer (2002) e Macal e North (2010), ao mencionar que na modelagem baseada em agentes é usual considerar ainda as seguintes características:

- Atividade: Agentes são ativos por exercerem influência na simulação, podendo ser identificados da seguinte forma:

- Proativos/direcionados a resultados: Agentes são frequentemente orientados a resultados, tendo objetivos a atingir;

- Reativos/perceptivos: Agentes podem ser criados para ter percepção ou sensibilidade ao ambiente. Podem ser dadas informações prévias sobre outras entidades, obstáculos ou destinos dentro do ambiente de simulação.

- Racionalidade: A forma dominante de modelagem em ciências sociais considera o paradigma racional, em que é assumido que os agentes são otimizadores racionais perfeitos sem restrição de acesso a informações, previsões e capacidade analítica infinita, sendo capazes de resolver otimizações matemáticas complexas para maximizar seu bem-estar considerando recompensas a curto e longo prazo. Entretanto, agentes podem ser configurados para ter racionalidade limitada (heterogeneidade), dessa forma possuindo restrições de informação disponível e percepção;

Para Axelrod (1997), o objetivo de modelos baseados em agentes é o melhor entendimento de processos fundamentais em diversas aplicações, e não necessariamente a replicação desses processos de forma acurada. No passado, as aplicações mais comuns dos modelos baseados em agentes não faziam uso de informações espaciais (LI; LIU, 2008). Apesar dos modelos baseados em agentes e os sistemas de informações geográficas terem se desenvolvido independentemente, a sua integração ocorreu de forma natural com diversas aplicações que permitem o uso de agentes no auxílio de decisões espaciais (BROWN et al., 2005; O’SULLIVAN, 2008).

Os modelos baseados em agentes se destacam em aplicações em sistemas urbanos, que são altamente complexos (WISE; CROOKS; BATTY, 2017). A complexidade dos sistemas urbanos se explica, em parte, pelo seu ambiente formado por diversos atores com características heterogêneas e que muitas vezes possuem objetivos conflitantes (LIGMANNZIELINSKA; JANKOWSKI, 2007). Apesar da alta complexidade dos sistemas urbanos, a ideia dos modelos baseados em agentes aplicados aos sistemas urbanos é relativamente 
simples, pois é necessária a criação de agentes em locais específicos com distintos mecanismos de decisão e avaliação da realidade social e física urbana, permitindo que eles tomem decisões de acordo com suas regras (BENENSON, 2004).

Para Benenson (2004), os modelos espaciais propiciam o entendimento do comportamento dos agentes e assim auxiliam na proposição de políticas sociais. Barros (2012) argumenta que os processos urbanos são influenciados diretamente pelas decisões humanas, sendo a modelagem baseada em agentes uma ferramenta que permite explicitar tais processos urbanos de maneira dinâmica, avaliando seus impactos no âmbito social e espacial.

Diversos modelos foram desenvolvidos para cidades brasileiras e latino-americanas, como nos trabalhos de Almeida et al. (2005), Feitosa, Bao e Vlek (2011), Barros (2012). Almeida et al. (2005) desenvolveram um modelo de uso e ocupação do solo dinâmico através de dados de sensoriamento remoto para uma cidade de médio porte no estado de São Paulo, simulando a mudança no uso e ocupação do solo para identificar vetores de expansão urbana e tendências gerais de ocupação.

Barros (2012) também investigou o crescimento urbano, mas focando no processo dinâmico de periferização das cidades latino-americanas. A autora considerou três grupos socioeconômicos (baixa, média e alta-renda) e explorou, através de um modelo baseado em agentes, o processo de segregação em que grupos de alta-renda se instalam em regiões centrais dos municípios, enquanto os grupos de baixa-renda se instalam nas regiões periféricas.

Feitosa, Bao e Vlek (2011) simularam a segregação espacial através do modelo intitulado Multi-Agent Simulator for Urban Segregation (MASUS), que é uma plataforma virtual para simulação de cenários alternativos e exploração de mecanismos que podem influenciar nos padrões de segregação urbana. Os autores trabalharam em um estudo de caso onde um cenário base é confrontado com outros dois cenários alternativos em que são aplicadas políticas de mobilidade residencial para aliviar a exclusão social em uma cidade de médio porte no estado de São Paulo. Os autores concluíram que a modelagem baseada em agentes é um instrumento promissor para o melhor entendimento e simulação de políticas com relação à segregação espacial. 


\subsection{Acessibilidade e Escolha Residencial em Modelos Baseados em Agentes}

Waddell et al. (2007) afirmam que a influência da acessibilidade na localização de empreendimentos residenciais, comerciais, densidade populacional e no valor da terra é conhecido de longa data. Uma das primeiras teorias de organização do território foi proposta por Von Thünen, em que a acessibilidade ao mercado de uma cidade monocêntrica é representada pelo custo de transporte de produtos agrícolas (SINCLAIR, 1967). Dessa forma, Von Thünen apresentou um modelo em que os custos de transporte inibem um cultivo de maior intensidade em áreas distantes dos centros urbanos (SINCLAIR, 1967). Em uma estrutura urbana, Wingo (1961) e Alonso (1964), foram os pioneiros na abordagem do processo de escolha residencial, considerando o trade-off entre o custo de transporte e o aluguel de habitações (VICKERMAN, 1974).

A escolha do local de residência é uma das decisões mais críticas que podem ser tomadas por um indivíduo ou família, já que impacta profundamente os padrões de viagem de seus membros e daqueles que interagem com eles (SENER; PENDYALA; BHAT, 2011). O processo de escolha residencial é tratado por Kim, Pagliara e Preston (2005) como uma função complexa que envolve um amplo espectro de atributos de residências e de localização, onde o peso de cada um desses atributos varia a depender da família. Uma família formada por dois trabalhadores e duas crianças, certamente, estará mais interessada na acessibilidade a escolas e trabalho, ao passo que uma família formada por dois aposentados estará mais interessada na acessibilidade a amenidades e a seus contatos sociais (ZONDAG; PIETERS, 2005).

De acordo com Benenson (2004), uma vez que uma família resida em um determinado local, o processo de mudança residencial envolve a análise de três componentes: o benefício da localização da atual residência; o custo de mudança da atual residência; e os potenciais benefícios da nova localização residencial. Os benefícios podem ser calculados de diversas formas, sendo um exemplo clássico a relação de proximidade entre a residência e o trabalho (BENENSON, 2004). O conceito de acessibilidade pode ser aplicado para estimar tais benefícios.

O estudo da escolha residencial é de grande importância na modelagem do uso e ocupação do solo e transportes, pois influencia diretamente a evolução do ambiente construído, moldando o sistema de transporte, uso e ocupação do solo e forma urbana (GUO; BHAT, 2007; SENER; PENDYALA; BHAT, 2011). Outro fator de interesse para a área de planejamento de transportes é o entendimento das causas que influenciam na 
escolha residencial e suas consequências no sistema de transporte (GUO; BHAT, 2007).

Os primeiros modelos criados para estudar as relações entre o uso e ocupação do solo e transportes eram modelos agregados, mas, com o passar do tempo, eles foram sendo desagregados até famílias e residências serem representadas por agentes, demandando melhores regras para alocação e escolha residencial (ETTEMA, 2011).

Waddell (2002) desenvolveu um modelo de escolha residencial onde são selecionadas aleatoriamente amostras de residências vagas para famílias não alocadas e, através de um modelo logístico calibrado para os dados observados, as residências são avaliadas em relação à sua atratividade. As variáveis que integram o modelo de escolha residencial são a acessibilidade regional aos empregos, as características das residências (preço, densidade e idade) e as características da vizinhança (uso e ocupação do solo, densidade, valores médios das residências e acessibilidade a estabelecimentos de varejo). A medida de acessibilidade utilizada é a cumulativa, ou seja, considera a soma de atividades (empregos, etc.) dentro de um limite pré-determinado de tempo ou distância para cada uma das zonas de tráfego. Além de ser aplicada no modelo de escolha residencial, a acessibilidade ainda foi utilizada nos modelos de desenvolvimento imobiliário e de valor da terra.

Zhou e Kockelman (2008) desenvolveram um modelo para simular a distribuição de novas famílias na cidade de Austin, Texas, e seu impacto nos preços das habitações através de microssimulação. O modelo possui uma função de utilidade onde a acessibilidade é incorporada indiretamente através de uma variável de tempo de viagem ao trabalho. Caso a família em análise não seja composta por pelo menos um trabalhador, a variável de tempo de viagem ao trabalho perde importância. Caso a família seja composta por mais de um trabalhador, a variável de tempo de viagem ganha ainda mais importância.

Fontaine e Rounsevell (2009) modelaram a atratividade potencial de residências na região de Norwich, Inglaterra, se utilizando de uma função de utilidade composta por dois fatores: externalidades locais e acessibilidades. No modelo, os agentes podem se mudar de residência apenas quando passam de um ciclo de vida para outro, ou seja, quando se casam, ganham novos membros, se aposentam ou perdem membros. Uma vez alterado o atributo da família, os agentes passam a buscar novas residências ordenando suas opções de moradia de acordo com a atratividade potencial, que varia de acordo com o ciclo de vida dos agentes. O fator acessibilidade é incorporado ao modelo através do cálculo das distâncias entre as residências e os sistemas de transporte, empregos, locais de lazer e centros de serviços. Uma função exponencial negativa é aplicada para refletir a importância dos pontos de interesse para cada uma das famílias.

No modelo de escolha residencial proposto por Lee et al. (2010), foram utilizadas 
quatro variáveis de acessibilidade em conjunto com outras variáveis que caracterizam as residências e as famílias. As variáveis de acessibilidade foram empregadas para captar a facilidade de acesso a diversas oportunidades, incluindo empregos e estabelecimentos comerciais. As acessibilidades foram calculadas através de diferentes métodos, como a baseada na utilidade, cumulativa e prisma espaço-tempo.

Jordan, Birkin e Evans (2014) apresentaram um modelo baseado em agentes para explorar a migração de famílias, a escolha residencial e a análise de políticas públicas de regeneração na cidade de Leeds (Inglaterra). A acessibilidade é empregada indiretamente no modelo através de variáveis de atratividade de residências em relação a infraestrutura de transporte e proximidade de escolas. As residências localizadas a até 1 milha de distância de vias principais recebem um atributo de atratividade máxima. Da mesma forma, as residências localizadas a até 3 milhas de escolas recebem atributos de atratividade máxima. Os autores concluíram que políticas de regeneração podem levar a posse de habitações por grupos socioeconômicos mais heterogêneos.

Babakan e Taleai (2015) desenvolveram um modelo para investigar a influência da implantação de novas infraestruturas de transporte na escolha residencial de inquilinos. Foram construídos três cenários distintos na área de estudo, sendo o primeiro a criação de uma nova rodovia, o segundo a implantação de uma nova linha de metrô, e por fim, simulada a implantação de uma linha de Bus Rapid Transit (BRT). Para cada cenário, são recalculadas as acessibilidades aos trabalhos e equipamentos urbanos, que compõem uma das várias funções de utilidade que devem ser maximizadas. Os resultados mostram que os diferentes cenários impactam significativamente a composição dos grupos socioeconômicos da área de estudo e levam a mudanças na posse de veículos, demanda por residências e composição dos residentes.

Babakan e Alimohammadi (2016) propuseram uma nova abordagem do problema de escolha da localização residencial através de um modelo baseado em agentes. O objetivo dos autores foi criar um modelo de escolha residencial para inquilinos na cidade de Teerã, Irã, considerando que os inquilinos são agentes com preferências distintas por moradia. As moradias possuem uma série de atributos, como aluguel, acessibilidade a equipamentos e serviços, distância ao trabalho e poluição do ambiente. Os atributos das moradias são ponderados pelos inquilinos para escolherem qual a melhor alternativa. A acessibilidade aos equipamentos, serviços, transportes e demais características das residências são inseridas em uma função-objetivo que é utilizada para otimizar o processo de escolha de acordo com as preferências de cada um dos agentes.

Zhuge et al. (2016) propuseram um modelo baseado em agentes de escolha de localização residencial e valor imobiliário para integrar o SelfSim. O SelfSim é um modelo 
baseado em agentes criado com o objetivo de explorar a dinâmica evolutiva do uso e ocupação do solo e transportes. Para simular o comportamento de famílias no processo de escolha residencial, foi desenvolvida uma função de utilidade que possui apenas duas variáveis: acessibilidade e preço. Para quantificar a acessibilidade, é empregado um modelo de atividades e gerado um score médio que considera todas as atividades das pessoas que integram as famílias. A acessibilidade é calculada para o local da residência atual e para as residências alternativas que, em conjunto com o preço, integram a função de utilidade a ser maximizada.

Guo, Buchmann e Schwarz (2019) exploraram a segregação de pessoas com diferentes níveis de renda e o espraiamento urbano através de um modelo baseado em agentes. $\mathrm{Na}$ modelagem da escolha da localização residencial, os autores seguiram o modelo de Alonso. Para o cálculo dos gastos de transporte, a distância até o centro de negócios é utilizada como proxy da acessibilidade. Uma vez calculados o consumo e a área de moradia, é maximizada uma função de utilidade.

O presente trabalho buscou preencher a lacuna da literatura de explorar as desigualdades de acessibilidade aos empregos. Assim como os autores citados anteriormente, foi implementado um modelo baseado em agentes, porém com uma dinâmica de escolha residencial e função de utilidade distintas.

Nos estudos citados anteriormente, uma das preocupações dos autores foi explicitar a capacidade do modelo em representar o fenômeno modelado na área de estudo. Muitos modelos são calibrados utilizando dados históricos (WADDELL, 2002; BABAKAN; ALIMOHAMMADI, 2016; ZHUGE et al., 2016), enquanto a sua validação é realizada com dados observados na realidade (WADDELL, 2002; BABAKAN; TALEAI, 2015; ZHUGE et al., 2016; GUO; BUCHMANN; SCHWARZ, 2019). A seção 3.2 apresenta maiores detalhes sobre verificação, calibração e validação de modelos.

\subsection{Verificação, Calibração e Validação de Modelos}

Para Midgley, Marks e Kunchamwar (2007), a qualidade de um modelo baseado em agentes é algo difícil de ser avaliada devido a heterogeneidade dos agentes e a possibilidade de surgimento de novos padrões de acordo com a interação entre agentes ao longo das simulações. Para Crooks, Castle e Batty (2008), as etapas de verificação, calibração e validação constituem alguns dos maiores desafios na utilização de modelos baseados em agentes. 


\subsubsection{Verificação}

O processo de verificação consiste no teste de consistência interna do modelo (BATTY, 2009b). A verificação foca na teoria base do modelo e sua implementação computacional, sendo a exatidão da implementação do modelo teórico o foco do processo de verificação (MANSON, 2003; BOERO; SQUAZZONI, 2005). De acordo com Xiang, Kennedy e Madey (2005), a verificação pode incluir desde depuração de software, na busca de erros de implementação do modelo conceitual, até a verificação de cálculos e resultados oriundos das simulações.

Com o objetivo de minimizar erros de implementação e de sub-representação do problema, Castle et al. (2018) propõem que a documentação do código fonte do modelo e de seus resultados esteja contemplada na fase de verificação, permitindo sua reprodução e interpretação dos resultados.

\subsubsection{Calibração}

Uma vez criado um modelo, é essencial que seus parâmetros sejam ajustados para que os resultados sejam os mais próximos possíveis da realidade, sendo esse processo de ajuste de parâmetros de um modelo denominado calibração (GON; ZEIGLER; PRAEHOFER, 2000). A calibração é um processo de dimensionamento do modelo, através de um conjunto de dados, que se dá por meio da identificação e do ajuste fino de parâmetros que permitam que o modelo reproduza características dos dados da melhor forma possível (BATTY, 2009b; CROOKS; CASTLE; BATTY, 2008). Para Crooks, Castle e Batty (2008), a calibração frequentemente envolve a validação, pois o conjunto de dados selecionado para a calibração usualmente é escolhido de acordo com o melhor ajuste do modelo.

Werker e Brenner (2004) propuseram três passos para a calibração empírica de um modelo:

a) Identificar fatores e variáveis relevantes para a criação da estrutura do modelo. Normalmente essa etapa é realizada através do conhecimento teórico sobre o tema, sendo o detalhamento e a especificação dos parâmetros do modelo ajustados através de dados empíricos ou simulações;

b) Rodar separadamente simulações para cada um dos parâmetros do modelo e estudar suas características. Para cada parâmetro, deverá ser observado se os resultados das simulações se encontram dentro de um intervalo teórico aceitável; 
c) Manter apenas os parâmetros do modelo que apresentam maior probabilidade de estarem relacionados ao fenômeno modelado e, através do conhecimento teórico sobre o fenômeno, limitar ao máximo o espaço dos parâmetros no modelo.

A calibração de um modelo geralmente ocorre de maneira iterativa até que os seus resultados, dentro de uma tolerância, se ajustem aos dados coletados no mundo real (CASTLE et al., 2018). Uma vez que os resultados do modelo não consigam ser ajustados aos dados do mundo real, o programador poderá ter que alterar regras de comportamento ou interação dos agentes, de modo que a etapa de calibração apoie a etapa de verificação (CASTLE et al., 2018).

Windrum, Fagiolo e Moneta (2007) propuseram um método de calibração indireta, em que primeiramente é realizada a validação do modelo, e seu resultado é utilizado como entrada no processo de calibração. Nesse método de calibração, devem ser identificados os fatos de interesse que o modelo deve reproduzir ou explicar calibrando seus parâmetros da maneira mais próxima possível das evidências empíricas do comportamento e interações no mundo real. Por fim, através de dados empíricos e resultados da validação, são selecionados e calibrados os parâmetros e condições iniciais do modelo.

\subsubsection{Validação}

Um modelo é considerado válido quando ele representa adequadamente o sistema que está sendo modelado (CASTLE et al., 2018). De acordo com Batty (2009b), os primeiros modelos computacionais implementados foram vistos como traduções de teorias e hipóteses em ambientes virtuais, que poderiam ser testados em relação a dados empíricos. O confronto de modelos teóricos com dados empíricos, permitindo aceitar ou rejeitar teorias, é denominado validação (BATTY, 2009b). De acordo com Batty (2009b), a validação de um modelo é essencial antes de sua utilização para fins profissionais. Para North e Macal (2007), o processo de validação geralmente se refere ao quanto o modelo representa e reproduz corretamente os sistemas do mundo real. Para Boero e Squazzoni (2005), a validação de um modelo se dá através da comparação intensa de dados artificiais, resultantes da simulação, com dados empíricos.

Para Tesfatsion (2007), existem quatro aspectos de validação de modelos computacionais:

a) Validação dos dados de entrada: análise da relevância e validade dos dados e parâmetros de entrada do modelo para o seu propósito; 
b) Validação do processo: análise de como os processos representados no modelo refletem aspectos do mundo real. Deve ser avaliado se todos os parâmetros essenciais para a representação do fenômeno estão sendo modelados;

c) Validação descritiva da saída: através dos dados de saída e dos dados empíricos, analisar o quanto o modelo está captando as especificidades do fenômeno modelado;

d) Validação da predição: análise de quão bem o modelo gera previsões. Para a validação, devem ser utilizados conjuntos de dados para o período previsto, sendo possível coletá-los futuramente.

Como resultado final da validação, ao invés do modelo ser classificado como válido ou inválido, ele recebe um grau de validade relacionado ao seu ajuste aos dados empíricos (HEPPENSTALL et al., 2012).

Para Axelrod e Tesfatsion (2006), frequentemente, é necessário avaliar a "história" de uma simulação para validar um modelo. A "história" de uma simulação pode incluir uma seleção de elementos chave de eventos em ordem cronológica, a documentação das ações ou ainda padrões globais da distribuição de agentes (AXELROD; TESFATSION, 2006). Segundo Castle et al. (2018), avaliar a "história" de uma simulação pode passar uma falsa impressão de sua validade, especialmente quando incluídos elementos aleatórios. Para determinar se o resultado de uma simulação é considerado típico, são necessárias várias simulações com parâmetros e condições iniciais iguais considerando diferentes sementes, permitindo identificar se as "histórias" são típicas ou idiossincráticas (CASTLE et al., 2018).

Outra técnica para identificar a robustez de um modelo é a análise de sensibilidade, em que o modelador estima como mudanças nos dados e parâmetros de entrada afetam os resultados finais de um modelo (KELTON, 1999). Se o comportamento do modelo é demasiadamente sensível a pequenas alterações em um ou mais parâmetros, devem ser tomados cuidados extras com a exatidão desses valores (CASTLE et al., 2018). Para a análise de sensibilidade, podem ser criadas diferentes versões do modelo em questão, com diferentes parâmetros, e rodados experimentos em ambientes controlados para avaliar os efeitos das mudanças (CASTLE et al., 2018). 


\section{Modelo para Análise das Desigualdades de Acessibilidade aos Empregos}

O presente modelo foi desenvolvido para explorar as desigualdades de acessibilidade a empregos considerando diferentes grupos sociais. Foi adotada uma abordagem generativa conforme Epstein (1999), em que os padrões espaciais de localização residencial, que resultam nas desigualdades de acessibilidade aos empregos, emergem de agentes que são inicialmente alocados aleatoriamente no espaço. No modelo, três grupos de agentes, com diferentes prioridades de realocação, disputam as habitações em um ambiente em que transporte, empregos e oferta de habitações podem ser simulados. O modelo simula a localização residencial dos agentes sem considerar a competição entre diferentes tipos de uso do solo.

A proporção de agentes por grupo social, configuração do transporte público e a oferta de emprego e habitação são exógenas ao modelo, permitindo que ele seja adaptado a diferentes realidades. O processo de localização residencial considera uma função de utilidade composta por acessibilidade aos empregos e status da vizinhança. Na inicialização do modelo, os agentes são alocados aleatoriamente no ambiente de acordo com a oferta de habitação de cada célula. Ao longo da simulação, o tempo é discretizado na forma de iterações do modelo. A localização residencial simulada resulta em diferentes padrões de acessibilidade a empregos para os agentes de cada grupo social, sendo monitorada ao longo da simulação através do índice de Gini e curvas de Lorenz.

O modelo é composto pelos submodelos de ambiente e trabalhadores (Figura 2), que são apresentados nas subseções seguintes. No submodelo trabalhadores, é apresentada a função de utilidade. A utilidade é a variável utilizada pelos agentes para o processo de escolha residencial e possui como variáveis explicativas a acessibilidade aos empregos e o status da vizinhança. São apresentados também os fatores experimentais, que são os parâmetros configuráveis do modelo. Por fim, é apresentada a plataforma de implementação do modelo.

\subsection{Submodelo Ambiente}

O submodelo ambiente é composto por uma grade de células com três atributos constantes representando o uso do solo: emprego, habitação e oferta de transporte. Os 


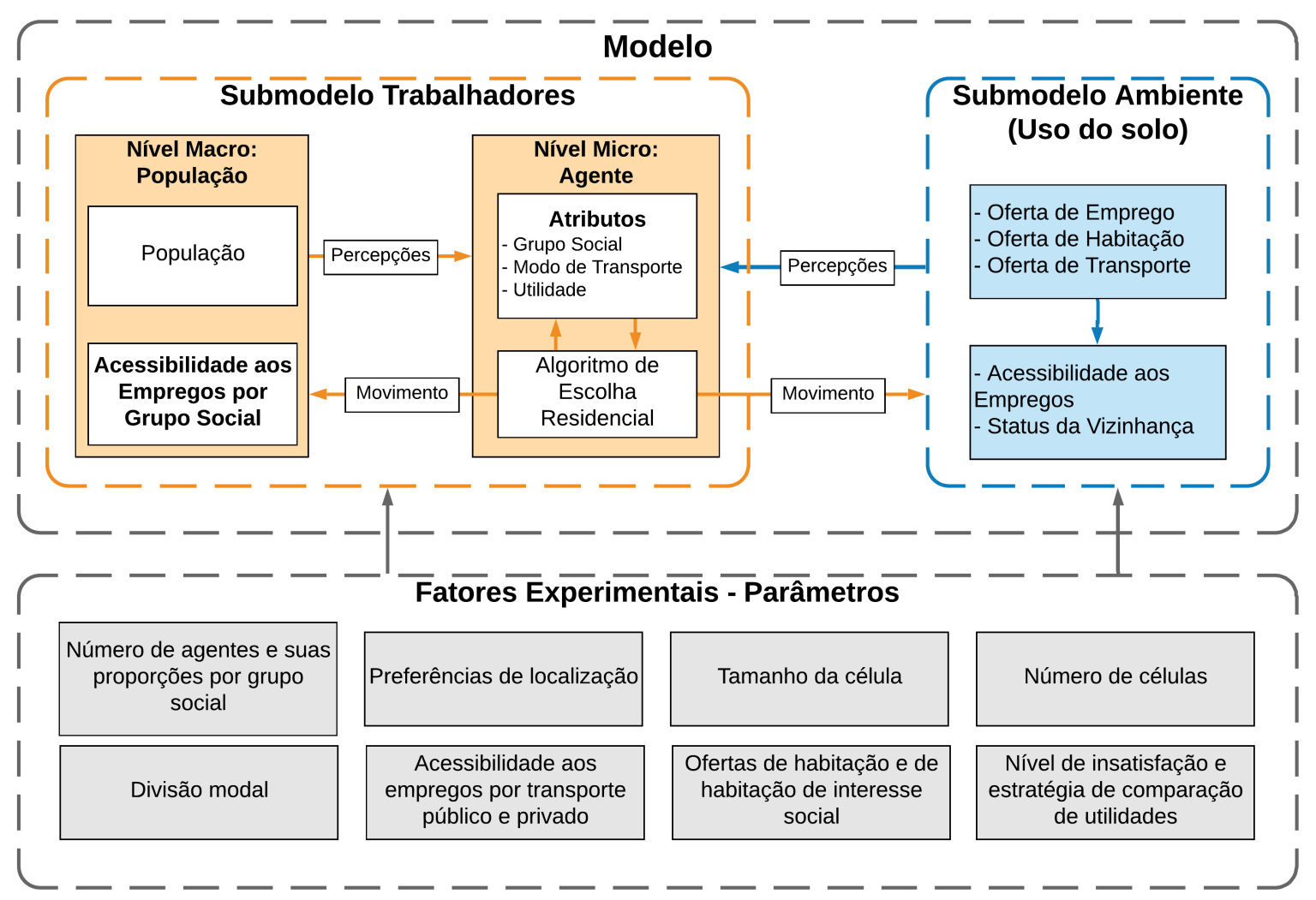

Figura 2 - Modelo conceitual e fatores experimentais.

atributos de oferta de empregos e de transporte são utilizados no cálculo da acessibilidade por transporte público e privado, que se mantêm constantes ao longo da simulação. A oferta de habitação é utilizada no cálculo do status da vizinhança, que é dinâmico, pois é influenciado diretamente pela alocação dos agentes.

A acessibilidade aos empregos é um componente exógeno ao modelo, sendo o usuário livre para escolher a medida que melhor caracteriza a área de interesse.

O status da vizinhança é um componente endógeno ao modelo, representando a atratividade da célula com base na localização residencial dos agentes de cada grupo social. Cada agente possui um atributo de status que varia de 1 a 3 , de acordo com seu grupo social. O status da vizinhança de uma célula é calculado a partir da média dos status dos agentes alocados na célula e em sua vizinhança de Moore $^{1}$.

Tanto a acessibilidade aos empregos quanto o status da vizinhança são normalizados para o cálculo da utilidade dos agentes.

\footnotetext{
1 A vizinhança de Moore é formada pela célula de referência e suas oito células vizinhas.
} 


\subsection{Submodelo Trabalhadores}

O submodelo trabalhadores foi criado para simular a dinâmica de localização da população trabalhadora. O submodelo é estratificado em níveis micro e macro.

No nível micro, temos os agentes com seus atributos e o algoritmo de escolha residencial. Os agentes são caracterizados por três atributos: grupo social; modo de transporte; e utilidade.

O atributo de grupo social é utilizado para definir o grupo social do agente. O grupo social 1 representa o grupo de alto status, o grupo 2 de médio status e o grupo 3 de baixo status. O modelo foi concebido para representar diferentes realidades considerando as bases de dados disponíveis, logo, variáveis de renda ou demais variáveis podem ser utilizadas como proxy para os grupos sociais.

Os grupos sociais são diferenciadas de acordo com suas prioridades no processo de escolha residencial. Conforme proposto por Guo, Buchmann e Schwarz (2019), a prioridade é modelada para representar o poder político e financeiro dos grupos sociais mais altos em transformar e ocupar locais de acordo com seus interesses. Agentes do grupo social 1 têm prioridade sobre agentes do grupo social 2 e 3, enquanto agentes do grupo social 2 têm prioridade sobre agentes do grupo social 3.

O atributo de modo de transporte é usado para definir se o agente utilizará transporte público ou privado. O atributo de modo de transporte é designado de acordo com a divisão modal de cada grupo social. Uma vez designado, o agente considerará a acessibilidade aos empregos correspondentes ao modo de transporte para o cálculo da acessibilidade.

O objetivo de cada agente é maximizar sua função de utilidade, que leva em consideração a acessibilidade aos empregos e o status da vizinhança. O parâmetro de acessibilidade aos empregos foi inspirado no trabalho clássico de Fujita (1989) em escolha residencial, em que uma família leva em consideração três variáveis: acessibilidade, espaço e ambiente. O parâmetro de status da vizinhança é baseado no trabalho pioneiro de Schelling (1978) e trabalhos mais recentes de Benenson, Omer e Hatna (2002), Barros (2005) e Feitosa, Bao e Vlek (2011) sobre segregação residencial e a relevância da composição populacional em processos de escolha residencial.

Este trabalho adotou a função de utilidade (Eq.(4.1)), que considera a literatura 
supramencionada e procura capturar os conceitos mais importantes em uma função simples:

$$
U_{i}=\text { acessibilidade }_{l m}^{\alpha} \times \text { status }_{l}^{(1-\alpha)}
$$

Na Eq.(4.1), $U_{i}$ é a utilidade do indivíduo $i$, acessibilidade é a acessibilidade aos empregos normalizada da célula $l$ onde o agente se localiza e de acordo com o seu modo de transporte $m$, status é o status da vizinhança normalizado na célula $l$ e $\alpha$ é o peso dado aos parâmetros. O conjunto de alternativas dos indivíduos é formado pelo número de residências, que varia de acordo com a área de estudo.

O parâmetro de peso $(\alpha)$, é utilizado para ponderar a acessibilidade aos empregos e o status da vizinhança na função de utilidade. O parâmetro $\alpha$ varia entre 0 e 1 , sendo que 0 representa peso total para o status da vizinhança e 1 peso total para acessibilidade aos empregos. Através do parâmetro $\alpha$, é possível simular diferentes comportamentos dos agentes e, dessa forma, calibrar o modelo para diferentes realidades.

No nível micro está o algoritmo de localização residencial. O algoritmo seleciona uma célula aleatória e avalia se a utilidade do agente aumentará na nova célula. Uma vez encontrada uma célula com maior utilidade, é avaliado se existe disponibilidade de habitação. Se sim, o agente se move para a nova célula deixando a sua célula anterior com uma habitação vaga. Caso seja identificada uma célula de maior utilidade, porém sem habitação disponível, é avaliado se existe algum agente com menor prioridade para ser expulso.

O agente expulso realiza uma escolha aleatória no ambiente para se realocar em uma célula de maior utilidade. Se não houver células de maior utilidade, o agente será alocado em uma célula com utilidade igual ou menor que a sua célula anterior, desde que haja disponibilidade de habitação.

No algoritmo de localização residencial, o nivel de insatisfação dos agentes e a estratégia de comparação das utilidades são configuradas. Ambos os parâmetros são intrinsecamente relacionados ao dinamismo do modelo e foram inspirados pela satisfação individual e geral de Guo, Buchmann e Schwarz (2019).

O nível de insatisfação dos agentes é um parâmetro utilizado para tornar o processo de realocação dos agentes mais ou menos acentuado na simulação. O parâmetro varia de 0 a 100 e define o percentual de agentes que buscarão novas moradias. O nível de insatisfação é atribuído aleatoriamente aos agentes na inicialização do modelo. Atribuída a insatisfação aos agentes, são selecionados os agentes com insatisfação maior ou igual ao 
parâmetro adotado na simulação para que eles busquem novas habitações.

A estratégia de comparação de utilidade é usada para definir se os agentes compararão suas utilidades com agentes do mesmo ou diferentes grupos sociais. De acordo com o parâmetro adotado, os agentes se tornam mais ou menos exigentes em relação ao local de moradia. Por exemplo, a estratégia de comparação de utilidade entre diferentes grupos diminui o nível de exigência dos agentes do grupo 1, pois suas utilidades são comparadas as dos agentes dos grupos 2 e 3. Para agentes do grupo social 3, o efeito é inverso, pois sua utilidade é comparada com o todos os demais agentes, incluindo aqueles com maior prioridade que, consequentemente, possuem maior utilidade. Por outro lado, quando a estratégia de comparação de utilidade é entre agentes do mesmo grupo social, o grupo social 1 se torna mais exigente, pois suas utilidades são comparadas com agentes do mesmo grupo, que possuem a mais alta prioridade de realocação. Pelo mesmo motivo, agentes do grupo social 3 se tornam menos exigentes.

No nível macro está a população, que apresenta atributos sociodemográficos como a população total, proporção de agentes em cada grupo social e prioridades de realocação. Através desses atributos, os agentes são criados para representar características sociodemográficas específicas da área de interesse.

Definidos os parâmetros e atributos, inicia-se a etapa de processamento. Na etapa de processamento, ocorrem as buscas aleatórias dos agentes insatisfeitos por habitações em novas células. A ordem dos agentes para as buscas de novas habitações é aleatória e o modelo completa uma iteração quando todos os agentes insatisfeitos da simulação fazem a busca por novas habitações. São realizadas diversas iterações ao longo das simulação até que as utilidades dos agentes sejam maximizadas e eles não consigam mais se mover para habitações com maior utilidade. Quando os agentes não conseguem mais se realocar, a acessibilidade aos empregos por grupo social é analisada.

A Figura 3 mostra o procedimento do modelo, incluíndo: (1) os dados de entrada e configurações dos agentes e ambiente; (2) A inicialização das células e agentes, com seu nível de insatisfação, estratégia de comparação de utilidade e alocação inicial aleatória dos agentes; (3) o procedimento de simulação; e (4) as saídas das simulações.

\subsection{Fatores Experimentais}

Os fatores experimentais consistem nos parâmetros que permitem ao modelo simular cenários alternativos. 


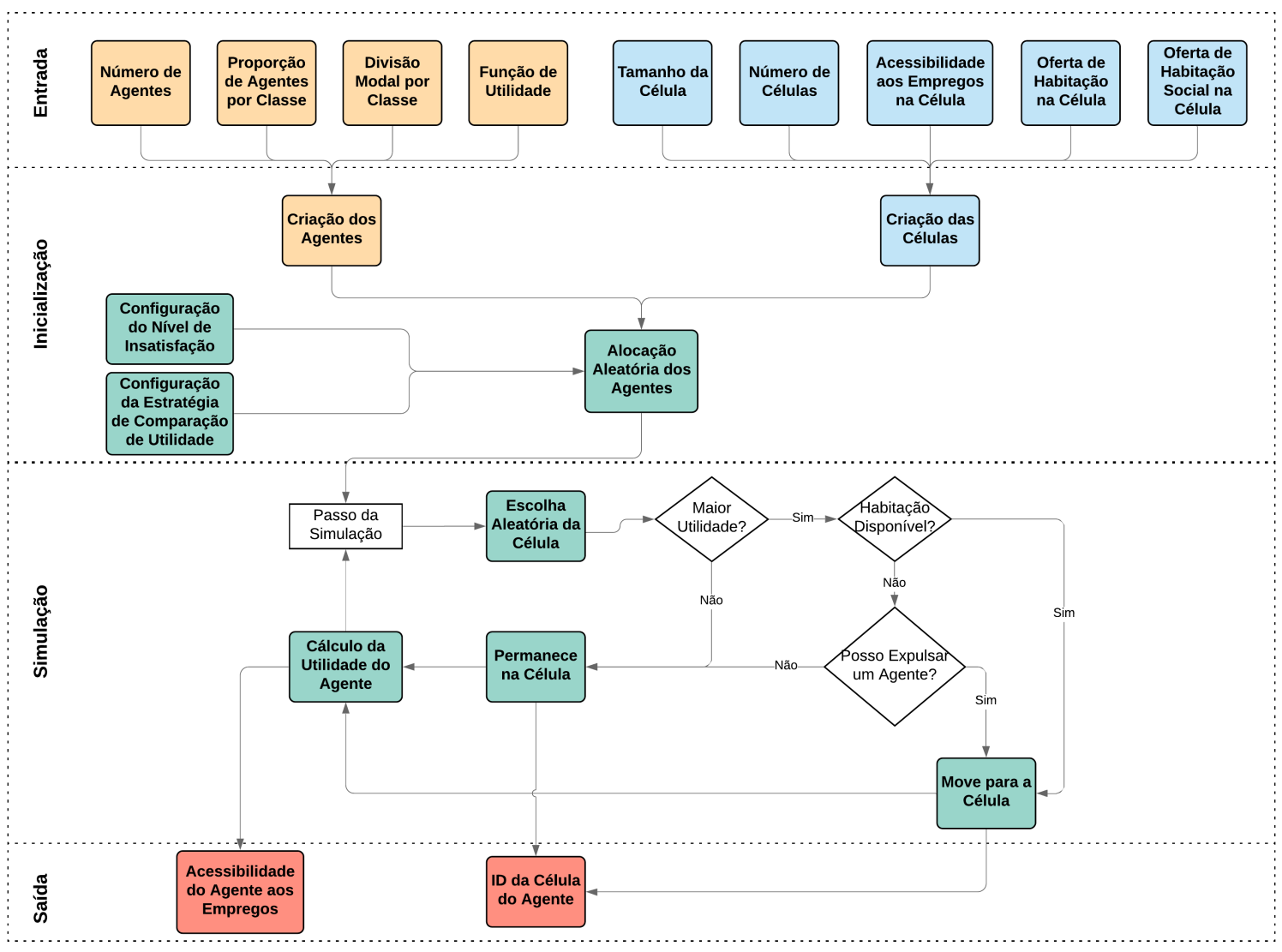

Figura 3 - Fluxograma do Modelo.

O número de agentes e suas proporções por grupo social são fatores experimentais chave para adaptar o modelo a diferentes realidades. Através desses parâmetros, cidades com diferentes populações e composições sociais podem ser simuladas.

As preferências de localização dos agentes são utilizadas para definir o peso da acessibilidade aos empregos e status da vizinhança no algoritmo de escolha residencial. Na prática, esse fator experimental consiste no parâmetro $\alpha$ da função de utilidade. Através desse fator, é possível adaptar o modelo e simular o processo de realocação considerando agentes com diferentes comportamentos.

O tamanho e número de células são fatores experimentais que permitem simular áreas de interesse com maior ou menor nível de detalhe.

O parâmetro de divisão modal influencia a localização residencial de acordo com a oferta de transporte público e privado em cada uma das células do ambiente. O parâmetro pode ser usado para simular sociedades com diferentes níveis de posse de automóvel.

As acessibilidades aos empregos por transporte público e privado são fatores experimentais que podem ser utilizados na simulação de cenários alternativos de oferta de 
transporte e empregos. Uma vez que o usuário do modelo queira simular um cenário com diferentes ofertas de transporte e empregos, as acessibilidades devem ser recalculadas e importadas ao modelo.

As ofertas de habitação e de habitação de interesse social permitem simular cenários com diferentes densidades residenciais. O objetivo de simular habitações de interesse social é investigar o impacto de habitações exclusivas para os agentes do grupo social 3 em diferentes locais do ambiente de simulação em conjunto com distintas ofertas de transporte.

Os últimos fatores experimentais são o nível de insatisfação e a estratégia de comparação de utilidades. O nível de insatisfação pode ser utilizado para simular sociedades ou cenários com processos mais rápidos ou mais lentos de dinâmica de realocação residencial. A estratégia de comparação de utilidades pode ser utilizada para simular realidades com distintos padrões de segregação.

\subsection{Plataforma de Implementação do Modelo}

A plataforma escolhida para implementar o modelo foi o NetLogo. Com aplicações em diversas áreas do conhecimento, a plataforma é disponibilizada gratuitamente pela universidade Northwestern (SKLAR, 2007). De acordo com Thiele, Kurth e Grimm (2014), a utilização do NetLogo requer baixo esforço por parte do usuário, pois seu processo de instalação é consideravelmente simples, se comparado com outras plataformas, e existe uma extensa documentação disponível na internet sobre a plataforma e sua linguagem de programação. Para Sondahl, Tisue e Wilensky (2006), apesar da plataforma permitir que iniciantes criem modelos, existe um trade-off inevitável entre a complexidade do modelo e a facilidade de implementação, sendo possível gerar modelos simples (para iniciantes) e extremamente complexos para usuários mais experientes.

A plataforma dispõe de ferramentas para análise de modelos, como interfaces gráficas onde diversos parâmetros do modelo podem ser alterados dinamicamente e se integra com o pacote estatístico R para análises mais avançadas (THIELE; GRIMM, 2010).

No processo de modelagem no NetLogo existem três tipos de agentes (WILENSKY, 2001):

a) Turtles: são os agentes a serem modelados; 
b) Patches: da mesma forma que as turtles, são agentes, porém que não se movem e estão em todo o ambiente de simulação. Quando iniciada a simulação, a grade do ambiente é definida em termos de quantidade de patches;

c) Links: são agentes que conectam duas turtles. Podem ser utilizados para definir as interações entre as turtles.

Para o modelo implementado, foram criados agentes e o ambiente de simulação. O ambiente de simulação é formado por células quadradas com atributos de oferta de emprego, habitação, transporte, acessibilidade aos empregos e status da vizinhança, enquanto os agentes trabalhadores se movimentam no ambiente de simulação.

O resultado das simulações é a escolha de uma habitação pelos agentes no ambiente de simulação. Os agentes apresentam uma utilidade em cada uma das células, que pode variar de acordo com o parâmetro $\alpha$ de cada grupo social. A quantidade de agentes que podem habitar uma célula é dada pelo número de habitações na célula, havendo dessa forma células com diferentes densidades demográficas. Conforme são alterados os cenários de oferta de transporte, habitação e emprego, as utilidades das células são alteradas e refletem nos padrões de escolha residencial dos agentes nas simulações.

O fluxograma geral (Figura 4) sintetiza as etapas desenvolvidas no trabalho. A primeira etapa foi a definição do modelo conceitual, incluindo os submodelos e fatores experimentais. Definido o modelo conceitual, foram coletados dados socioeconômicos, de transportes e uso do solo (habitação e emprego) para parametrizar o modelo. Após parametrizar o modelo, foi feita a sua implementação na plataforma Netlogo e em seguida a sua verificação. Na etapa de verificação do modelo foi avaliado se o modelo foi implementado de acordo com os requisitos técnicos especificados no modelo conceitual. Após a etapa de verificação, passou-se para a etapa de simulação, onde foi feita a reconstituição da situação observada através do modelo. Na etapa de simulação foi realizada a calibração do modelo, que consistiu em alterar os valores do parâmetro $\alpha$ e avaliadas as correlações das saídas do modelo com a situação observada. Por fim, temos as saídas do modelo que consistem na localização dos agentes com suas utilidades e acessibilidade aos empregos. 


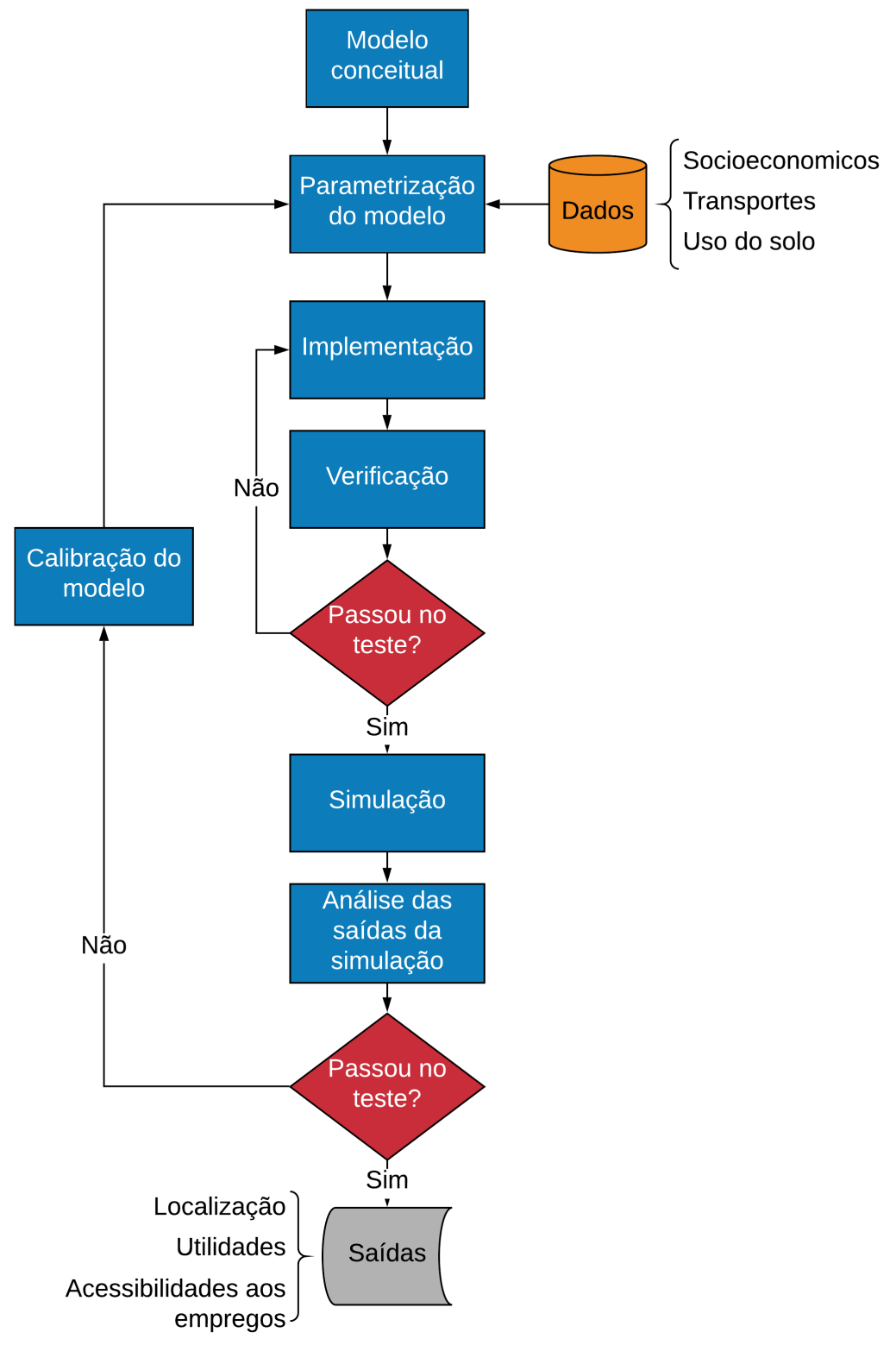

Figura 4 - Fluxograma geral do trabalho. 


\section{Aplicações do modelo}

O presente capítulo apresenta as aplicações do modelo para análise das desigualdades de acessibilidade aos empregos. São apresentadas, respectivamente, aplicações no município de São Paulo, Curitiba e Melbourne (Austrália).

\subsection{Município de São Paulo}

Com população de 11.253.503 pessoas $^{1}$, o município de São Paulo é o mais populoso do Brasil. Na economia se destaca no setor de serviços e apresenta um PIB per capita de $\mathrm{R} \$ 54.357,81^{1}$. Na área de transportes, a frota contratada de ônibus e micro-ônibus para o transporte público somou 13.979 veículos e o número de linhas operadas em dezembro de 2019 foi de $1.336^{2}$.

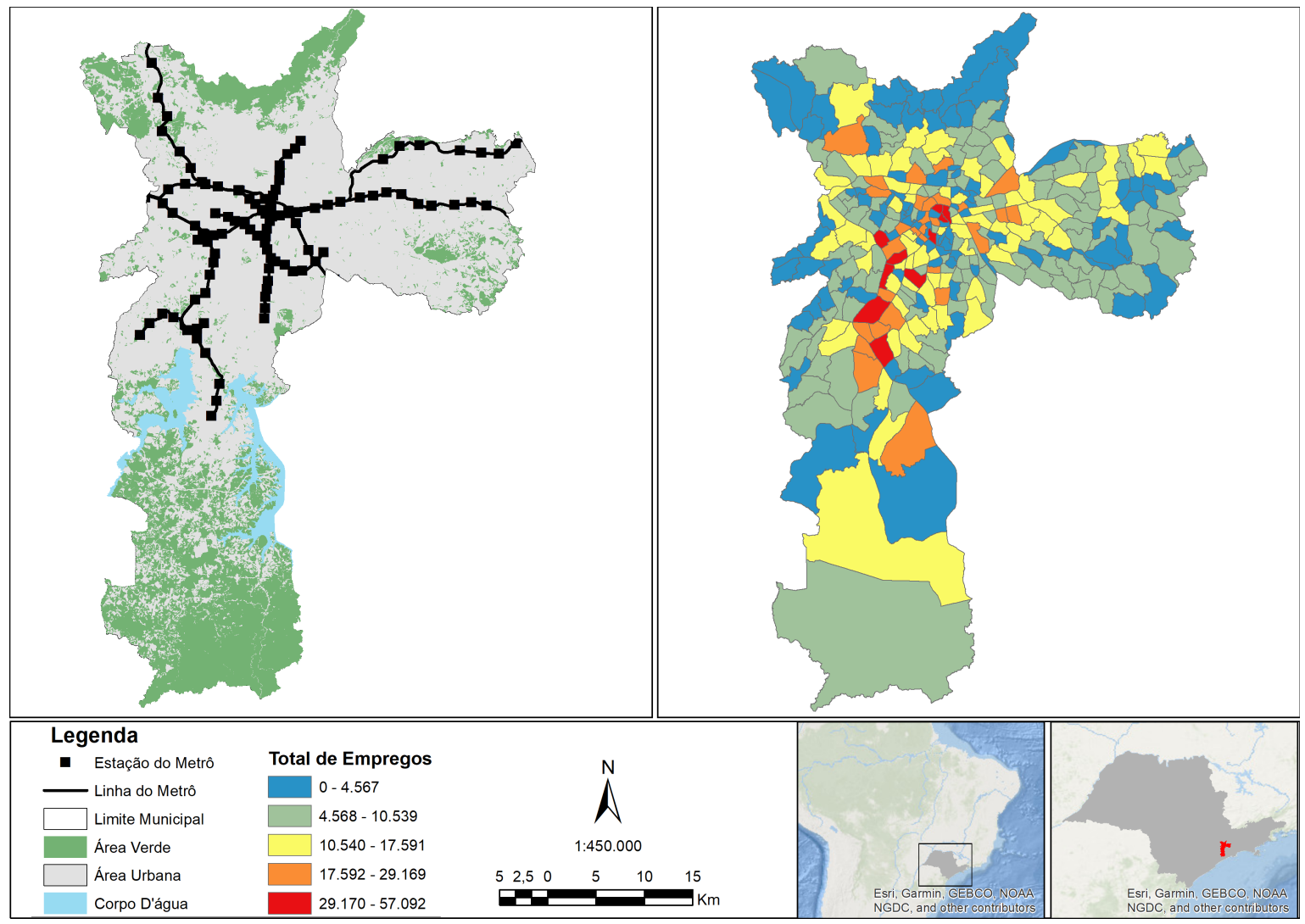

Figura 5 - Município de São Paulo.

$1<$ https://cidades.ibge.gov.br/brasil/sp/sao-paulo/panorama> Acesso em 27 de Fevereiro de 2020.

$2<$ https://www.prefeitura.sp.gov.br/cidade/secretarias/transportes/institucional/sptrans/acesso_a_ informacao/index.php?p=152415> Acesso em 27 de Fevereiro de 2020 
O modelo foi implementado para o município de São Paulo devido à disponibilidade de dados e o contexto de alta desigualdade no acesso aos empregos. No município, grande parte da oferta de empregos e de transporte público sobre trilhos está localizada no centro, enquanto a maioria dos trabalhadores alocados em ocupações elementares residem nas periferias (Figura 5).

\subsubsection{Implementação do modelo}

Os agentes foram criados utilizando dados de indivíduos presentes nos microdados da pesquisa origem-destino de 2007 do Metrô. Na pesquisa origem-destino do Metrô de 2007, o município de São Paulo é composto por 320 zonas de tráfego que contém informações como quantidade de habitantes e de empregos. Através dos microdados, foram filtradas as origens das viagens por motivo de trabalho para extrair a quantidade de trabalhadores em cada zona de tráfego. Os atributos de ocupação, educação e renda foram utilizados para adequar a classificação das ocupações para o padrão National Statistics Socioeconomic Classification (NS-SEC). O padrão NS-SEC é adotado no Reino Unido e foi utilizado nesse estudo por permitir que dados ocupacionais sejam reclassificados para um padrão socioeconômico, o que é fundamental para estudos de desigualdade.

No presente modelo, foram implementados três grupos socio-ocupacionais baseados no padrão NS-SEC: o grupo de alto status é composto por empreendedores e profissionais de alto nível; o grupo de médio status é formado por trabalhadores em ocupações de nível técnico ou profissional de médio e baixo nível; e o grupo de baixo status por trabalhadores em ocupações rotineiras e semi-rotineiras. Filtrando as viagens por motivo de trabalho com origem e destino dentro do município de São Paulo e aplicando os fatores de expansão, foram encontrados 3.001.600 trabalhadores. Do total de trabalhadores encontrados, $9 \%$ pertencem ao grupo de alto status, $31 \%$ ao grupo de médio status e $60 \%$ ao grupo de baixo status. A distribuição espacial dos grupos socio-ocupacionais é apresentada na Figura 6.

Como o esforço computacional para gerar uma simulação com 3.001 .600 agentes trabalhadores é alto, foi adotado um fator de simplificação de duzentas vezes para gerar os agentes trabalhadores. Com isso, foram criados 15.008 agentes representando a população total de trabalhadores no município de São Paulo.

O ambiente de simulação foi criado através de uma grade de células de $1 \mathrm{~km}^{2}$. O tamanho das células foi escolhido com base no esforço computacional para as simulações e por ser adequado para representar a área de interesse.

A oferta de empregos e habitação também foram extraídas dos microdados da 


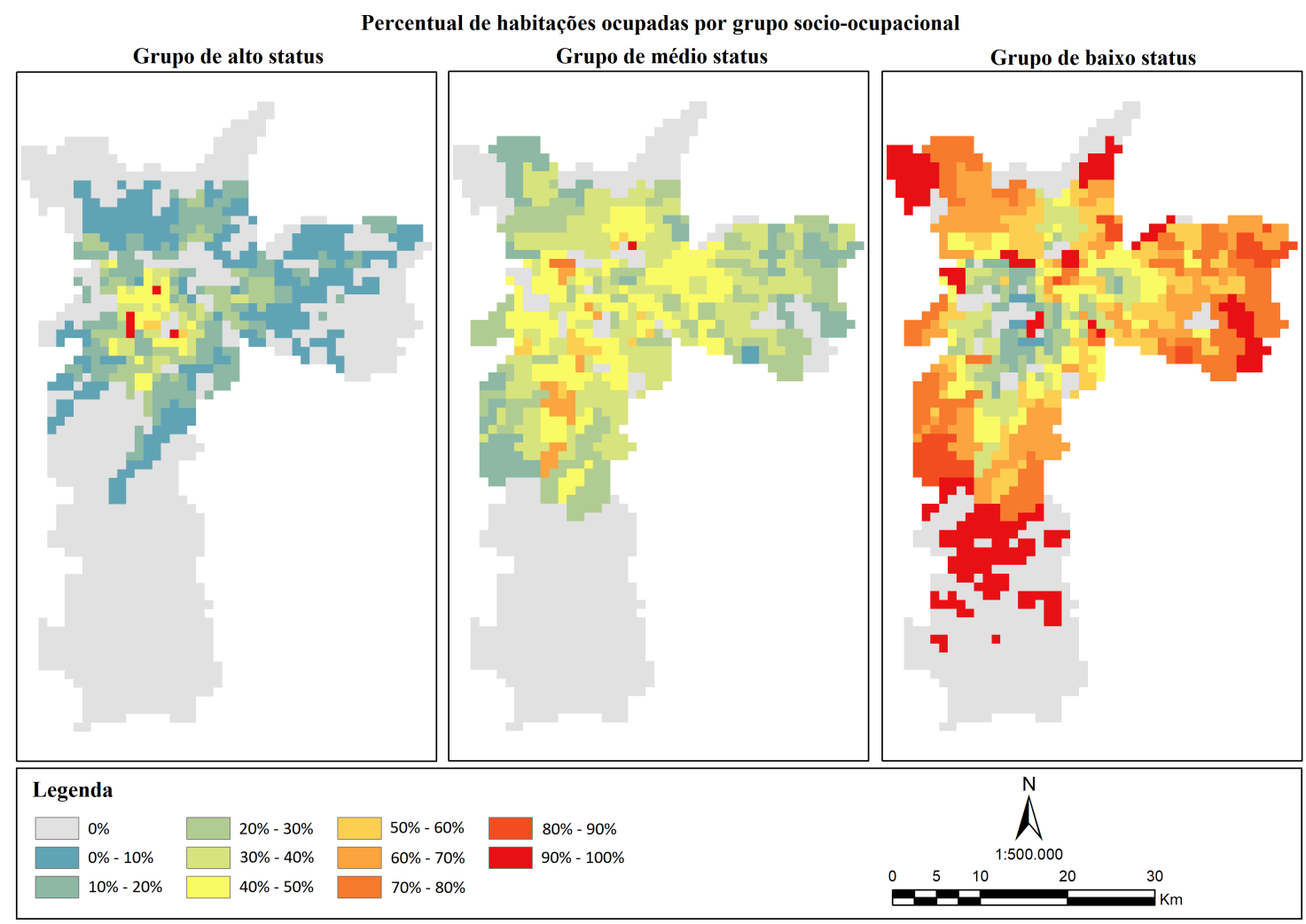

Figura 6 - Distribuição dos grupos socio-ocupacionais no município de São Paulo.

pesquisa origem e destino do Metrô. Filtrando as viagens com origem na residência e com destino ao trabalho, foram extraídas as disposições de domicílios e empregos da amostra estudada. Em seguida, foram interseccionadas as zonas de tráfego com as setores censitários de áreas urbanas de 2010 do IBGE para desconsiderar parques, corpos d'água e demais locais onde não há habitações ou empregos. Desconsideradas as áreas desocupadas das zonas de tráfego, foram calculadas as densidades de domicílios e empregos e feita a intersecção dessas zonas com as células de $1 \mathrm{~km}^{2}$ do ambiente de simulação. No caso de uma célula compartilhar mais de uma zona de tráfego, a população e os empregos foram atribuídos considerando diferentes densidades populacionais.

A oferta de transporte público foi obtida através dos dados em formato General Transit Feed Specification $\left(\mathrm{GTFS}^{3}\right)$ disponibilizados pela SPTrans ${ }^{4}$, para o município de São Paulo, e uma matriz de tempos de viagem por transporte público do ano de 2015 para as subzonas de tráfego da região metropolitana disponibilizada pela Companhia Paulista de Trens Metropolitanas (CPTM). Os dados GTFS e a base de arruamento do Open Street Map $\left(\mathrm{OSM}^{5}\right)$ foram importados para o Open Trip Planner $\left(\mathrm{OTP}^{6}\right)$ para o cálculo dos tempos de viagem por transporte entre os centróides das células. Foi escolhido o

\footnotetext{
3 <https://developers.google.com/transit/gtfs > Acesso em 15 de Janeiro de 2019.

4 <http://www.sptrans.com.br/desenvolvedores> Acesso em 15 de Janeiro de 2019.

< https://www.openstreetmap.org/> Acesso em 10 de Janeiro de 2019.

6 <http://www.opentripplanner.org> Acesso em 15 de Janeiro de 2019.
} 
horário de partida das 07:00 da manhã para simular viagens motivo trabalho. Calculados os tempos de viagem, o arquivo GTFS foi então editado para simular cenários alternativos em diferentes ofertas de transporte público. A matriz de tempos de viagem para a Região Metropolitana de São Paulo, disponibilizada pela CPTM, foi calculada para o ano de 2015 e contém os tempos de viagem entre cada uma das 1.895 subzonas de tráfego. Como foram calculadas as acessibilidades das células de $1 \mathrm{~km}^{2}$ do município de São Paulo considerando os empregos na Região Metropolitana, foram incluídos nos cálculos de acessibilidade os tempos de viagem dos centróides das células do município de São Paulo até as subzonas de tráfego da Região Metropolitana. Para isso, foi feita a intersecção dos centróides das células de $1 \mathrm{~km}^{2}$ com as subzonas de tráfego do município de São Paulo e identificados os tempos de viagem dessas subzonas até as demais subzonas da Região Metropolitana. Como o OTP permite extrair com maior precisão os tempos de viagem entre pares de origem e destino, ele foi utilizado nos cálculos de acessibilidade aos empregos para o município de São Paulo e a matriz de tempos de viagem foi utilizada nos cálculos das acessibilidades considerando a região metropolitana.

A acessibilidade aos empregos por modo de transporte privado foi calculada através de uma matriz de tempos de viagem entre as subzonas de tráfego no modo carro de 2015 disponibilizada pela CPTM. A matriz de tempos de viagem inclui o município de São Paulo e a Região Metropolitana. Os tempos de viagem entre as células de $1 \mathrm{~km}^{2}$ foram atribuídos considerando a intersecção entre os centróides das células e as subzonas de tráfego. A divisão modal foi calculada para cada grupo social com base nos microdados da pesquisa origem e destino do Metrô e atribuídos aos agentes de forma aleatória. O percentual de agentes que se utilizam de carro para viagens motivo trabalho é de 64,8\% para o grupo de alto status, $41,3 \%$ para o de médio status e $22,8 \%$ para o de baixo status.

A medida de acessibilidade utilizada no estudo é a cumulativa, conforme Eq. 5.1, baseada em Páez, Scott e Morency (2012). A medida de acessibilidade cumulativa conta a quantidade total de oportunidades que podem ser acessadas dentro de um limiar de tempo de viagem, custo ou distância (GEURS; WEE, 2004). Devido à facilidade de interpretação e necessidade de poucos dados para o seu cálculo, a medida é facilmente empregável em outras realidades. Como a média dos tempos de viagem por transporte público na pesquisa origem-destino de São Paulo de 2007 é de 67 minutos, foi adotado o limiar de 60 minutos para o cálculo da acessibilidade aos empregos:

$$
A_{i}^{p}=\sum_{j} W_{j} I\left(c_{i j} \leq \gamma_{i}^{p}\right)
$$

Na Eq.(5.1), $A_{i}^{p}$ é a acessibilidade cumulativa aos empregos no local $i ; W_{j}$ é a 
quantidade de empregos no local $j ; c_{i j}$ é o limiar de tempo de viagem do local $i$ ao local $j$; e $I$ é um valor lógico, que recebe 1 quando verdadeiro e 0 quando falso.

O modelo foi implementado no software NetLogo (WILENSKY, 1999), por suprir as necessidades para a simulação dos experimentos e ser de fácil uso e integrado ao software estatístico R (THIELE; GRIMM, 2010).

\subsubsection{Calibração do modelo}

Para calibrar o modelo, os agentes foram aleatoriamente distribuidos no ambiente de simulação e realizada uma análise de sensibilidade alterando o parâmetro $\alpha$ em intervalos de 0.1 para cada um dos grupos sociais, resultado em 1.331 combinações de alfa. As saídas das simulações foram então comparadas com a distribuição residencial da pesquisa origem-destino do Metrô de 2007 através da correlação de Pearson e, espacialmente, através do algoritmo de similaridade de múltiplas janelas (HAGEN, 2003), conforme implementado no software Dinamica EGO $4^{7}$. A correlação de Pearson compara as quantidades de agentes por grupo social em cada uma das células da situação observada com a distribuição de agentes resultante da simulação. Quanto maior a semelhança na distribuição dos agentes, mais próximo de 1 é o valor da correlação.

O parâmetro $\alpha$ que melhor representa a situação observada no município de São Paulo é aquele com a maior soma de correlações considerando os três grupos sociais. O parâmetro $\alpha$ que resultou na maior soma de correlações foi de 0,6 para o grupo de alto status e 1 para o grupo de médio status. O parâmetro $\alpha$ adotado para o grupo de baixo status foi de 0,2 , mesmo sendo identificado como não relevante ao longo do processo de calibração, pois os agentes acabam residindo em locais não atrativos para agentes de alto e médio status.

Os parâmetros $\alpha$ foram utilizados para criar o cenário base e os demais experimentos. O cenário base consiste na simulação criada a partir dos agentes distribuidos aleatoriamente no ambiente de simulação, aplicando os parâmetros $\alpha$ que levaram as maiores correlações e considerando a presente oferta de transporte, empregos e habitações. É o cenário sem alterações de políticas, servindo de base de comparação com os demais experimentos.

Os resultados da calibração indicam que os agentes priorizam a acessibilidade aos empregos ao status da vizinhaça. Apesar dos agentes priorizarem a acessibilidade aos empregos, os agentes de alto status também consideram o status da vizinhança em sua utilidade, tendendo a segregarem-se dos agentes de menor status. A correlação de Pearson

\footnotetext{
$\overline{7}$ <https://csr.ufmg.br/dinamica> Acesso em 19 de Janeiro de 2020.
} 
encontrada foi de 0,49 para o grupo de alto status, 0,58 para o grupo de médio status e 0,78 para o grupo de baixo status. O algoritmo de similaridade por múltiplas janelas resultou em uma similaridade mínima de 0,71 em uma janela móvel de 3x3.

Apesar das altas correlações entre a situação observada e o cenário base, o modelo foi incapaz de representar algumas comunidades de baixo status no centro do município e próximas a bairros ricos (Figura 8). Além disso, na situação observada, a parte noroeste do município é predominantemente habitada por pessoas pertencentes a grupos de baixo status, porém no cenário base a maioria dos agentes na região pertencem ao grupo de médio status. A inconsistência pode ser justificada pela alta acessibilidade aos empregos por transporte individual na região devido à proximidade a diversas rodovias.

\subsubsection{Experimentos}

Além do cenário base descrito na seção anterior, cinco outros experimentos foram realizados. Todos os experimentos se iniciam com os agentes aleatoriamente alocados no ambiente de simulação e com o parâmetro $\alpha$ de 0,6 para o grupo de alto status, 1 para o grupo de médio status e 0,2 para o grupo de baixo status.

No primeiro experimento, duas novas linhas de transporte público sobre trilhos, que fazem parte do plano de investimentos do governo, foram simuladas: uma linha perimetral e outra em radial. O segundo experimento simula o impacto de habitações de interesse social na área de melhoria de oferta de transporte público devido às linhas simuladas no primeiro experimento. O terceiro experimento simula o impacto de novos empregos na mesma área do segundo experimento. No quarto experimento são explorados os impactos de um aumento fixo de oferta de empregos em conjunto com diferentes estratégias de habitações de interesse social no município de São Paulo. Por fim, no experimento cinco é explorada a oferta de habitações de interesse social baseada em um programa de habitação do governo.

\subsubsection{Primeiro experimento - linhas perimetral e radial}

A simulação das linhas de transporte perimetral e radial objetiva o entendimento dos impactos potenciais dessas novas infraestruturas de transporte na igualdade da acessibilidade aos empregos. As linhas e estações simuladas foram propostas pela CPTM como parte de um plano de expansão do transporte público para o ano de 2030 (Figura 7).

A linha perimetral é composta por 30 novas estações de metrô no município de 


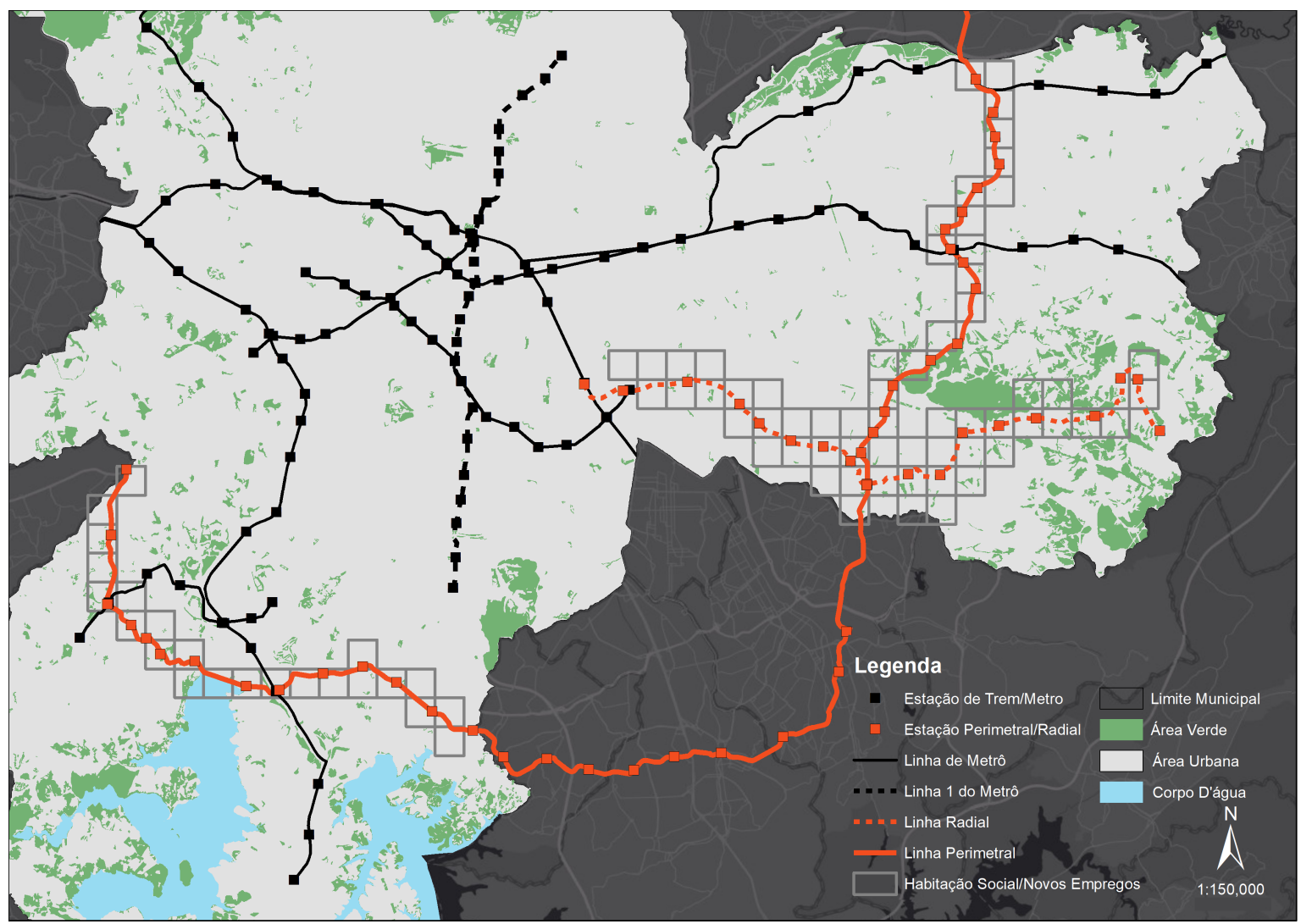

Figura 7 - Localização das linhas perimetral, radial, habitações de interesse social e empregos simulados.

São Paulo. A linha cruza as zonas sul e leste de São Paulo, permitindo a transferência a outras 6 linhas de transporte público sobre trilhos. A linha radial se localiza na zona leste de São Paulo e são planejadas 18 estações, que permitirão a conexão com outras 3 linhas de transporte sobre trilhos, incluindo linhas de trem e metrô.

As novas linhas de transporte simuladas foram adicionadas aos arquivos GTFS. Ambas as linhas de transporte tiveram seus atributos de tempo de viagem entre estações, horários de operação e frequência determinados com base na linha 1 do Metrô (Figura 7).

Após incorporar as novas linhas de transporte no arquivo GTFS, foi utilizada a ferramenta Open Trip Planner (OTP) para calcular a nova matriz origem-destino de tempos de viagem considerando o horário de partida das viagens às $07 \mathrm{~h} 00$ para simular viagens motivo trabalho. Calculada a nova matriz origem-destino de tempos de viagem, as acessibilidades aos empregos, associadas as células de $1 \mathrm{~km}^{2}$, foram recalculadas e importadas para o ambiente de simulação.

Como pode ser observado na Figura 8 (ambiente de simulação do primeiro experimento), a linha radial exerce grande influência na escolha residencial dos agentes devido ao aumento da acessibilidade aos empregos nas proximidades da linha. A influência pode ser explicada pela alta densidade de empregos no centro do município, logo, simular uma 
linha de transporte sobre trilhos que permita aos moradores acesso rápido ao centro do município causará um alto impacto na acessibilidade aos empregos. Em contraste, a linha perimetral simulada pouco impactou a acessibilidade aos empregos. É importante enfatizar que o primeiro experimento não considera o aumento da oferta de empregos próximo às linhas de transporte perimetral e radial.

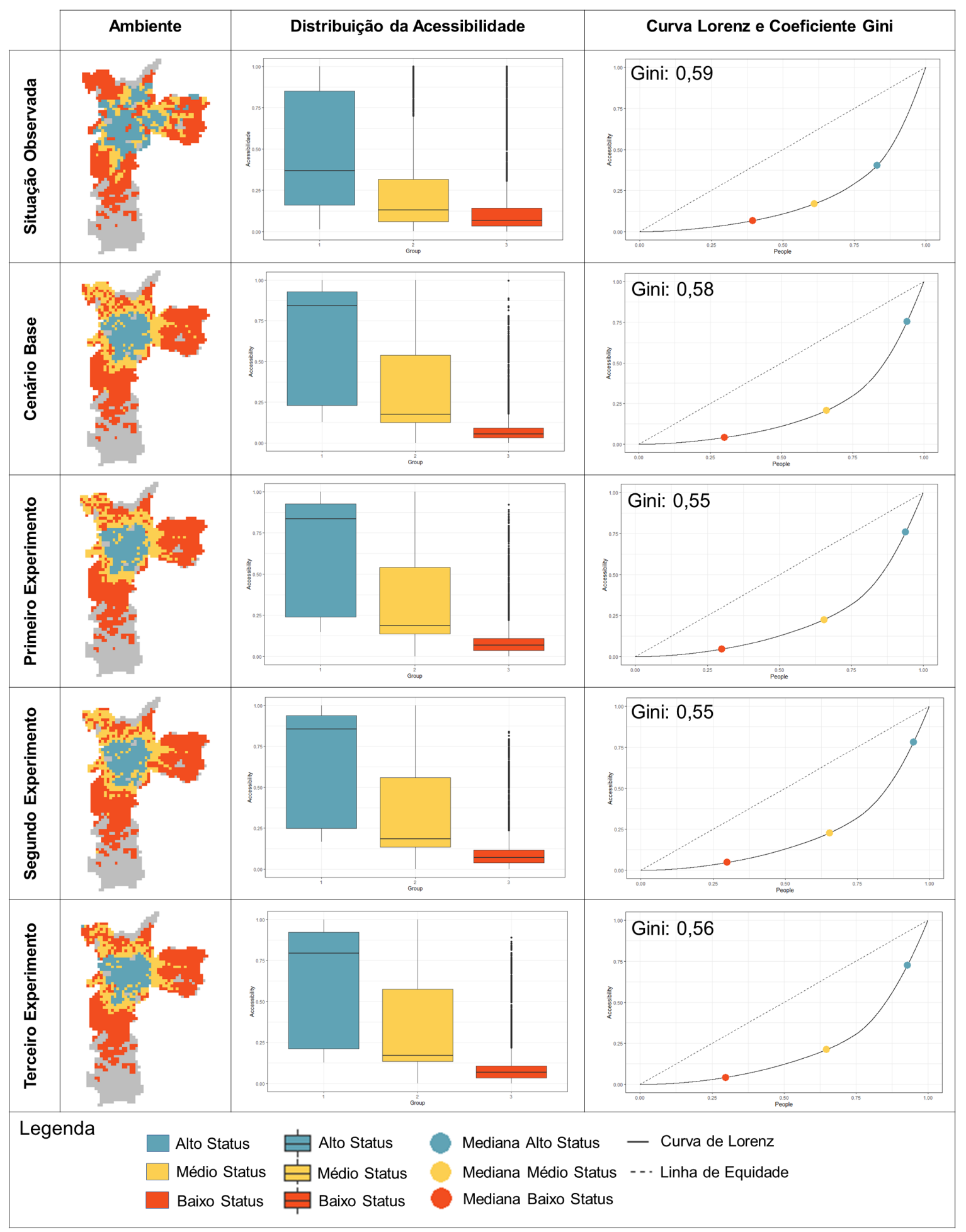

Figura 8 - Situação observada, cenário base e saídas das simulações dos experimentos. 
A localização residencial simulada dos agentes revelou um processo de gentrificação, no qual os agentes de médio status moveram-se para as áreas com aumento de acessibilidade ao trabalho ao redor da linha radial (Figura 8). Áreas com aumento de acessibilidade ao emprego tornam-se mais atraentes para agentes de médio status e, consequentemente, agentes de baixo status foram expulsos dessas áreas.

Embora a acessibilidade aos empregos em torno das linhas propostas aumente, esse experimento mostra um efeito fraco na desigualdade de acessibilidade aos empregos. Como pode ser visto na Figura 8, a nova infraestrutura de transporte público não influenciou a localização residencial de agentes de alto status, porque eles já residem em locais de alta utilidade. No cenário base, a mediana da acessibilidade aos empregos é de 0,84 para o grupo de alto status, 0,17 para o grupo de médio status e 0,05 para o grupo de baixo status. No primeiro experimento, a mediana da acessibilidade aos empregos do grupo de alto status diminuiu para 0,83 , e as acessibilidades aos empregos dos grupos de médio e baixo status aumentaram, respectivamente, em 0,18 e 0,06.

A nova distribuição das acessibilidades aos empregos é refletida no coeficiente de Gini, mostrando um cenário mais equitativo, com um coeficiente de 0,55.

\subsubsection{Segundo experimento - linhas perimetral, radial e habitações de interesse social}

No segundo experimento, incluímos habitações de interesse social ao redor das linhas perimetral e radial. No primeiro experimento, observou-se que agentes de médio status expulsaram agentes de baixo status em áreas com aumento de acessibilidade aos empregos. O objetivo do segundo experimento é explorar os impactos das habitações no grupo de baixo status em áreas com aumento de acessibilidade e seus efeitos na desigualdade de acessibilidade aos empregos.

Foi adicionado o equivalente a $5 \%$ do total de agentes de baixo status como habitações de interesse social. As novas habitações foram distribuídas uniformemente nas células que tocam as linhas de transporte público de massa sobre trilhos (Figura 8).

Os resultados mostram que, diferentemente do primeiro experimento, os agentes de médio status não são mais o grupo predominante nas áreas com aumento de acessibilidade aos empregos (Figura 8). Ao invés disso, a inclusão de habitações de interesse social causou a realocação de agentes de baixo status para as áreas circundantes às novas linhas de transporte. Consequentemente, houve uma queda no status do bairro, o que diminuiu sua atratividade para os agentes de médio status. 
Em relação à distribuição geral das acessibilidades aos empregos e à desigualdade entre grupos sociais, pode-se observar que ocorreram pequenas mudanças. Neste experimento, a mediana das acessibilidades aos empregos é de 0,85 para o grupo de alto status, 0,18 para o grupo de médio status e 0,07 para o grupo de baixo status. Comparado ao cenário base, vemos que, embora a mediana das acessibilidades aos empregos do grupo de alto e médio status permaneçam semelhantes, a acessibilidade aos empregos do grupo de baixo status aumentou 0,02 .

Em relação ao coeficiente de Gini e à curva de Lorenz, pode-se observar uma pequena aproximação entre as medianas das acessibilidades dos grupos de médio e baixo status e uma distribuição de acessibilidade mais igual, considerando um coeficiente de Gini resultante de 0,55.

\subsubsection{Terceiro experimento - linhas perimetral, radial e novos empregos}

No terceiro experimento, foram incluídos novos empregos em torno das linhas de transporte público perimetral e radial. A motivação para incluir os novos empregos é explorar os impactos de um cenário de densificação de empregos na desigualdade de acessibilidade aos empregos nos três grupos sócio-ocupacionais estudados.

Para comparar esse experimento com o anterior, a mesma quantidade de habitação de interesse social simulada no segundo experimento foi simulada como novos empregos no terceiro experimento. Portanto, $5 \%$ do total de agentes de baixo status foram adicionados como empregos nas células em torno das linhas de transporte público propostas. A densidade de empregos resultante é compatível com a de outras regiões de média densidade de empregos no município.

Como pode ser visto na Figura 8, a nova simulação causou um baixo impacto na redução das desigualdades de acessibilidade aos empregos. Por um lado, a acessibilidade aos empregos aumentou em torno das novas linhas de transporte devido a maior quantidade de empregos nas áreas periféricas. Por outro lado, a área afetada tornou-se mais atraente para agentes de médio status, causando a expulsão de agentes de baixo status, principalmente perto da linha de transporte público radial.

Em relação à distribuição da acessibilidade aos empregos, pode-se observar que há uma pequena melhora na acessibilidade do grupo de baixo status, mas não é o suficiente para reduzir as diferenças entre os grupos. A mediana da acessibilidade aos empregos é de 0,79 para o grupo de alto status, 0,17 para o grupo de médio status e 0,06 para o grupo de baixo status. Comparado ao cenário base, vemos uma redução na acessibilidade aos 
empregos para o grupo de alto status e uma pequena melhoria para os agentes do grupo de baixo status, aumentando seu valor mediano em 0,01, enquanto no segundo experimento os principais beneficiários são os agentes de baixo status.

A curva de Lorenz e o coeficiente de Gini mostram que, embora haja uma melhora no coeficiente de Gini, a distância entre a mediana da acessibilidade dos grupos sócioocupacionais ainda é preservada. Comparado ao primeiro e ao segundo experimentos, o coeficiente de Gini mostra um cenário de distribuição de acessibilidade aos empregos menos equitativo.

\subsubsection{Quarto experimento - linhas perimetral, radial, novos empregos e habitações de interesse social}

No quarto experimento, as linhas de transporte público perimetral e radial foram simuladas juntamente com os novos empregos e habitações de interesse social. O objetivo deste experimento é explorar as diferentes políticas de habitação de interesse social, considerando um aumento fixo de empregos em torno das novas linhas de transporte público e seus impactos resultantes nas desigualdades de acessibilidade aos empregos.

Nove simulações foram realizadas considerando diferentes locais e ofertas de habitação de interesse social. Os locais simulados foram: ao longo das linhas de transporte público perimetral e radial; metade da oferta de habitação de interesse social em torno das linhas de transporte público perimetral e radial e a outra metade em áreas de maior acessibilidade aos empregos no município de São Paulo; ou toda a oferta de habitação de interesse social nas áreas de maior acessibilidade aos empregos do município.

Em relação à oferta total de habitação de interesse social, três cenários foram simulados: no primeiro, a oferta de habitação de interesse social representa $5 \%$ do total de agentes do grupo de baixo status; no segundo, é de 10\%; e no terceiro, é considerado $20 \%$ (Figura 9). Todas as simulações apresentam os mesmos números e locais de novos empregos implementados no terceiro experimento.

Conforme pode ser visto na Figura 10, a localização e a oferta de habitações de interesse social podem alterar significativamente o padrão geral de localização residencial no município de São Paulo. Considerando a oferta de habitações de interesse social em torno das linhas de transporte perimetral e radial, a localização resultante dos agentes por grupo sócio-ocupacional se altera ligeiramente se comparado ao cenário base, mas os padrões espaciais permanecem. As outras duas estratégias de localização de habitações de interesse social são mais eficazes na alteração geral do padrão de localização residencial. 
Estratégia de Localização das Habitações de Interesse Social
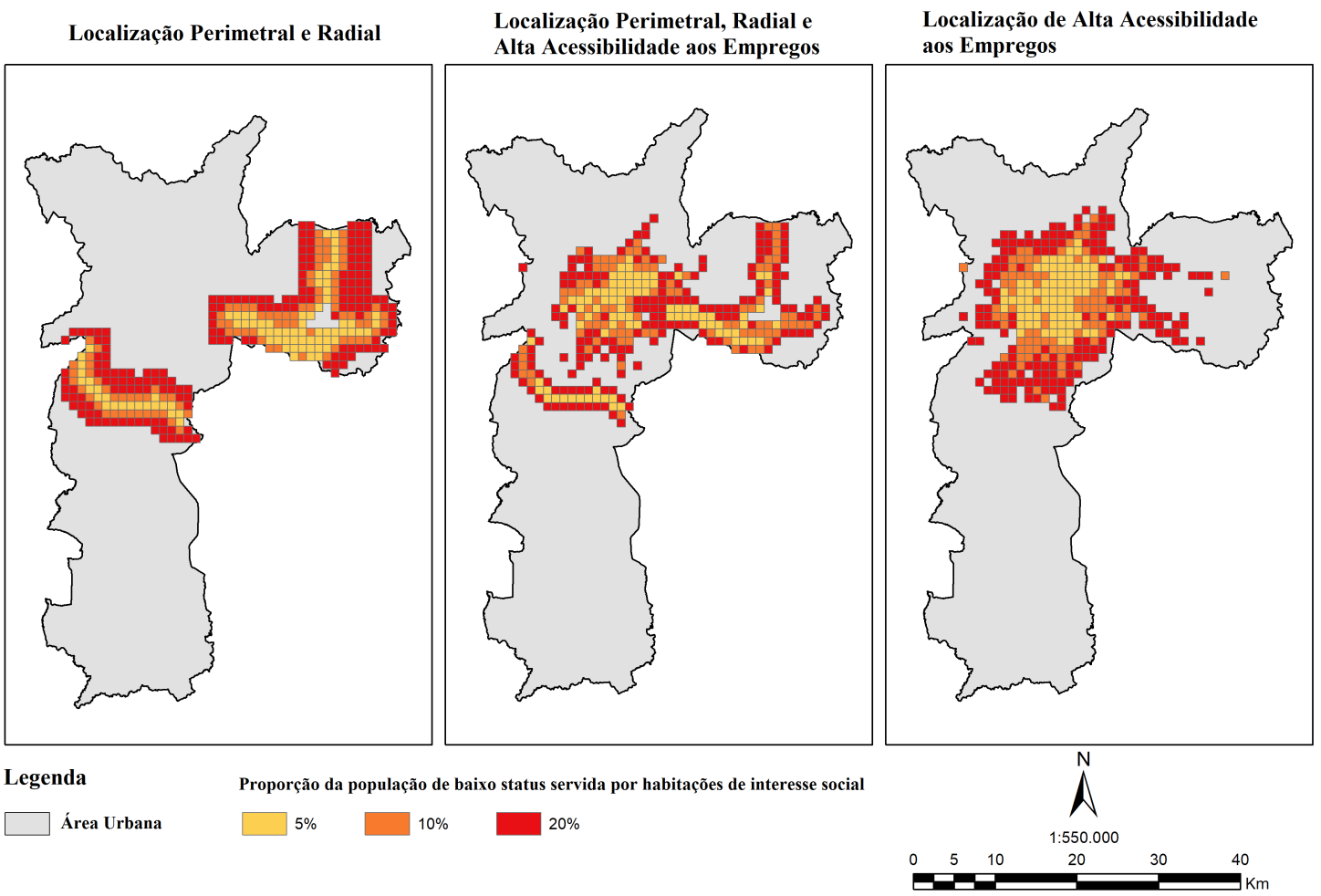

Figura 9 - Cenários de localização das habitações de interesse social.

A oferta de habitações de interesse social no centro da cidade, uma região anteriormente ocupada por agentes de alto status, alterou consistentemente a localização dos agentes. Agentes de alto e médio status tiveram que escolher entre morar no centro

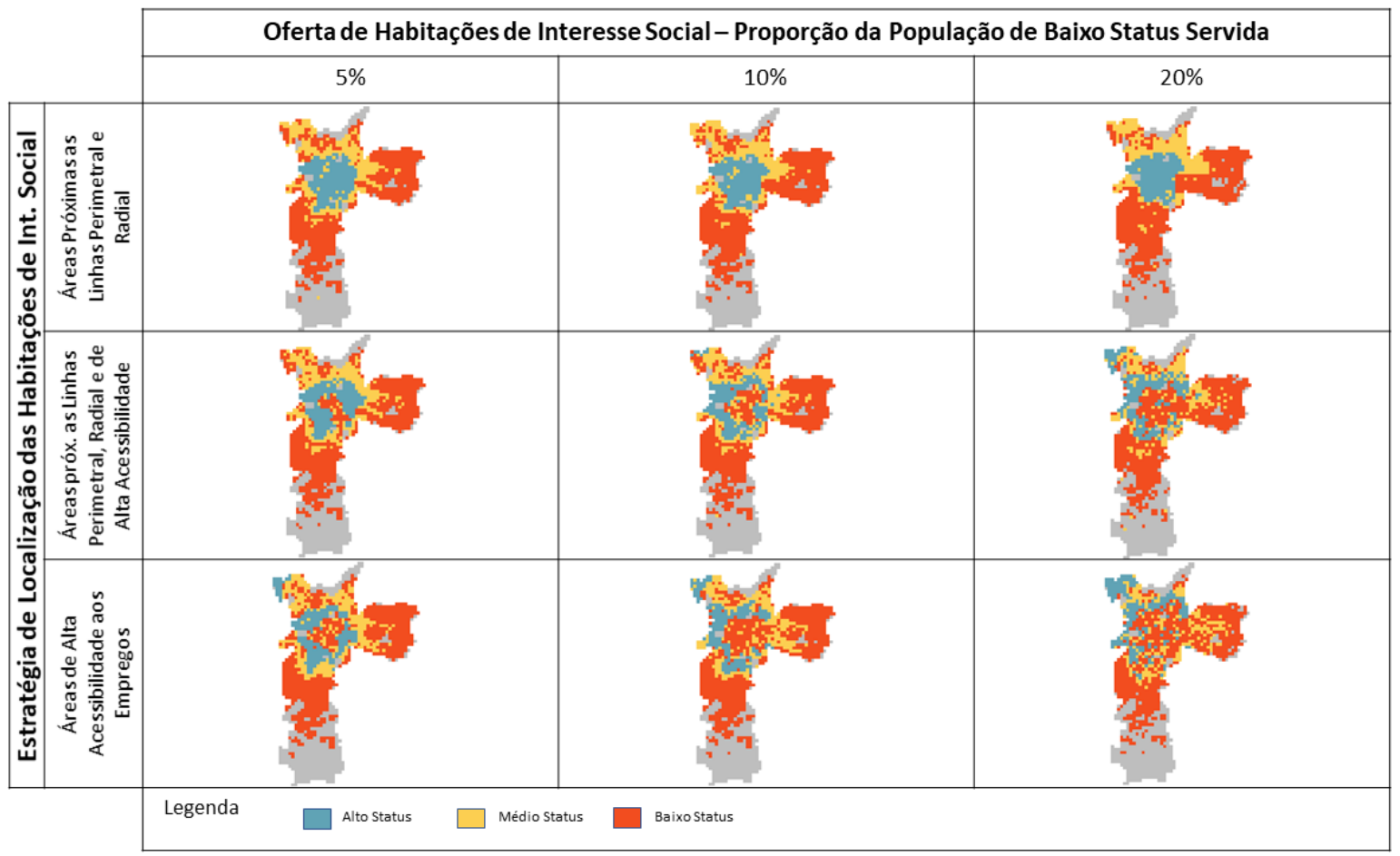

Figura 10 - Quarto Experimento - Localização residencial resultante. 


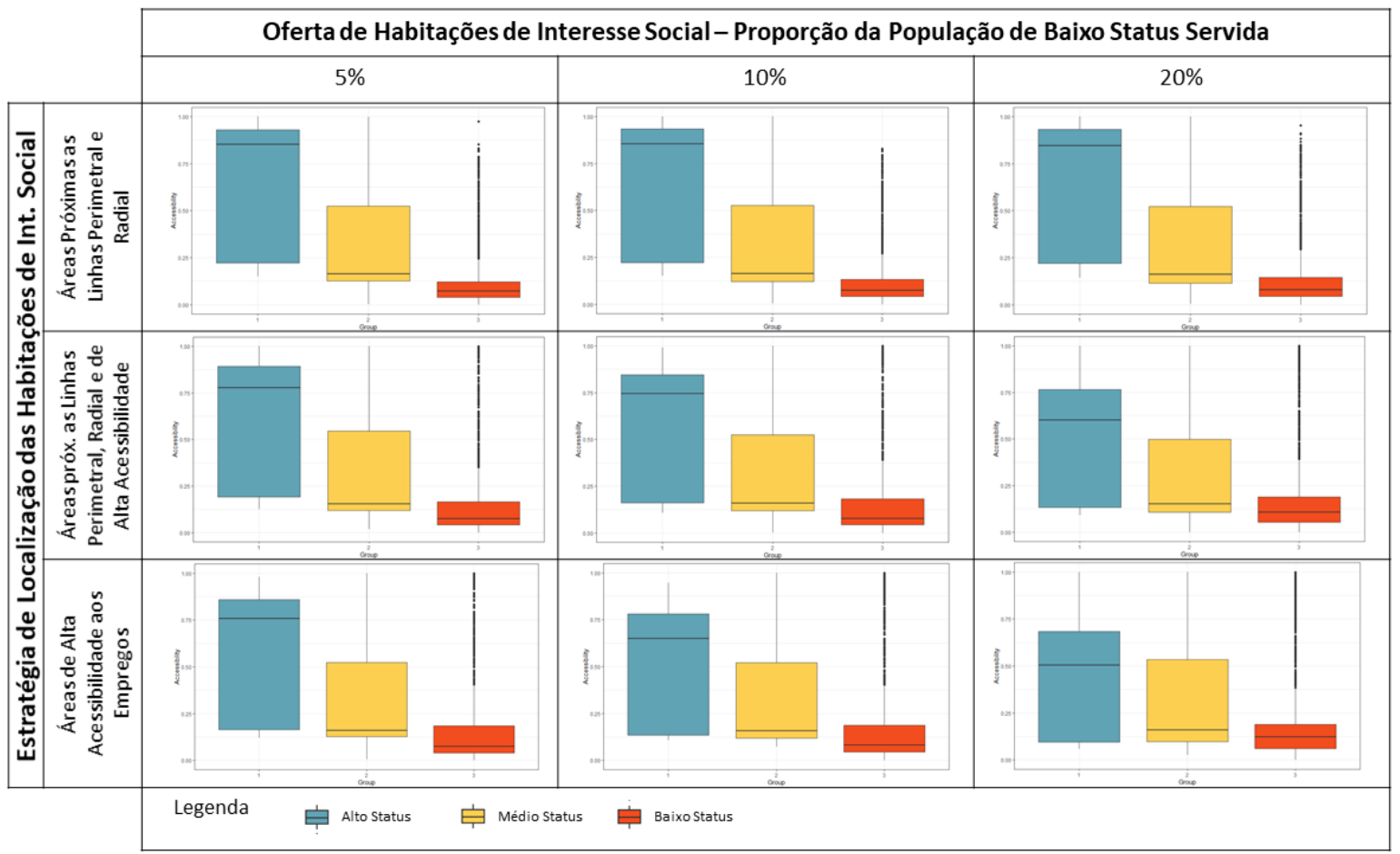

Figura 11 - Quarto Experimento - Distribuição resultante das acessibilidades ao emprego por grupo socio-ocupacional.

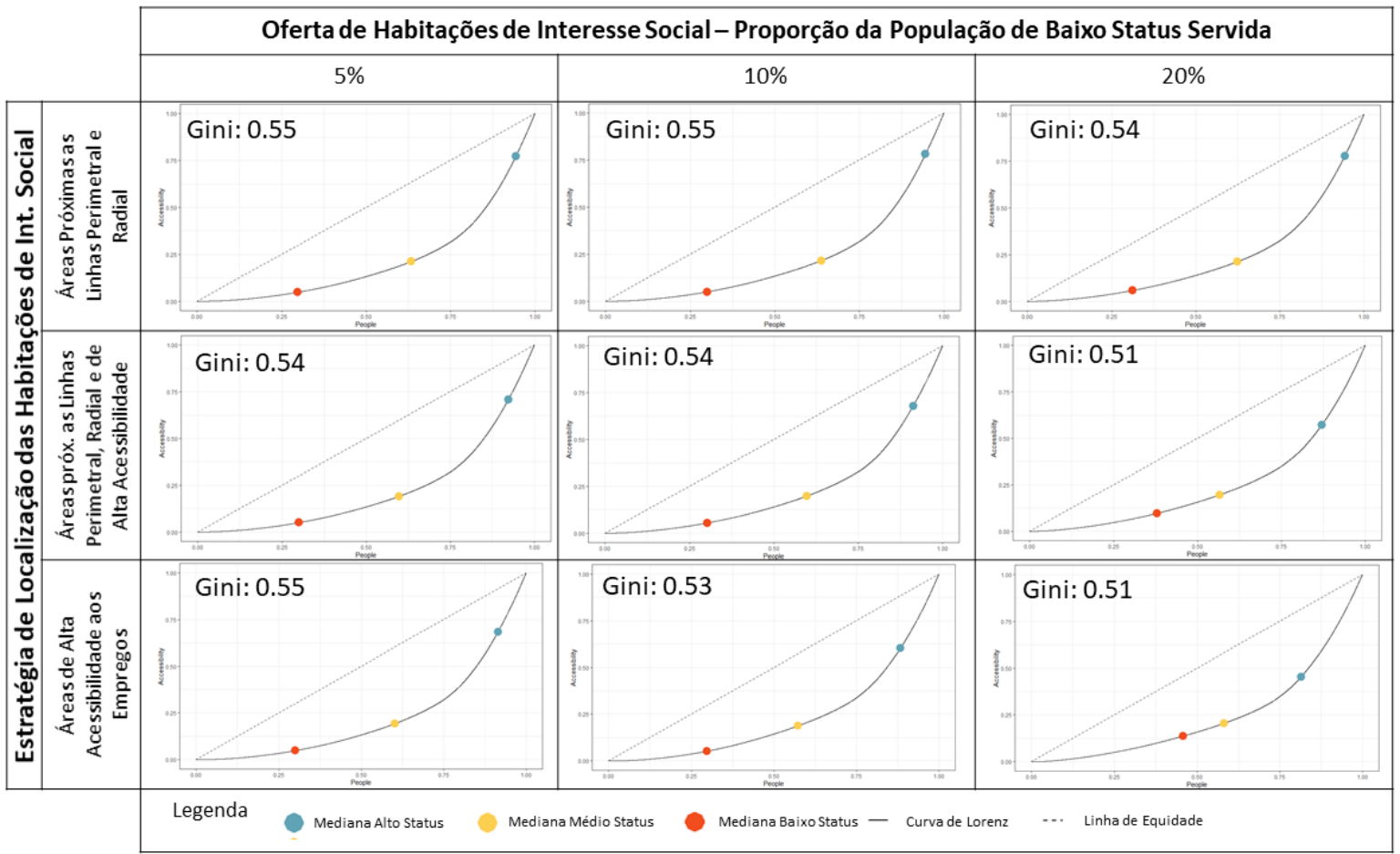

Figura 12 - Quarto Experimento - Curvas de Lorenz e coeficiente de Gini resultantes.

da cidade, área com maior acessibilidade aos empregos, mas com status de vizinhança baixo, ou em regiões distantes do centro da cidade com menor acessibilidade ao emprego, mas com um status de vizinhança mais alto. Os resultados mostram que poucos agentes pertencentes aos grupos de alto e médio status se alocaram no centro da cidade, perto dos 
agentes de baixo status, enquanto a maior parte se alocou em áreas menos densas e com status de vizinhança mais alto.

Os impactos da oferta de habitação de interesse social e suas diferentes estratégias de distribuição espacial nas desigualdades de acessibilidade aos empregos podem ser vistos nas Figuras 11 e 12. Podemos observar que quanto maior a oferta de habitação de interesse social, maior a equidade na distribuição de acessibilidade aos empregos e que diferentes estratégias de distribuição espacial das habitações causam impactos distintos na desigualdade de acessibilidade aos empregos entre os grupos. Por exemplo, o cenário com $20 \%$ de oferta de habitações de interesse social localizadas ao longo das linhas perimetral e radial resultam em uma mediana de acessibilidade aos empregos de 0,84 para o grupo de alto status, 0,16 para o grupo de médio status e 0,07 para o grupo de baixo status; a mesma oferta de habitação de interesse social alocada em áreas de alta acessibilidade aos empregos resulta em uma mediana de acessibilidade de 0,50 para o grupo de alto status, 0,15 para o grupo de médio status e 0,12 para o grupo de baixo status.

Em relação às curvas de Lorenz e aos coeficientes de Gini (Figura 12), os resultados corroboram com a distribuição de acessibilidade aos empregos, na qual uma maior oferta de habitações de interesse social localizada em áreas de alta acessibilidade resulta em um coeficiente de Gini mais equitativo e com uma mediana de acessibilidade mais próxima entre os grupos.

\subsubsection{Quinto experimento - Programa de habitação Minha Casa Minha Vida (MCMV) e zonas especiais de interesse social (ZEIS)}

No quinto experimento, foram utilizados os dados do programa habitacional Minha Casa Minha Vida (MCMV) e os dados das zonas especiais de interesse social (ZEIS). O MCMV é uma iniciativa do governo federal que oferece condições atraentes para o financiamento de moradias para famílias de baixa renda. Os dados foram fornecidos pelo Departamento de Habitação do Estado $\left(\mathrm{Sihab}^{8}\right)$. A quantidade total de unidades habitacionais no município de São Paulo é 6.652. As ZEIS são partes do território destinadas à habitação de baixa renda por meio de restauração urbana ou provisão de habitação social. Os polígonos do ZEIS foram fornecidos pelo Geosampa ${ }^{9}$. Três cenários foram considerados neste experimento: (i) nenhuma oferta de habitação de interesse social; (ii) a oferta habitacional do MCMV como habitação de interesse social; e (iii) a mesma oferta habitacional do cenário anterior, mas localizado nas ZEIS a 500 metros das estações de metrô do centro expandido de São Paulo (Figura 13).

\footnotetext{
8 < https://sihab.emplasa.sp.gov.br/> Acesso em 15 de Outubro de 2019.

9 <http://geosampa.prefeitura.sp.gov.br/> Acesso em 15 de Outubro de 2019.
} 
Cenário base

Sem oferta de habitações de interesse social

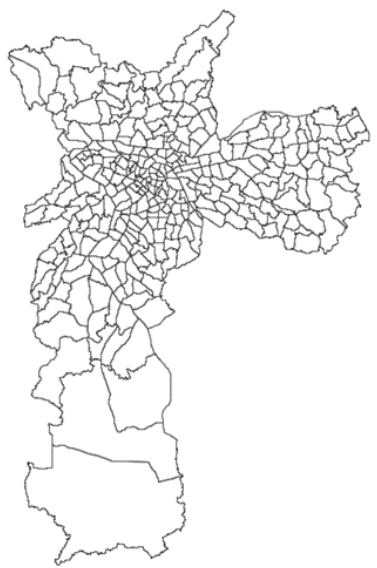

Experimento 1

Oferta de habitações de interesse social Programa minha casa minha vida

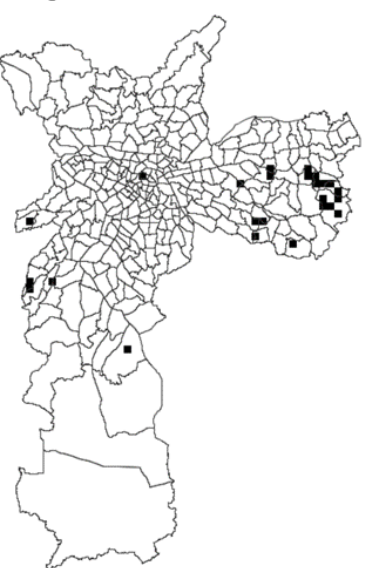

Experimento 2

Oferta de habitações de interesse social - ZEIS Centro expandido próximo a estações do Metrô

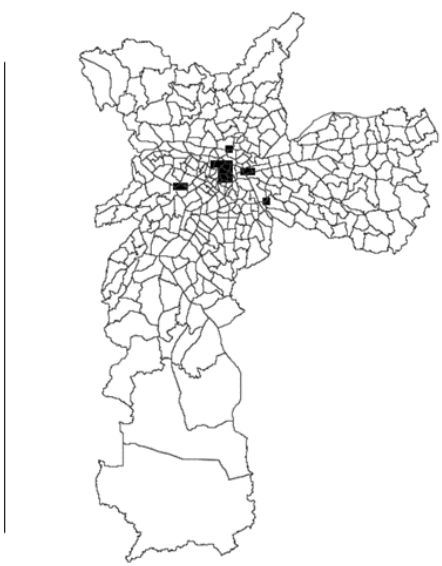

Figura 13 - Oferta de habitações de interesse social.

Cenário base

Sem oferta de habitações de interesse social

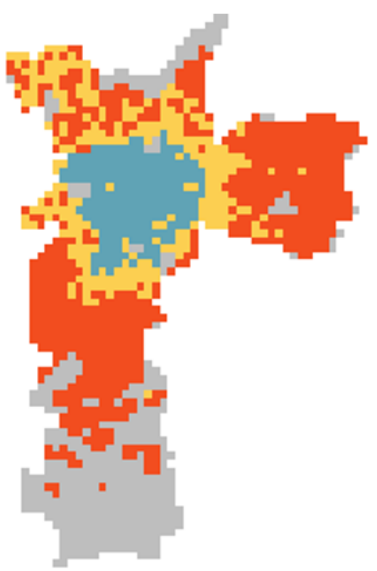

Experimento 1

Oferta de habitações de interesse social Programa minha casa minha vida

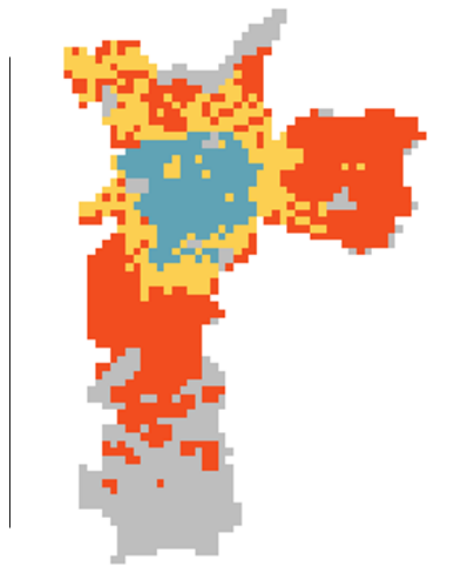

Experimento 2

Oferta de habitações de interesse social - ZEIS Centro expandido próximo a estações do Metrô

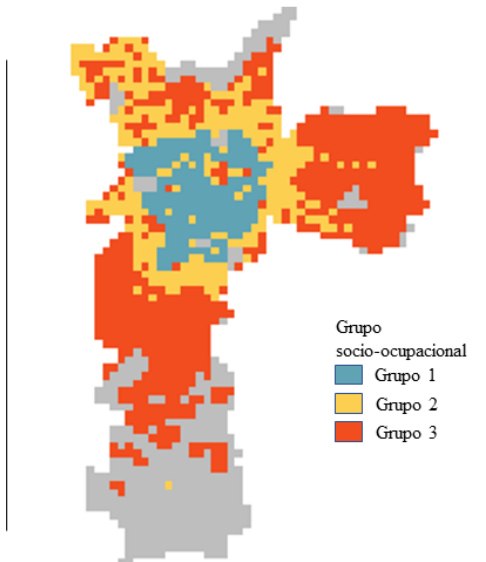

Figura 14 - Localização residencial resultante.

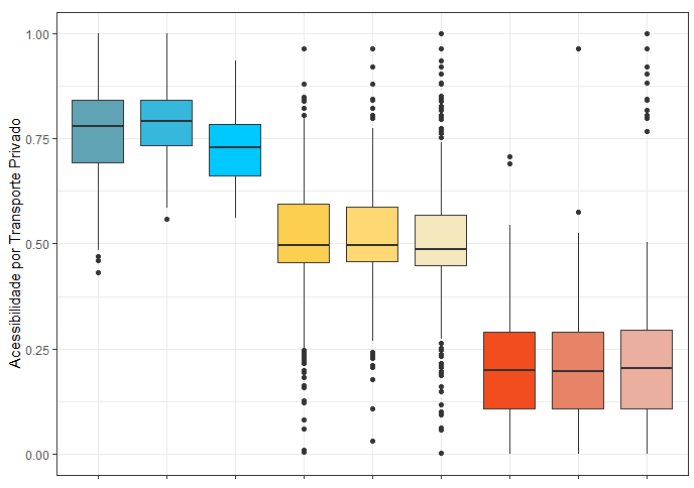

(a) Distribuição das acessibilidades aos empregos por transporte público

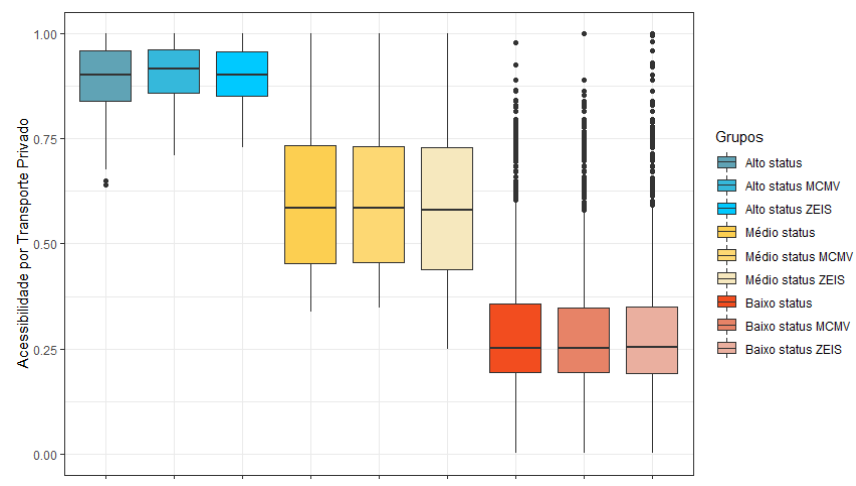

(b) Distribuição das acessibilidades aos empregos por transporte privado

Figura 15 - Quinto experimento - Distribuição das acessibilidades aos empregos por modo de transporte 
Nos três cenários, as linhas planejadas de transporte público perimetral e radial foram simuladas em conjunto com os novos empregos. Como visto na Figura 14, a oferta de habitação de interesse social do MCMV causa um baixo impacto no ambiente de simulação resultante, uma vez que a maior parte da oferta de habitações está localizada longe do centro da cidade. Quando considerado o suprimento de habitação de interesse social nas áreas da ZEIS, pode-se observar um pequeno impacto na área central simulada de São Paulo. O impacto do experimento na igualdade de acessibilidade aos empregos foi pequeno. Comparado ao cenário base, a simulação que considerou o fornecimento de habitação de interesse social nas ZEIS no centro expandido foi a que mais impactou na redução da desigualdade de acessibilidade aos empregos (Figura 15).

Embora a oferta de habitação de interesse social possa impactar a acessibilidade aos empregos dos indivíduos atendidos, pouco impacto é observado no grupo de baixo status como um todo devido à composição da população de São Paulo (60\% da população é de baixo status), ou seja, a nova oferta de habitação de interesse social simulada estava longe de ser suficiente, considerando a enorme demanda do grupo de baixo status.

\subsubsection{Discussões e conclusões}

Este experimento visou simular os possíveis impactos de novas infraestruturas de transporte, juntamente com políticas de uso do solo relacionadas à habitação de interesse social e programas de emprego na acessibilidade aos empregos no município de São Paulo. Para explorar os impactos das políticas de uso da terra nas desigualdades de acessibilidade no emprego, foi desenvolvido o presente modelo.

O modelo foi concebido para ser uma ferramenta de apoio a tomada de decisão, fornecendo informações sobre os diferentes impactos de políticas de transporte e uso do solo em realidades alternativas, bem como para estimular o debate sobre as desigualdades de acessibilidade aos empregos e como reduzí-las através de políticas de uso do solo e transportes.

Para avaliar o potencial do modelo, foram realizados experimentos com estudos de caso no município de São Paulo, que é conhecido por suas desigualdades. Os experimentos tiveram como objetivo entender qual o peso da acessibilidade aos empregos e o status da vizinhança na escolha da localização residencial em São Paulo, os impactos de novas infraestruturas de transporte público de massa, juntamente com empregos e habitações de interesse social nas desigualdades de acessibilidade aos empregos, e os efeitos de diferentes ofertas e distribuições espaciais de habitações de interesse social na acessibilidade aos empregos. 
A investigação do peso das acessibilidades aos empregos e do status da vizinhança na escolha residencial em São Paulo demonstrou que a acessibilidade aos empregos tem maior influência no processo. Apesar da maior influência da acessibilidade aos empregos, o peso é assimétrico entre os grupos, sendo a acessibilidade aos empregos mais importante para o grupo de médio status do que para o grupo de alto status.

Em relação às linhas de transporte público de massa sobre trilhos, observou-se que a linha perimetral e a linha radial influenciam de forma distinta a acessibilidade aos empregos. Enquanto a linha radial permite acesso rápido a áreas com altas densidades de empregos no centro da cidade, a linha perimetral conecta áreas com menor oferta de empregos. Os impactos na acessibilidade aos empregos sugerem que a linha radial é mais eficaz no aumento da acessibilidade aos empregos, mas é importante mencionar que a oferta de transporte pode potencialmente promover o desenvolvimento de novas áreas quando planejada em conjunto com políticas de uso do solo (MEJIA-DORANTES; LUCAS, 2014).

Em relação às políticas de uso do solo, o modelo permitiu simular cenários com diferentes ofertas de habitações de interesse social e empregos. Para o município de São Paulo, verificou-se que apenas políticas de transporte público são insuficientes na redução das desigualdades de acessibilidade aos empregos. Políticas de transporte público devem ser implementadas juntamente com programas de habitação de interesse social e empregos, a fim de evitar o processo de gentrificação, no qual as áreas com aumento de acessibilidade aos empregos são ocupadas por pessoas com maior poder aquisitivo, reduzindo assim seus impactos sociais.

Conforme explorado no quarto experimento, tanto a estratégia de localização das habitações de interesse social, quanto a sua oferta, causam diferentes impactos nas desigualdades de acessibilidade aos empregos. Quanto maior a oferta de habitação de interesse social e mais próxima de locais com alta oferta de empregos, maior o impacto na igualdade de acessibilidade aos empregos entre os grupos analisados.

É importante destacar que o processo de escolha residencial é mais complexo do que o implementado no modelo. Embora simples, o modelo permitiu capturar os principais padrões do processo de localização residencial. A correlação de Pearson resultante da comparação entre as distribuições dos agentes por grupos sociais na situação observada e no cenário base (0,49 para G1, 0,58 para G2 e 0,78 para G3) e o algoritmo de similaridade de múltiplas janelas (0,71 na janela móvel 3x3) mostraram que o modelo foi capaz de capturar os macropadrões de localização residencial em São Paulo. 


\subsection{Município de São Paulo 2007 e 2017}

O modelo desenvolvido anteriormente para o município de São Paulo também foi utilizado para explorar alterações temporais nos dados empíricos de entrada. O objetivo de utilizar os dados empíricos da pesquisa origem-destino do Metrô do ano de 2007 e 2017 é avaliar se houve alterações nos parâmetros de calibração do modelo decorrente de alterações na localização residencial dos grupos de renda da população e alterações de acessibilidade aos empregos ocasionadas por mudanças na localização dos empregos e obras de infraestrutura de transporte público.

\subsubsection{Implementação dos modelos de São Paulo 2007 e 2017}

Para a implementação dos modelos de São Paulo para os anos de 2007 e 2017, foram utilizados os microdados da pesquisa origem e destino do Metrô. Diferentemente do que foi implementado na seção anterior, em que foram gerados grupos socio-ocupacionais, ou seja, foram utilizados dados de ocupação para gerar os grupos sociais, nos presentes modelos foram utilizados dados de renda. O motivo de utilizar dados de renda foi a impossibilidade de compatibilizar os dados ocupacionais de 2007 e 2017, uma vez que os dados ocupacionais da pesquisa origem-destino do ano de 2007 possuem maior nível de detalhamento do que os da pesquisa origem-destino de 2017. Essa diferença no nível de detalhamento dos dados impossibilitou a reclassificação dos dados ocupacionais do ano de 2017 para o padrão NS-SEC, conforme adotado na implementação do modelo da seção anterior.

Foram aplicados os fatores de expansão dos microdados das pesquisas origemdestino do Metrô de 2007 e 2017 e utilizada a renda familiar. Os dados de renda foram utilizados para gerar os grupos de alta, média e baixa renda através do algoritmo k-means. O algoritmo possibilitou gerar os três grupos de renda e observar uma pequena variação na composição dos grupos do ano de 2007 para 2017 (Tabela 1).

Como pode ser observado na Tabela 1, do ano de 2007 para o ano de 2017 a proporção da população que compõe o grupo de alta e média renda diminuiu, passando de $4.4 \%$ para $2.7 \%$ no caso do grupo de alta renda e de $21.4 \%$ para $21.2 \%$ no grupo de média renda. Quando analisado o grupo de baixa renda, observa-se um aumento da proporção da população que compõe esse grupo, passando de $74,2 \%$ para $76 \%$. Também pode ser observado que a renda dos grupos de alta, média e baixa renda variou significativamente no período de 2007 a 2017. Em relação à simulação, como foi utilizado um fator de simplificação de 200 para gerar os agentes, observamos que, proporcionalmente, o número 


\begin{tabular}{|c|c|c|c|c|}
\hline \multicolumn{5}{|c|}{ Distribuição dos Grupos de Renda } \\
\hline & & Alta Renda & Média Renda & Baixa Renda \\
\hline \multirow{3}{*}{ OD 2007 } & População & $143.572(4.4 \%)$ & $696.393(21.4 \%)$ & $2.415 .370(74.2 \%)$ \\
& Renda & $\mathrm{R} \$ 10.989,00$ & $\mathrm{R} \$ 4.328,00$ & $\mathrm{R} \$ 1.380,00$ \\
& Simulação & $419(2.8 \%)$ & $2.917(19.8 \%)$ & $11.375(77.3 \%)$ \\
\hline \multirow{3}{*}{ OD 2017 } & População & $109.498(2.7 \%)$ & $850.241(21.2 \%)$ & $3.044 .108(76.0 \%)$ \\
& Renda & $\mathrm{R} \$ 18.885,00$ & $\mathrm{R} \$ 7.034,00$ & $\mathrm{R} \$ 2.518,00$ \\
& Simulação & $330(1.8 \%)$ & $3.703(20.1 \%)$ & $14.423(78.1 \%)$ \\
\hline
\end{tabular}

Tabela 1 - Distribuição dos Grupos de Renda em São Paulo em 2007 e 2017.

de agentes do grupo de alta renda diminuiu de $2.8 \%$ para $1.8 \%$ e aumentou de $19.8 \%$ para $20.1 \%$ no grupo de média renda e de $77.3 \%$ para $78.1 \%$ no grupo de baixa renda. As Figuras 16 e 17 apresentam a distribuição dos grupos de renda para os anos de 2007 e 2017.

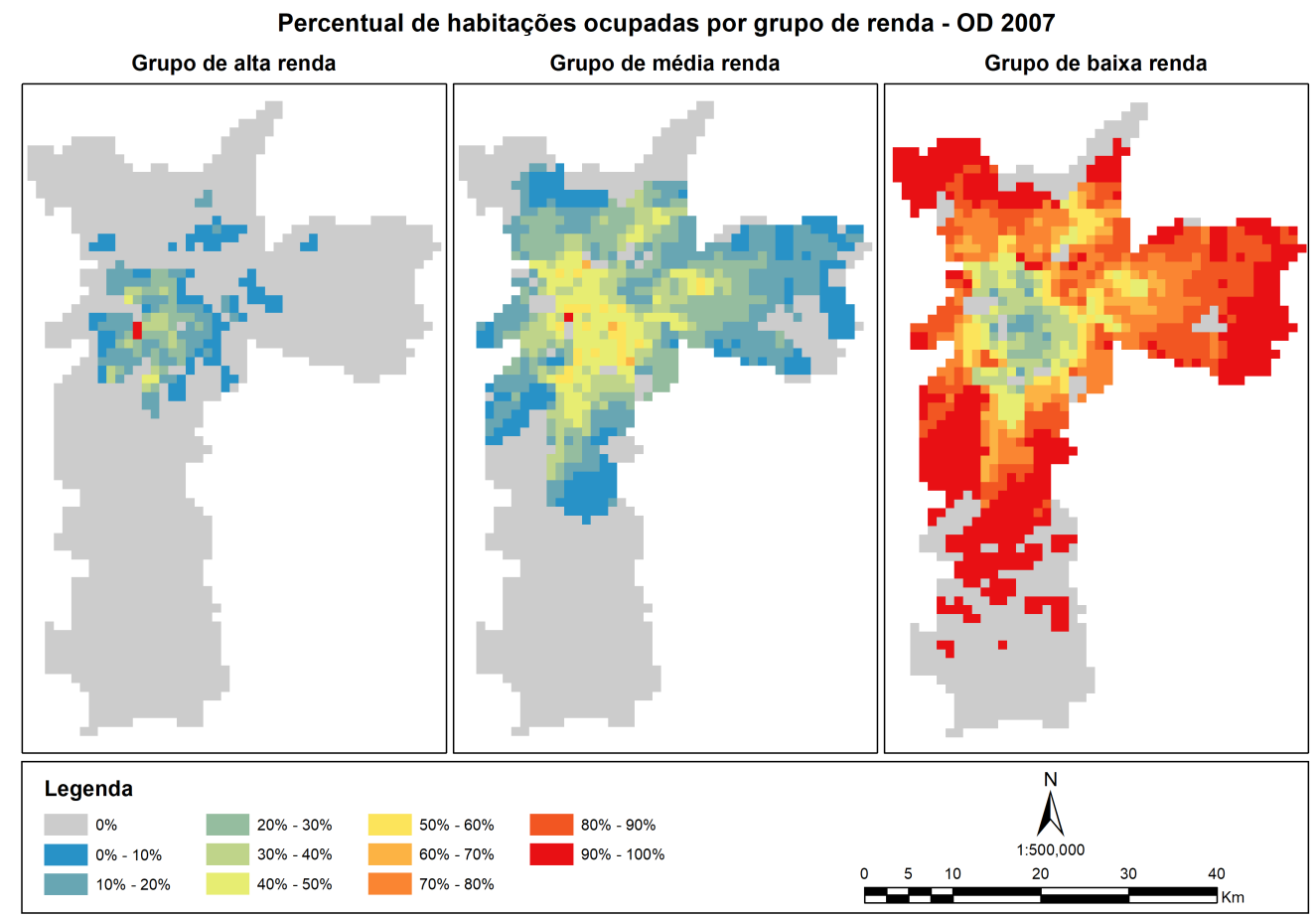

Figura 16 - Localização residencial dos grupos de renda para 2007.

Como pode ser observado nas Figuras 16 e 17, o grupo de alta renda se concentra principalmente no quadrante sudoeste do município de São Paulo. O grupo de média renda, se comparado ao grupo de alta renda, se distribui de maneira mais ampla no município de São Paulo e se concentra próximo às áreas onde reside a população de alta renda. $\mathrm{O}$ grupo de baixa renda se concentra nas regiões periféricas do município de São Paulo, 


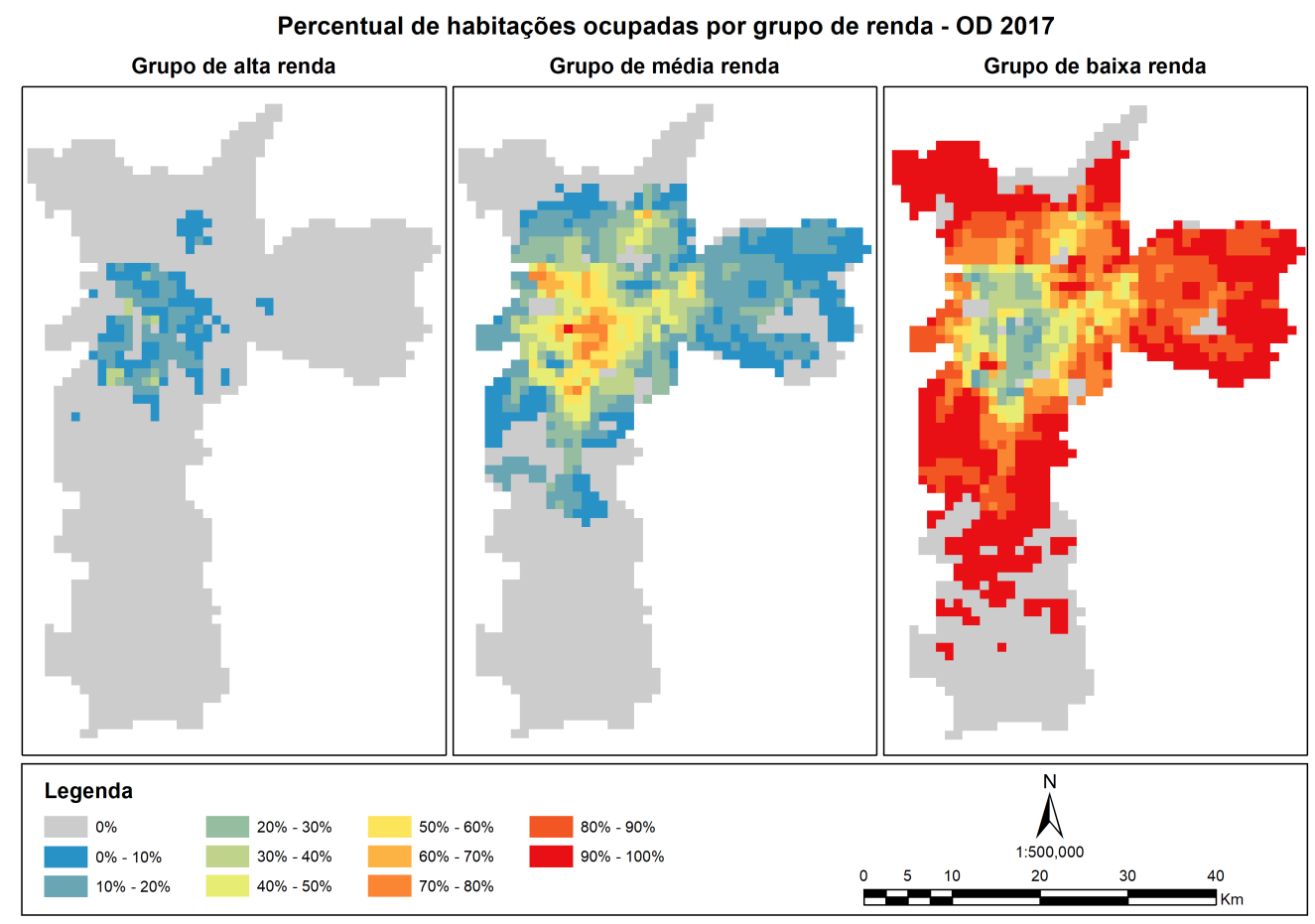

Figura 17 - Localização residencial dos grupos de renda para 2017.

com exceção da área degradada do centro de São Paulo e de Paraisópolis (localizada no quadrante centro-sudoeste), que são representadas nas Figuras 16 e 17.

Assim como os dados de renda, os dados de empregos formais foram obtidos através das pesquisas origem destino do Metrô dos anos 2007 e 2017 agregados por zona de tráfego. Os dados foram desagregados para as células do ambiente de simulação com o objetivo de utilizá-los posteriormente nos cálculos da acessibilidade aos empregos. A distribuição dos empregos nos anos de 2007 e 2017 mostra que houve pouca alteração no período, sendo possível observar que a maioria dos empregos ainda se concentram na região central do município. Fora da região central, é possível observar alterações na oferta de empregos formais principalmente nas zonas sul e leste do município (Figura 18).

A oferta de transporte público passou por alterações significativas no período. Conforme revelado no relatório da pesquisa origem e destino do Metrô de 2017, no período 2007-2017 a malha metroviária cresceu 28,4 km (46\%) e a implantação de corredores e faixas exclusivas de ônibus incrementaram a fluidez do transporte público sobre pneus (METRÔ, 2019).

A situação observada da oferta de transporte público para o ano de 2007 foi recuperada através de arquivos espaciais históricos das linhas de transporte público. Foi necessário utilizar os dados históricos, pois ainda não havia disponível o formato de arquivo GTFS, que começou a ser disponibilizado sistematicamente a partir de 2012 pela SPTrans. As velocidades médias das linhas de transporte público sobre pneus foram calculadas a 


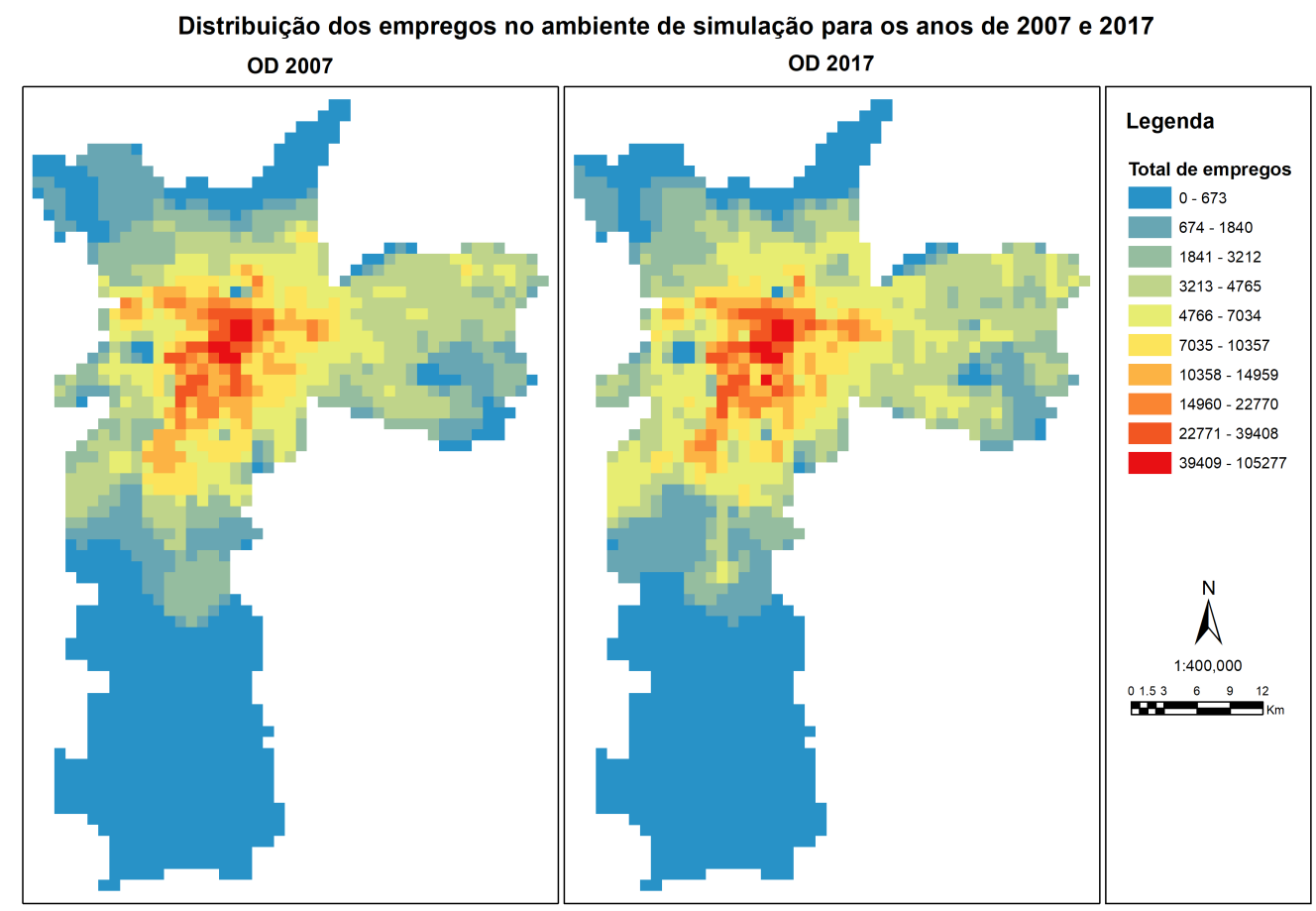

Figura 18 - Localização dos empregos em 2007 e 2017.

partir da extensão, frequência e frota de veículos de cada linha, enquanto que para o sistema sobre trilhos foram selecionadas apenas as estações em funcionamento até o ano de 2007. Os detalhes dos procedimentos realizados para criar o arquivo no formato GTFS com os dados de transporte público para o ano de 2007 estão disponíveis em Santos (2020). A oferta de transporte público para o ano de 2017 foi obtida através de dados GTFS disponibilizados pela SPTrans.

Conforme adotado nos experimentos na seção 5.1, o município de São Paulo foi dividido em células de $1 \mathrm{~km}^{2}$ para montar o ambiente de simulação. O centróide de cada uma das células foi utilizado como ponto de origem e destino para gerar as matrizes origem-destino por transporte público e modo caminhada dos anos de 2007 e 2017 através do Open Trip Planner (OTP).

Calculadas as matrizes de tempo de viagem por transporte público, foram calculadas as acessibilidades aos empregos por transporte público para os anos de 2007 e 2017 através da Eq.(5.1). Os atributos de acessibilidade aos empregos foram associados às células do ambiente de simulação. 


\subsubsection{Calibração dos modelos de São Paulo 2007 e 2017}

Seguindo o mesmo procedimento de calibração adotado na seção 5.1.2, os modelos foram calibrados distribuindo aleatoriamente os agentes no ambiente de simulação e executando uma análise de sensibilidade. A análise de sensibilidade foi feita alterando o parâmetro $\alpha$ da função de utilidade, responsável por atribuir maior peso a acessibilidade aos empregos ou status da vizinhança, em intervalos de 0.1 para cada um dos grupos de renda, o que resultou em 1.331 combinações. As distribuições residenciais resultantes da análise de sensibilidade foram comparadas com a distribuição residencial das situações observadas para os anos de 2007 e 2017, através da correlação de Pearson e através do algoritmo de similaridade de múltiplas janelas, conforme mencionado na seção 5.1.2.

Os parâmetros $\alpha$ que melhor representaram a situação observada no município de São Paulo foram aqueles com a maior soma de correlações considerando os três grupos de renda. Os parâmetros que apresentaram os melhores resultados para o ano de 2007 foram de 0,3 para o grupo de alta renda, 1 para o grupo de média renda e de 0 para o grupo de baixa renda. Para o ano de 2017 foram de 0,2 para o grupo de alta renda, 1 para o grupo de média renda e de 0,3 para o grupo de baixa renda.

Os resultados da calibração dos modelos de São Paulo indicam que os agentes pertencentes ao grupo de alta renda priorizam o status da vizinhança para ambos os anos em análise. Já o grupo de média renda considera somente a acessibilidade aos empregos como fator para a escolha residencial. O grupo de baixa renda, conforme discutido no experimento anterior, se aloca nas habitações não ocupadas pelos agentes dos grupos de alta e média renda, por isso, o seu parâmetro $\alpha$ varia consideravelmente ao longo do processo de calibração.

A correlação de Pearson encontrada para o modelo de 2007 foi de 0,44 para o grupo de alta renda, 0,55 para o grupo de média renda e de 0,78 para o grupo de baixa renda. $\mathrm{O}$ algoritmo de similaridade por múltiplas janelas resultou em uma similaridade mínima de 0,77 para uma janela 3x3. Para o modelo de 2017 a correlação encontrada foi de 0,44 para o grupo de alta renda, 0,56 para o grupo de média renda e de 0,77 para o grupo de baixa renda. Considerando o algoritmo de similaridade por janelas múltiplas, foi encontrado o valor de 0,81 de similaridade mínima para uma janela 3x3. 


\subsubsection{Resultados dos modelos de São Paulo 2007 e 2017}

Os modelos de 2007 e 2017 permitiram capturar os macropadrões espaciais de localização residencial dos 3 grupos de renda (Figuras 19 e 20). Como pode ser visto na situação observada, tanto para 2007 quanto para 2017, o grupo de alta renda se concentra no quadrante sudoeste, enquanto o grupo de baixa renda se concentra majoritariamente nas periferias do município de São Paulo. Em relação à distribuição das acessibilidades aos empregos por grupo de renda, apesar de apresentar maior variabilidade nas situações observadas em 2007 e 2017, o modelo permitiu retratar a distribuição das situações observadas. Da mesma forma, os resultados das calibrações resultaram em curvas de Lorenz e coeficientes Gini próximos dos encontrados na realidade.

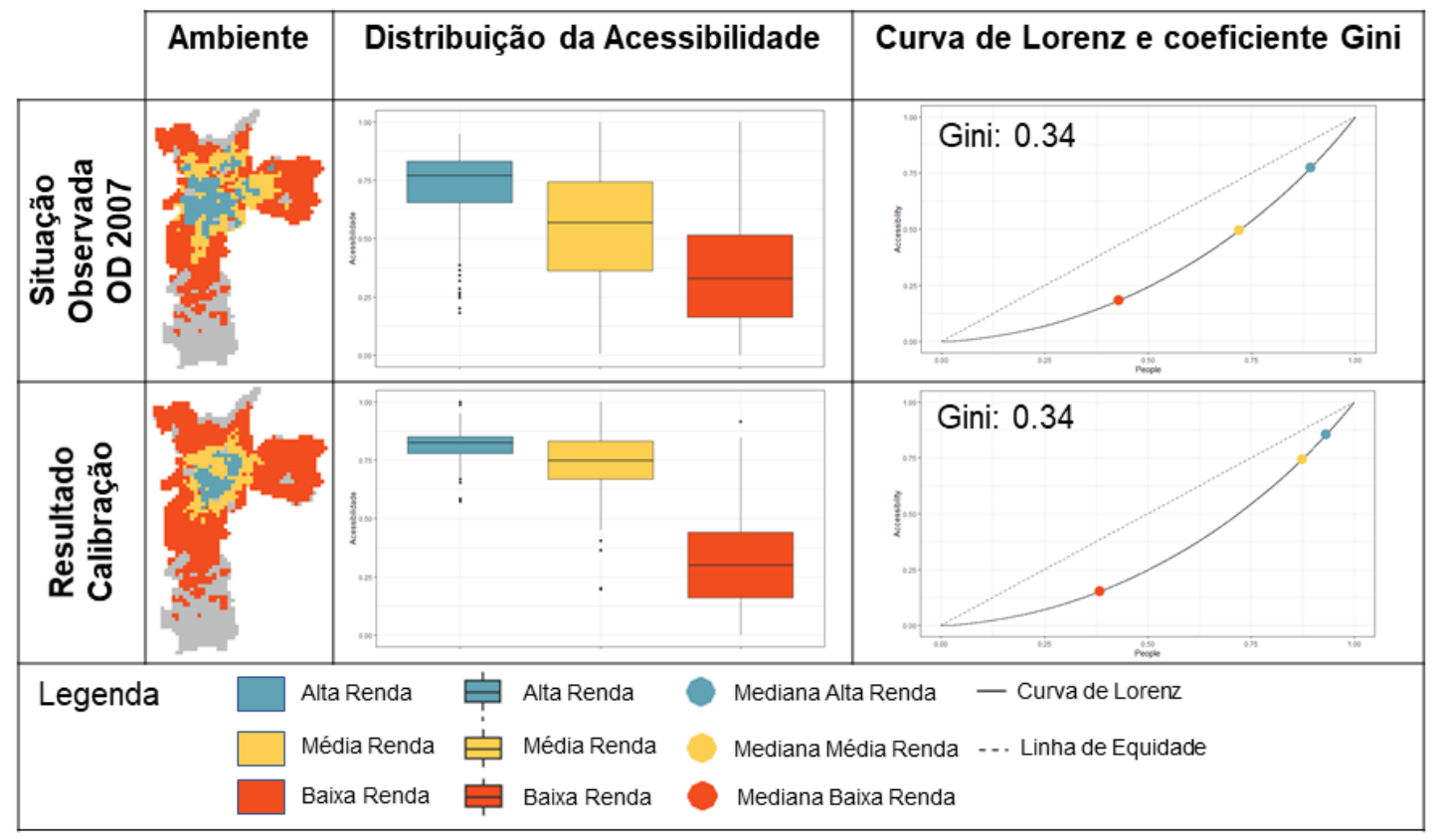

Figura 19 - Resultados do modelo de 2007.

Apesar das altas correlações entre as situações observadas e as simulações resultantes do processo de calibração, os modelos não permitiram representar algumas áreas com predomínio de população de baixa renda nas proximidades do centro do município e nas imediações de bairros ricos. Observando as distribuições das acessibilidades aos empregos por grupo de renda, nota-se que a dispersão das acessibilidades das simulações resultantes dos processos de calibração é menor do que nas situações observadas. Isso se deve ao fato dos agentes nas simulações se segregarem mais do que na realidade para maximizarem a sua utilidade. Com isso, podemos observar que tanto as medianas da distribuição das acessibilidades quanto as medianas representadas nas curvas de Lorenz, estão mais distantes entre si do que as encontradas nas situações observadas. 


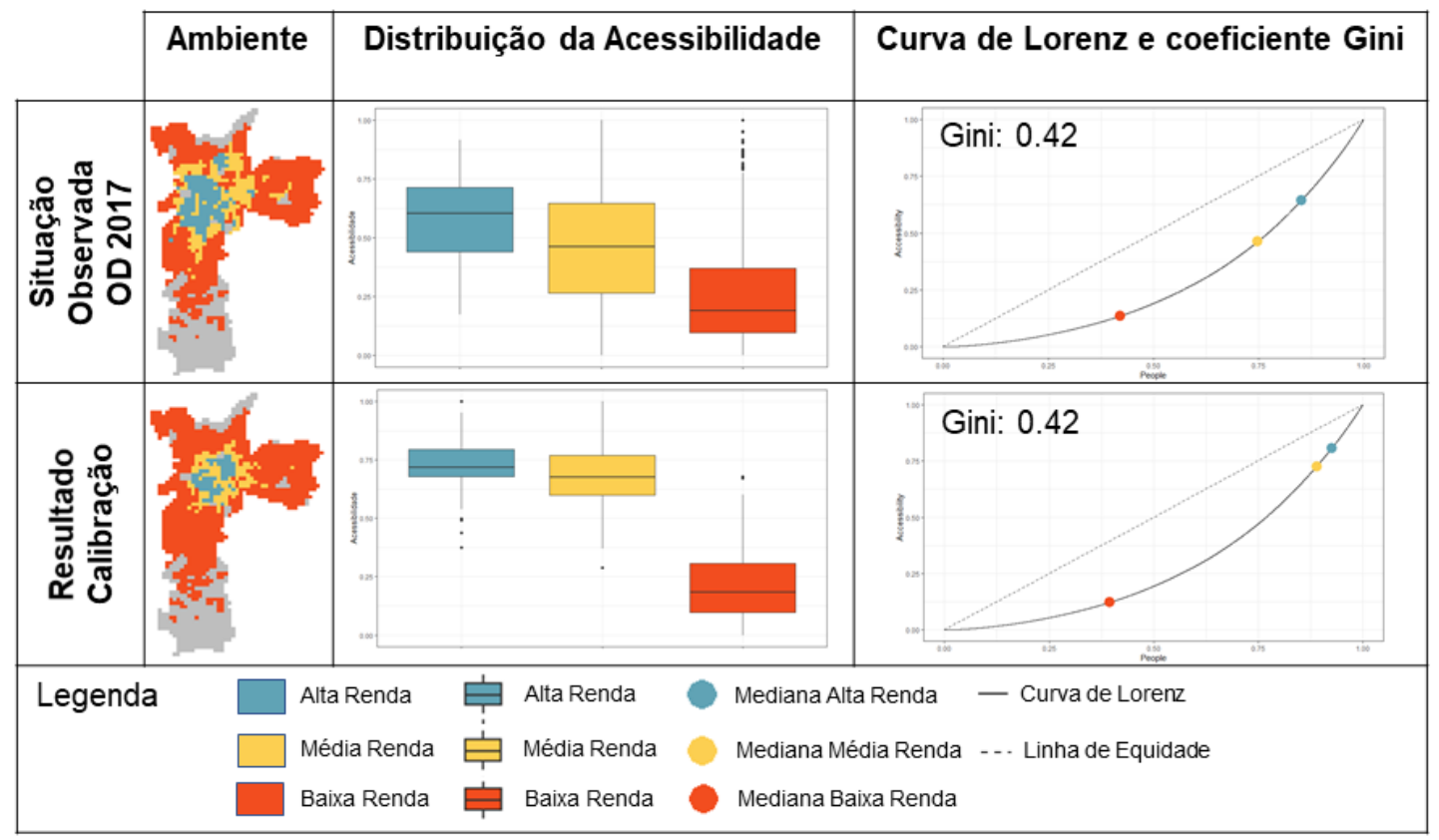

Figura 20 - Resultados do modelo de 2017.

\subsubsection{Discussões e conclusões sobre os modelos de São Paulo 2007 e 2017}

O presente estudo de caso tem como objetivo avaliar a potencialidade do modelo proposto em capturar os efeitos de alterações temporais de oferta de transporte público, habitações e empregos nos parâmetros de calibração do modelo. Para avaliar a potencialidade do modelo do proposto, ele foi adaptado para receber dados de entrada de duas datas distintas e, dessa forma, foram criados dois modelos para o município de São Paulo, sendo um do ano de 2007 e outro do ano de 2017. Os modelos foram parametrizados com dados provenientes das pesquisas origem e destino do Metrô do ano de 2007 e 2017, que possibilitaram atribuir às células do ambiente de simulação atributos de oferta de habitação, empregos e, através dos tempos de viagem obtidos através dos dados GTFS e dados de emprego, dados de acessibilidade aos empregos por transporte público.

No período de estudo, foi observado um aumento na quantidade de famílias no município, o que resultou em um salto de 14.711 agentes na simulação de 2007 para 18.456 agentes na simulação de 2017. Além da quantidade total de agentes, a composição de agentes por grupo de renda também se modificou no período, sendo o grupo de baixa renda o único em que houve incremento relativo de pessoas.

A quantidade de empregos no município de São Paulo aumentou em torno de 1\% no período de análise. Assim como houve pouca alteração no total de empregos, a sua distribuição também pouco mudou, sendo o centro do município a área que concentra a maior parte da oferta de empregos. Apesar disso, é possível encontrar aumento na 
concentração de empregos em partes da região sul e leste do município. Essas alterações na oferta de emprego podem estar relacionadas com a maior oferta de imóveis comerciais na zonal sul e investimentos realizados na zona leste para a Copa do Mundo de futebol de 2014 .

A parametrização para o modelo considerando os dados de 2007 e 2017 mostram uma leve mudança no parâmetro $\alpha$ para o grupo de alta renda. Essa mudança de 0.1 no parâmetro $\alpha$ do grupo de alta renda (passando de 0.3 para 0.2 ), mostra no período existe uma tendência de maior isolamento do grupo de alta renda, que aumentou o peso para o status da vizinhança no processo de escolha residencial. Em relação ao grupo de média renda, a acessibilidade aos empregos continua sendo o principal fator considerado no processo de escolha residencial.

Conforme mencionado na seção anterior, o processo de escolha residencial é mais complexo do que o implementado no modelo, porém ele permite a reflexão de como o sistema de transporte público, oferta de habitações e empregos podem influenciar na escolha residencial. O fato de ter ocorrido uma pequena alteração no parâmetro $\alpha$ do ano de 2007 para o ano de 2017, como resultado de uma também pequena alteração na situação observada no período, mostra que o modelo possui sensibilidade bastante para captar pequenas alterações na área de interesse.

É importante destacar que, apesar das simplificações inerentes ao modelo implementado, ele permitiu retratar a situação observada tanto para o ano de 2007 quanto para o ano de 2017. Algumas limitações, como a impossibilidade de representar áreas degradadas no centro de São Paulo e comunidades de menor renda próximas de áreas de alta renda, persistem. As simulações resultantes do modelo também possuem menor dispersão de acessibilidade aos empregos por grupo de renda, se comparado aos cenários observados. A menor dispersão resulta de um maior nível de concentração dos grupos de alta e média renda, que se segregam mais do que o observado na realidade.

\subsection{Avaliação Empírica do Modelo em Contextos Urbanos Distin- tos do de São Paulo}

Além do município de São Paulo, o modelo foi implementado e calibrado para outras duas áreas de estudo para avaliar a sua robustez na representação de áreas em contextos urbanos distintos. O modelo foi implementado e calibrado para o município de Curitiba por ele apresentar dimensões espaciais, populacionais e distribuição dos grupos de renda distintos do de São Paulo. O outro estudo de caso foi a zona central da região 
metropolitana de Melbourne, que se encontra em um contexto de país desenvolvido. A zona central da região metropolitana de Melbourne possui dimensões espaciais e populacionais semelhantes a do município de Curitiba, porém é limitada geograficamente pela Baía de Port Phillip, fazendo com que o centro de negócios não coincida com o centro geográfico da área de estudo. Outra característica do estudo de caso de Melbourne é a distribuição dos grupos de renda ser profundamente diferente do encontrado em Curitiba e São Paulo, pois o grupo de renda média é o predominante em Melbourne.

\subsubsection{Município de Curitiba}

Com população de 1.751 .907 pessoas $^{10}$, o município de Curitiba é a capital do Estado do Paraná. Apresenta um PIB per capita de $\mathrm{R} \$ 44.384,92^{10}$ e na área de transportes, a frota total contratada de ônibus e micro-ônibus para o transporte público somou 1.229 veículos e 251 linhas de transporte público operadas em $2019^{11}$.

O município de Curitiba é consideravelmente menor do que o município de São Paulo tanto em termos de população (11.253.503 habitantes em São Paulo ${ }^{1}$ e 1.751.907 habitantes em Curitiba ${ }^{10}$ ) quanto em termos de território (a área de São Paulo ${ }^{1}$ é de $1.521,110 \mathrm{~km}^{2}$ e a área de Curitiba ${ }^{10}$ é de $435,036 \mathrm{~km}^{2}$ ). O sistema de transporte de Curitiba também é organizado de forma distinta, recebendo um destaque especial o sistema BRT.

\subsubsection{Implementação do modelo de Curitiba}

Os agentes foram criados através dos dados de setores censitários de 2010. Os agentes foram estratificados em 3 grupos sociais através dos dados de renda. Para atribuir o grupo social de cada um dos agentes de acordo com sua renda, foi utilizado o algoritmo k-means para a definição dos intervalos de renda representativos de cada grupo. O valor central do cluster de alta renda foi de $\mathrm{R} \$ 5.342,00$, o de média renda foi de $\mathrm{R} \$ 1.637,00$ e o de baixa renda de $\mathrm{R} \$ 631,00$. A população total de Curitiba com renda e acima de 10 anos de idade encontrada foi de 1.076.402, sendo 207.914 (19\% do total) pertencente ao grupo de alta renda, 330.301 (31\% do total) ao grupo de média renda e 538.187 (50\% do total) pertencente ao grupo de baixa renda. A distribuição espacial dos grupos de renda pode ser observada na Figura 21.

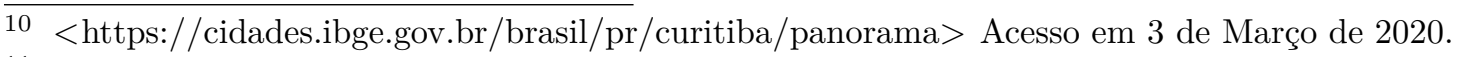

$11<$ https://www.urbs.curitiba.pr.gov.br/transporte/rede-integrada-de-transporte> Acesso em 3 de Março de 2020. 


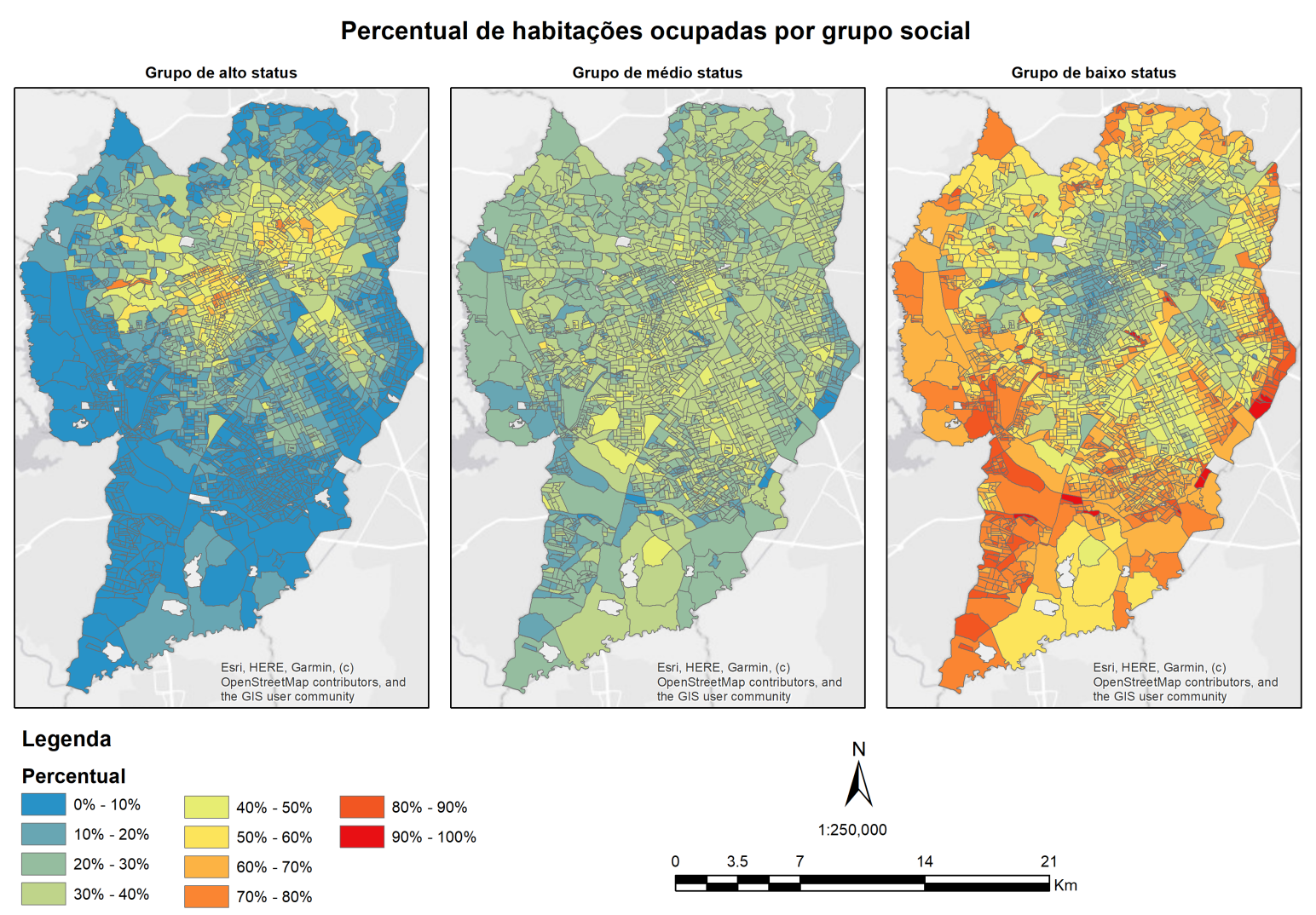

Figura 21 - Distribuição dos grupos sociais no município de Curitiba.

Para criar os agentes, foi aplicado um fator de simplificação de cem vezes, pois o esforço computacional impossibilita realizar as simulações com o total de 1.076 .402 agentes. Como resultado, foram criados 10.707 agentes representando a população total que possui rendimento no município de Curitiba.

O ambiente de simulação foi criado através de uma grade de células de $1 \mathrm{~km}^{2}$ cobrindo todo o município de Curitiba. O tamanho das células foi escolhido com base no esforço computacional para as simulações e por ser adequado para representar a área de interesse. No total o ambiente de simulação é composto por 497 células de 1 km².

O processo de distribuição da população em cada uma das células foi realizado calculando a densidade populacional de cada um dos grupos de renda nos setores censitários e interseccionando os setores censitários com a grade de células do ambiente de simulação. No caso de uma célula compartilhar mais de um setor censitário, a população foi atribuída considerando diferentes densidades populacionais.

A oferta de habitação em cada uma das células é representada pela quantidade de agentes existentes na situação observada, ou seja, a quantidade de habitantes de acordo com o Censo de 2010, somado ao estoque habitacional. O estoque habitacional adotado foi de 1 habitação a mais por célula com o objetivo de representar habitações desocupadas 
e dar dinamismo ao processo de escolha residencial no modelo.

Da mesma forma que o modelo desenvolvido na seção 5.2, o presente modelo considera apenas o transporte público para os cálculos da acessibilidade aos empregos. A acessibilidade aos empregos foi disponibilizada por Bittencourt (2020). A autora utilizou os arquivos GTFS de Curitiba em conjunto com a base de arruamento do OSM para gerar a matriz de tempo de viagem entre os centróides de hexágonos de 500 metros através do OTP. As viagens foram geradas para as 07:00h da manhã com o intuito de simular viagens com motivo de trabalho. Os dados de acessibilidade foram disponibilizados em hexágonos de 500 metros em formato shapefile, foram gerados os seus centróides e interseccionados com as células do ambiente de simulação. As acessibilidades dos centróides dos hexágonos foram atribuídos às células correspondentes. Nos casos em que havia mais de um centróide por célula do ambiente de simulação, foram geradas médias das acessibilidades e atribuídas as células. A medida de acessibilidade empregada no modelo foi a cumulativa, conforme Eq.5.1, e o tempo de viagem considerado foi de 30 minutos. O modelo foi implementado no software NetLogo (WILENSKY, 1999).

\subsubsection{Calibração do modelo de Curitiba}

A calibração do modelo foi realizada distribuindo aleatoriamente os agentes no ambiente de simulação e executando uma análise de sensibilidade. A análise de sensibilidade foi feita alterando o parâmetro $\alpha$ da função de utilidade, responsável por atribuir maior peso à acessibilidade aos empregos ou status da vizinhança, em intervalos de 0.1 para cada um dos grupos de renda, o que resultou em 1.331 combinações. Os resultados da análise de sensibilidade foram comparados com a distribuição residencial da situação observada, proveniente dos dados do Censo demográfico de 2010, através da correlação de Pearson e através do algoritmo de similaridade de múltiplas janelas, conforme mencionado na seção 5.1 .2 .

Os parâmetros $\alpha$ que melhor representaram a situação observada no município de Curitiba foram aqueles com a maior soma de correlações considerando os três grupos de renda. Os parâmetros que apresentaram os melhores resultados foram de 0,4 para o grupo de alta renda, 0,8 para o grupo de média renda e de 0,9 para o grupo de baixa renda.

Os resultados da calibração do modelo de Curitiba indicam que os agentes pertencentes ao grupo de alta renda priorizam o status da vizinhança, apesar de a acessibilidade aos empregos também exercer influência no processo de escolha residencial. O parâmetro $\alpha$ de 0,4 para o grupo de alta renda faz com que os agentes se estabeleçam na área central do município, segregando-se dos demais agentes. Já os grupos de média e baixa renda 
priorizam de maneira mais acentuada a acessibilidade aos empregos. A correlação de Pearson encontrada foi de 0,78 para o grupo de alta renda, 0,45 para o grupo de média renda e de 0,75 para o grupo de baixa renda. O algoritmo de similaridade por múltiplas janelas resultou em uma similaridade mínima de 0,75 em uma janela móvel de 3x3.

\subsubsection{Resultados do modelo de Curitiba}

O modelo permitiu capturar os macropadrões espaciais de localização residencial dos 3 grupos de renda (Figura 22). Como pode ser visto na situação observada, o grupo de alta renda se concentra na região central e norte do município de Curitiba, enquanto o grupo de baixa renda se concentra majoritariamente na região sul e periferias. Em relação à distribuição das acessibilidades aos empregos por grupo de renda, pode ser observado que o modelo permitiu retratar a distribuição da situação observada em 2010 em Curitiba. Da mesma forma, o resultado da calibração resultou em uma curva de Lorenz e coeficiente Gini próximos dos encontrados na realidade.

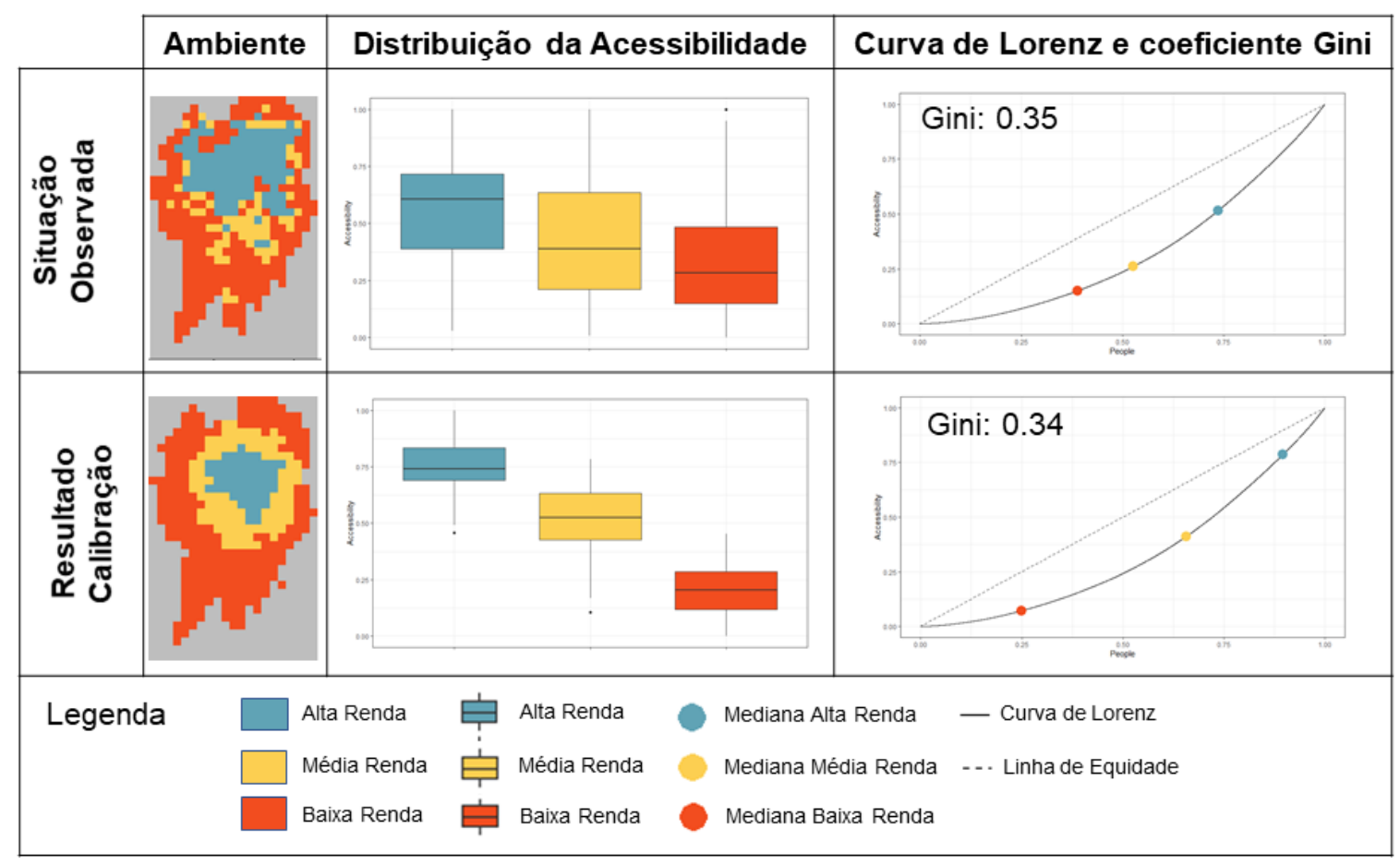

Figura 22 - Resultados do modelo de Curitiba.

Apesar das altas correlações entre a situação observada e a simulação resultante do processo de calibração, o modelo não permitiu representar algumas áreas com predomínio de população de baixa renda nas proximidades do centro do município, região norte e nas imediações de bairros ricos. Observando a distribuição das acessibilidades por grupo de renda, nota-se que a dispersão das acessibilidades aos empregos da simulação resultante do processo de calibração é consideravelmente menor do que na situação observada. Isso 
se deve ao fato dos agentes na simulação precisarem se segregar mais do que na realidade para maximizarem a sua utilidade. Com isso, podemos observar que tanto as medianas da distribuição das acessibilidades quanto as medianas representadas nas curvas de Lorenz, estão mais distantes entre si do que as encontradas na situação observada.

\subsubsection{Discussões e conclusões sobre o modelo de Curitiba}

O experimento de Curitiba teve como objetivo avaliar a robustez do modelo na representação de um município com área, população, perfil socioeconomico e ofertas de transporte, emprego e habitação distintas da do município de São Paulo. A área e o total de população do município são, respectivamente, 3,5 e 6,4 vezes menor do que do município de São Paulo.

Em relação ao perfil socioeconomico da população de Curitiba, o algoritmo de k-means mostrou uma distribuição dos grupos de renda distinta da encontrada em São Paulo. O grupo de alta renda representa $19 \%$ do total da população, o de média renda $31 \%$ da população e o de baixa renda $50 \%$ da população. No experimento anterior de São Paulo, 4,4\% da população pertencia ao grupo de alta renda, 21,4\% ao grupo de média renda e 74,2\% ao grupo de baixa renda. Aplicar o modelo em um município com proporção de agentes por grupo de renda melhor distribuída em relação ao município de São Paulo, permitiu avaliar a sua capacidade de representar um cenário de maior igualdade. Vale ressaltar que os valores centrais dos clusters de renda podem representar diferentes grupos em Curitiba e São Paulo, como, por exemplo, o grupo de alta renda de São Paulo pode apresentar maior renda do que o grupo de alta renda de Curitiba.

As configurações de perfil socioeconomico, bem como a oferta de transporte público, emprego e habitações resultaram nos parâmetros $\alpha$ de 0,4 para o grupo de alta renda, 0,8 para o grupo de média renda e 0,9 para o grupo de baixa renda. Os resultados da calibração corroboram com os resultados encontrados nos experimentos anteriores, em que o grupo de alta renda prioriza o status da vizinhança à acessibilidade aos empregos por transporte público, enquanto o grupo de média renda prioriza a acessibilidade aos empregos por transporte público. Esse resultado mostra que, apesar das diferenças no perfil socioeconomico e demais variáveis do modelo, a forma como os grupos de renda se localizam no espaço possuem semelhanças em relação a acessibilidade aos empregos por transporte público e status da vizinhança.

Algumas limitações do modelo para a representação da localização residencial dos grupos de renda persistem para Curitiba. Embora o grupo de alta renda se concentre na região central do município, algumas áreas com predomínio de grupos de baixa renda 
localizadas próximas a essas áreas ricas não foram representadas nas simulações. A menor dispersão da distribuição de acessibilidade aos empregos por grupo de renda também mostra como os agentes estão localizados de maneira mais homogênea no espaço em relação a situação observada.

\subsubsection{Zona Central da Região Metropolitana de Melbourne}

A região metropolitana de Melbourne é a segunda maior região metropolitana da Austrália, com aproximadamente 4,5 milhões de habitantes (ABS, 2016). O sistema de transporte público de Melbourne é formado por linhas de trem, tram e ônibus. Tanto o sistema de trem quanto o de tram possuem traçado radial e oferecem um alto nível de serviço para usuários na região central e nos subúrbios próximos ao centro (CURRIE; DELBOSC, 2011). O nível de serviço do sistema de transporte público por ônibus varia de acordo com a região, sendo as regiões central e próximas do centro as que possuem maior oferta (LOADER; STANLEY, 2009).

Para efeitos de comparação com o município de Curitiba, foi considerada a zona central da região metropolitana de Melbourne, que é formada pelas áreas estatísticas do centro, centro-sul e centro-leste da região metropolitana (Figura 23). A zona central da região metropolitana de Melbourne possui uma área de $432 \mathrm{~km}^{2}$ e uma população de 1.512.353 habitantes ${ }^{12}$. Como a área do município de Curitiba é de $435 \mathrm{~km}^{2}$ e a sua população é de 1.751.907 habitantes ${ }^{10}$, a comparação será realizada em áreas com similaridades de extensão geográfica e populacional.

\subsubsection{Implementação do modelo de Melbourne}

Os agentes foram criados através dos dados do censo demográfico de 2016 realizado pela Australian Bureau of Statistics (ABS, 2016). Os dados censitários apresentam a informação de renda de cada uma das pessoas por áreas estatísticas SA2 em que residem. A informação de renda é originalmente agregada em 13 intervalos de renda, que variam de 1 a mais de 3.000 doláres australianos por semana. Para cada um dos intervalos de renda foi considerado o valor médio da faixa de renda e atribuído como valor representativo de cada um dos indivíduos. Para atribuir o grupo social de cada um dos agentes de acordo com sua renda, foi utilizado o algoritmo de k means dividindo a população em 3 grupos (alta, média e baixa renda). O valor central do cluster de alta renda foi de AUD $\$ 2.502,00$ por semana, o de média renda foi de $\operatorname{AUD} \$ 1.233,00$ por semana e o de baixa renda foi

12 <https://itt.abs.gov.au/itt/r.jsp?databyregion\#/> Acesso em 17 de Março de 2020. 


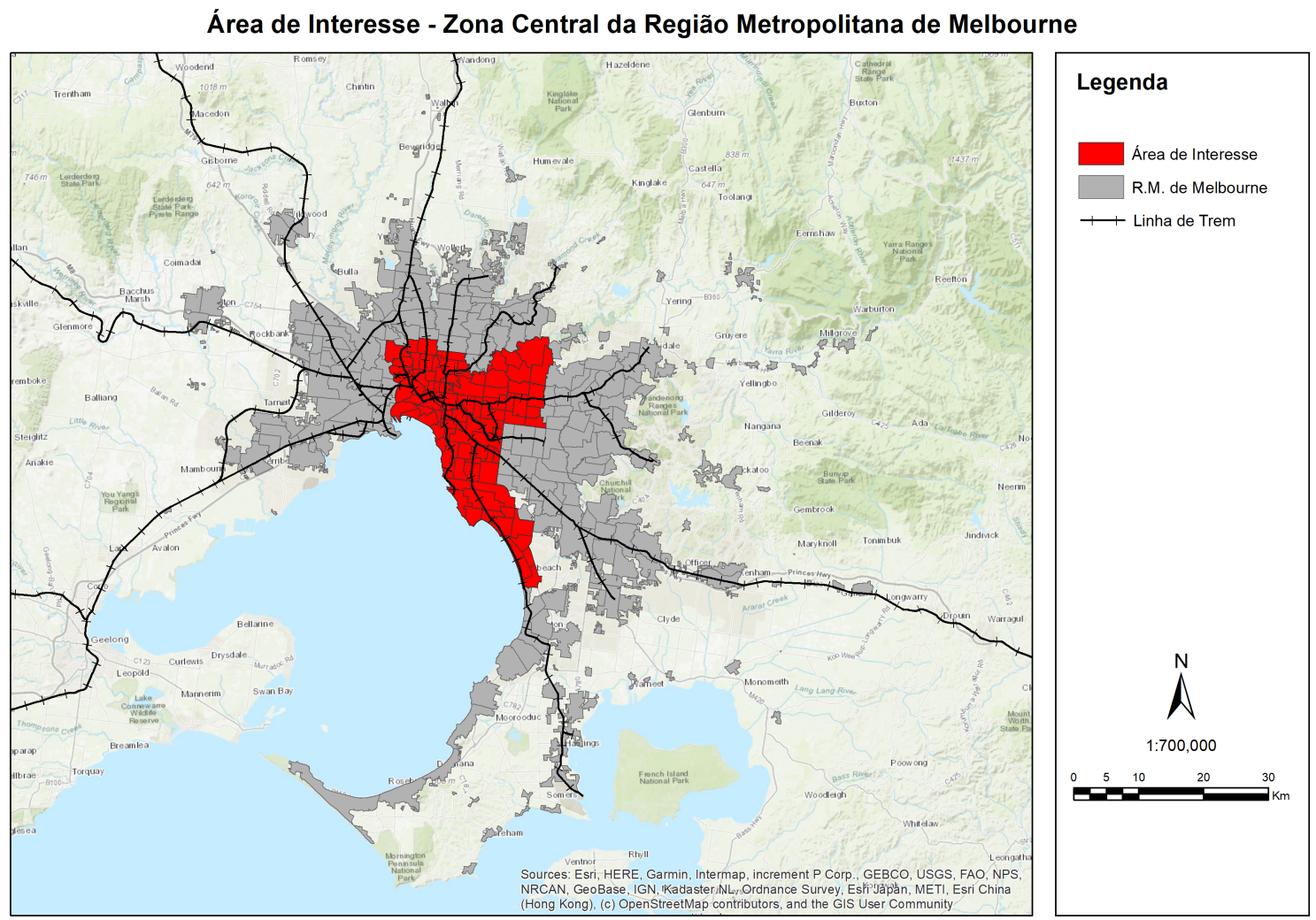

Figura 23 - Área de interesse - zona central da região metropolitana de Melbourne.

de $\operatorname{AUD} \$ 480,00$ por semana. A população total da área central com renda foi de 947.858 pessoas, sendo 258.951 pessoas (27\% do total) pertencentes ao grupo de alta renda, 417.145 pessoas (44\% do total) pertencentes ao grupo de média renda e 271.762 pessoas $(29 \%$ do total) percententes ao grupo de baixa renda. A distribuição espacial dos grupos de renda pode ser observada na Figura 24.

Comparativamente, a distribuição dos grupos de renda de Melbourne e Curitiba é bastante distinta. A Tabela 1 apresenta a distribuição encontrada para os grupos de renda em Melbourne e Curitiba:

\begin{tabular}{|c|c|c|c|}
\hline \multicolumn{4}{|c|}{ Distribuição dos Grupos de Renda } \\
\hline & Alta Renda & Média Renda & Baixa Renda \\
\hline Melbourne & $258.951(27 \%)$ & $417.145(44 \%)$ & $271.762(29 \%)$ \\
Curitiba & $207.914(19 \%)$ & $330.301(31 \%)$ & $538.187(50 \%)$ \\
\hline
\end{tabular}

Tabela 2 - Distribuição dos Grupos de Renda em Melbourne e Curitiba.

Como pode ser observado na Tabela 2, quando comparado a Curitiba, Melbourne apresenta maior quantidade de pessoas nos grupos de alta e média renda. Enquanto o 


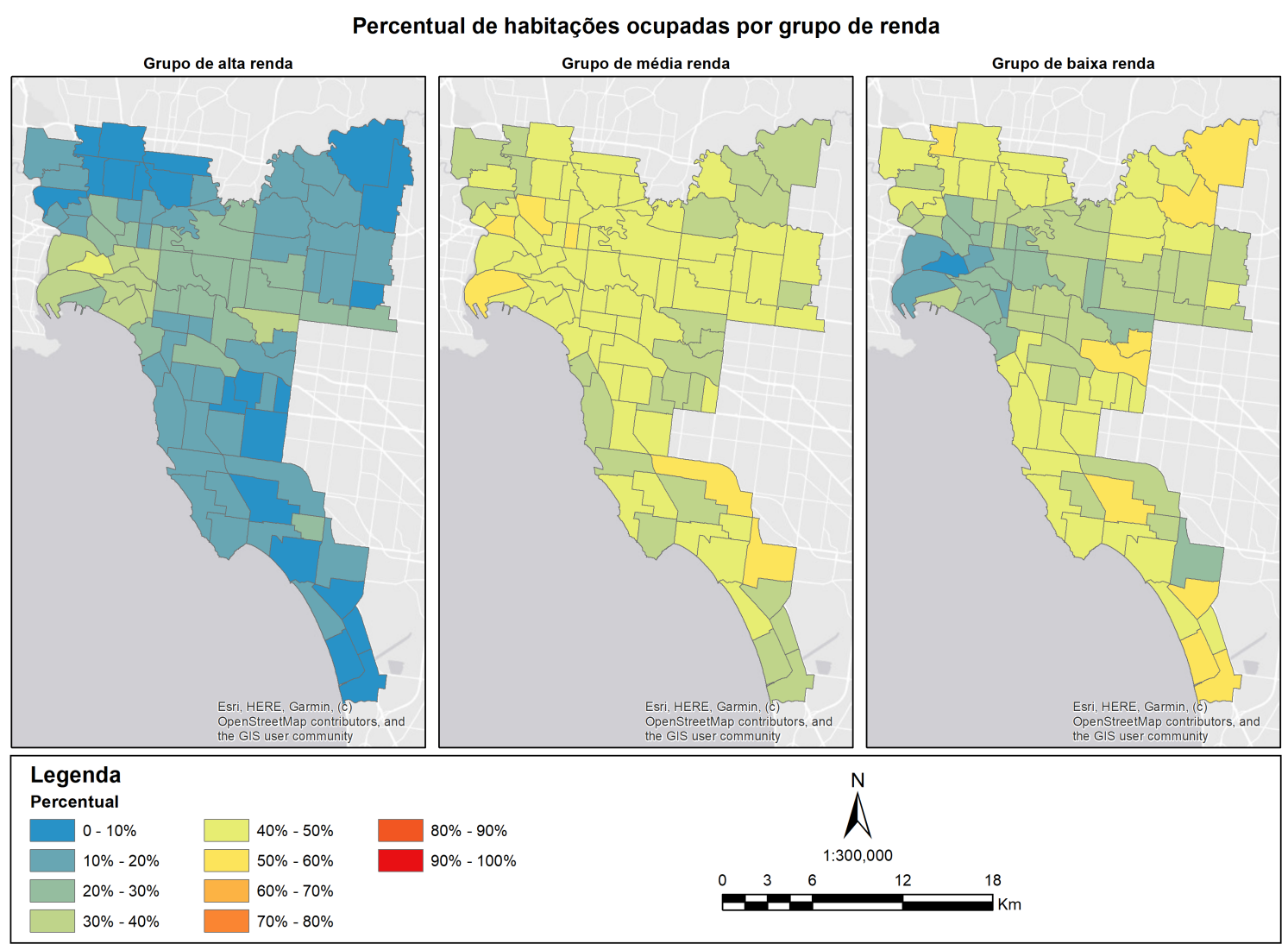

Figura 24 - Distribuição dos grupos sociais na zona central da região metropolitana de Melbourne.

grupo de média renda concentra a maior quantidade de pessoas em Melbourne, o grupo de renda predominante em Curitiba é o de baixa renda. Esse resultado reflete a comparação do nível de renda de uma população de um país desenvolvido com a de um país em desenvolvimento.

Da mesma forma que foi feito para Curitiba, foi aplicado um fator de simplificação de cem vezes o tamanho original da população para a criar os agentes de Melbourne. O fator de simplificação tem como objetivo reduzir o esforço computacional, pois o esforço seria muito alto se fossem realizadas simulações considerando o total de 947.858 pessoas como agentes. Como resultado, foram criados 9.233 agentes representando a população total com rendimento na zona central da região metropolitana de Melbourne.

O ambiente de simulação foi criado através de uma grade de células de $1 \mathrm{~km}^{2}$ cobrindo toda a área de interesse. O tamanho das células foi escolhido com base no esforço computacional para as simulações e por ser adequado para representar a área de interesse. No total o ambiente de simulação é composto por 480 células de $1 \mathrm{~km}^{2}$.

O processo de distribuição da população em cada uma das células foi realizado calculando a densidade populacional de cada um dos grupos de renda nas áreas estatísticas 
SA2 e interseccionando-as com a grade de células do ambiente de simulação. No caso de uma célula compartilhar mais de uma área estatística, a população foi atribuída considerando diferentes densidades populacionais.

A oferta de habitação de cada uma das células é representada pela quantidade de agentes existentes na situação observada, ou seja, a quantidade de habitantes de acordo com as áreas estatísticas SA2 provenientes do censo de 2016. Como forma de representar o estoque habitacional, foi reduzido em $2 \%$ a população total de agentes, como forma de representar habitações desocupadas e dar dinamismo ao processo de escolha residencial no modelo.

Os dados de emprego foram obtidos através do portal AURIN ${ }^{13}$, que disponibiliza os dados do censo 2015-2016 agregados por área estatística SA2 em formato shapefile. A Figura 25, mostra a distribuição espacial dos empregos por área estatística SA2 na zona central da região metropolitana de Melbourne. Da mesma forma que a distribuição da população e a oferta de habitação, a oferta de emprego foi atribuída para as células de $1 \mathrm{~km}^{2}$ interseccionando as células com as áreas estatísticas SA2.

Distribuição de Empregos por Área Estatística (SA2)

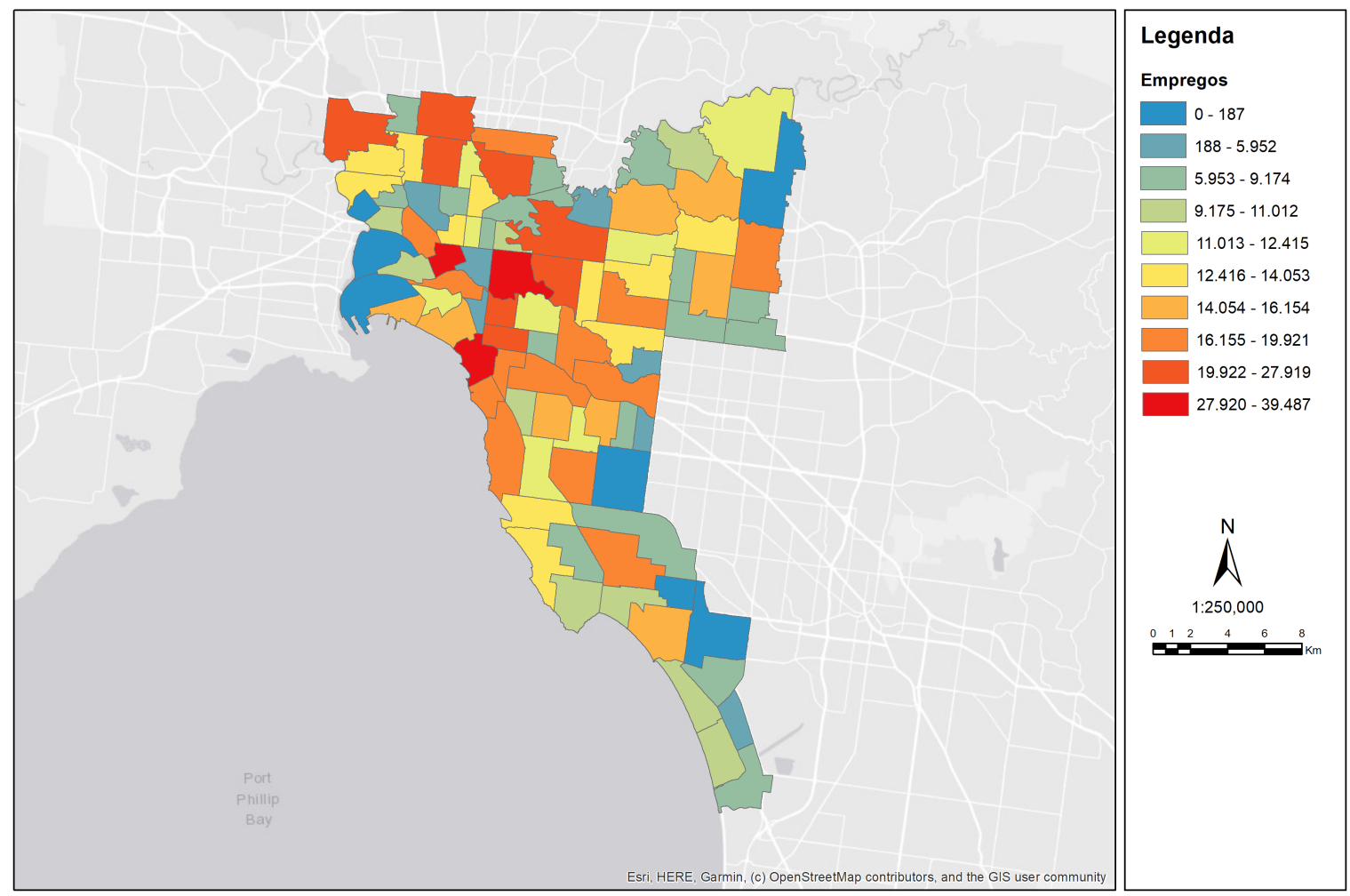

Figura 25 - Distribuição de empregos na zona central da região metropolitana de Melbourne.

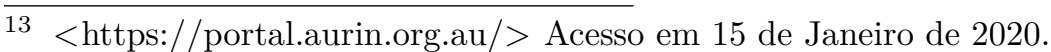


A oferta de habitações de interesse social foi extraída a partir dos dados de familias contempladas com habitações providas pelo governo ou aluguel social ${ }^{14}$. A base de dados agregada por áreas estatísticas SA2 foi criada pela University of New South Wales (UNSW) e disponibilizada em formato shapefile através do portal AURIN. Obtido o número total de famílias que recebem assistência social para moradia do governo, o número foi multiplicado por $2,7^{15}$, que representa a quantidade média de pessoas nas famílias da região metropolitana de Melbourne e, após isso, foi aplicado o parâmetro de simplificação de 100, que é o mesmo parâmetro aplicado para a criação dos agentes. A Figura 26 apresenta a distribuição das habitações de interesse social na zona central da região metropolitana de Melbourne.

Distribuição de Habitações de Interesse Social por Área Estatística (SA2)

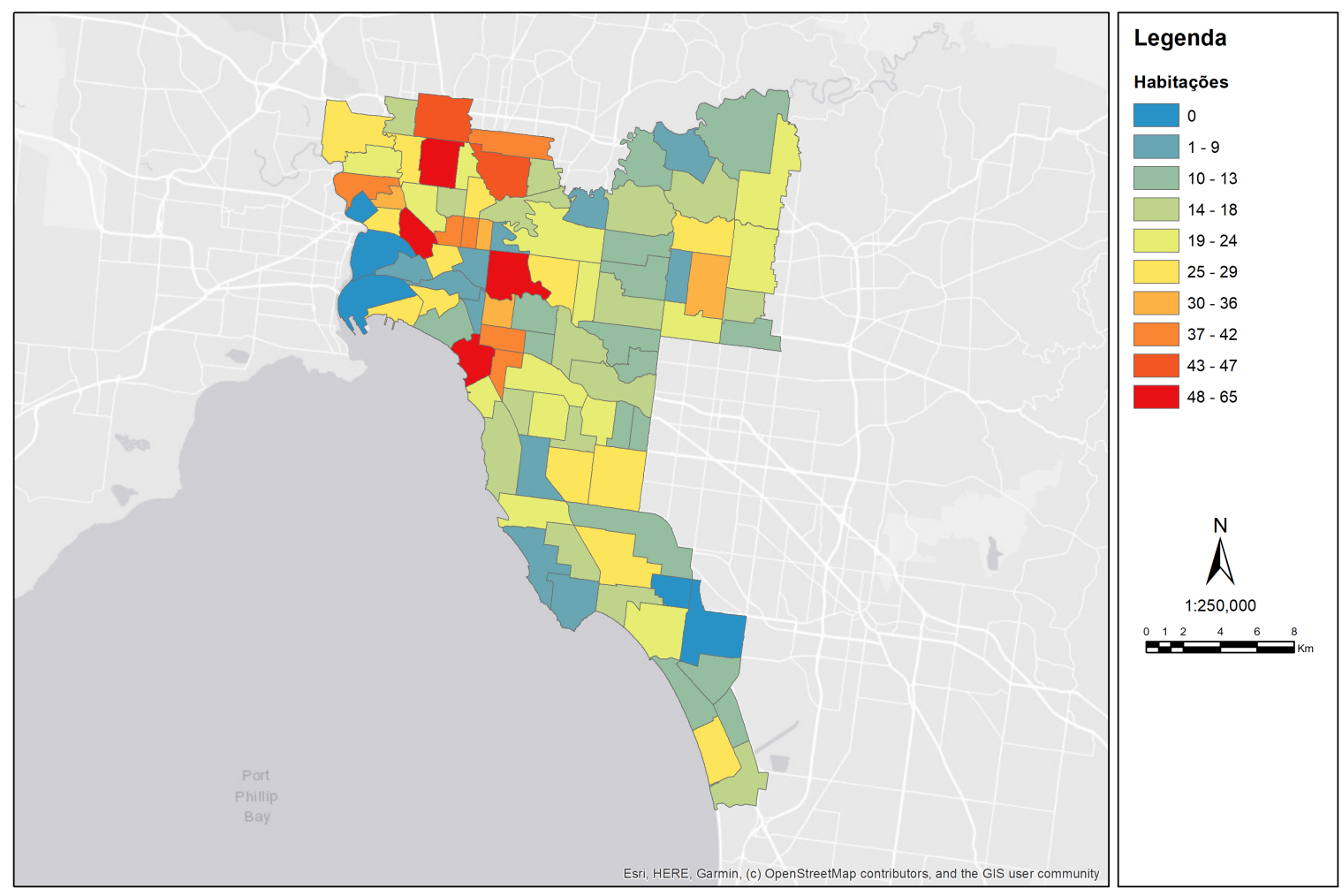

Figura 26 - Distribuição de habitações de interesse social na zona central da região metropolitana de Melbourne.

Da mesma forma que o modelo desenvolvido na seção 5.2, o presente modelo considera apenas o sistema de transporte público e o modo a pé para os cálculos da acessibilidade aos empregos. A acessibilidade aos empregos foi calculadas utilizando os arquivos GTFS disponibilizados pela Public Transport Victoria $\left(\mathrm{PTV}^{16}\right)$ e a base de dados

\footnotetext{
14 <https://citydata.be.unsw.edu.au/layers/geonode\%3AGovernmentAssistedHousing_2011> Acesso em 14 de Janeiro de 2020.

15 <https://quickstats.censusdata.abs.gov.au/census_services/getproduct/census/2016/quickstat/

2GMEL > Acesso em 05 de Janeiro de 2020.

$16<$ https://transitfeeds.com/p/ptv/497> Acesso em 15 de Janeiro de 2020.
} 
de arruamento disponibilizada pelo Open Street Map $\left(\mathrm{OSM}^{5}\right)$. Da mesma forma que foram obtidos os tempos de viagem para o município de São Paulo e Curitiba, utilizou-se a plataforma Open Trip Planner $\left(\mathrm{OTP}^{6}\right)$ para calcular os tempos de viagem em Melbourne. Foram extraídos os centróides das 91 áreas estatísticas SA2 de Melbourne e gerada uma matriz origem-destino com as viagens iniciando as 7 A.M. visando simular viagens motivo trabalho.

Através dos dados de emprego e tempos de viagem, foram calculadas as acessibilidades cumulativas (Eq.5.1) considerando 30 minutos de viagem para cada uma das áreas estatisticas da área de interesse. Foram considerados 30 minutos de viagem porque é a mediana dos tempos de viagem motivo trabalho encontrada na pesquisa origem-destino de Melbourne ${ }^{17}$. O modelo foi implementado no software NetLogo (WILENSKY, 1999).

\subsubsection{Calibração do modelo de Melbourne}

Da mesma forma que foi feita a calibração para São Paulo e Curitiba, a calibração do modelo de Melbourne foi realizada distribuindo aleatoriamente os agentes no ambiente de simulação e executando uma análise de sensibilidade. A análise de sensibilidade foi feita alterando o parâmetro $\alpha$ da função de utilidade, responsável por atribuir maior peso a acessibilidade aos empregos ou status da vizinhança, em intervalos de 0.1 para cada um dos grupos de renda, o que resultou em 1.331 combinações. Os resultados da análise de sensibilidade foram comparados com a distribuição residencial da situação observada, proveniente dos dados censitários de 2016, através da correlação de Pearson e através do algoritmo de similaridade de múltiplas janelas, conforme mostrado na seção 5.1.2.

Os parâmetros $\alpha$ que melhor representaram a situação observada na zona central da região metropolitana de Melbourne foram aqueles com a maior soma de correlações considerando os três grupos de renda. Os parâmetros que apresentaram os melhores resultados foram de 0,5 para o grupo de alta renda e 1 para o grupo de média renda. Como o grupo de baixa renda acaba ocupando as habitações de interesse social e as habitações que os grupos de alta e média renda não ocuparam, a parâmetro $\alpha$ do grupo de baixa renda varia bastante e acaba não apresentando um padrão. O parâmetro adotado para o grupo de baixa renda foi de 0,2 , pois corresponde ao valor para a simulação de maior correlação com a situação observada.

Os resultados da calibração do modelo de Melbourne indicam que os agentes pertencentes ao grupo de alta renda consideram o mesmo peso para a acessibilidade aos empregos e o status da vizinhança no processo de escolha residencial. O parâmetro $\alpha$ de

$\overline{17}$ <https://transport.vic.gov.au/about/data-and-research/vista> Acesso em 15 de Janeiro de 2020. 
0,5 para o grupo de alta renda faz com que os agentes se estabeleçam nas áreas de alta acessibilidade e segreguem-se dos demais agentes de média e baixa renda. Já o grupo de média renda prioriza somente a acessibilidade aos empregos, pois seu parâmetro $\alpha$ é 1. Os agentes de média renda buscam se estabelecer em habitações de alta acessibilidade aos empregos por transporte público. A correlação de Pearson encontrada foi de 0,50 para o grupo de alta renda, 0,55 para o grupo de média renda e de 0,62 para o grupo de baixa renda. O algoritmo de similaridade por múltiplas janelas resultou em uma similaridade mínima de 0,61 considerando uma janela móvel de 3x3.

\subsubsection{Resultados do modelo de Melbourne}

Adotando os parâmetros identificados no processo de calibração, o modelo permitiu simular a localização residencial dos 3 grupos de renda e a distribuição das acessibilidades aos empregos resultante (Figuras 27 e 28). Como pode ser visto na situação observada, tanto o grupo de alta renda quanto o grupo de média renda concentram-se na região oeste da área de interesse, enquanto o grupo de baixa renda se concentra nas demais regiões. Considerando os resultados da calibração, observamos que o grupo de alta renda se localiza entre a região central e a região oeste da zona central da região metropolitana de Melbourne. O grupo de média renda se concentra principalmente na região central, oeste e leste da área de interesse. O grupo de baixa renda se concentra nos extremos das regiões sul, noroeste e nordeste.

Em relação à distribuição das acessibilidades aos empregos por grupo de renda, pode ser observado que o modelo a reconstituíu de forma aproximada. A distribuição da acessibilidade aos empregos encontrado na situação observada mostra uma distribuição mais igualitária do que aquela encontrada como resultado da calibração.

Da mesma forma, o resultado da calibração resultou em uma curva de Lorenz e coeficiente Gini próximos dos encontrados na realidade. Apesar da proximidade da curva de Lorenz e do coeficiente Gini encontrados na situação observada e calibração, podemos observar que as medianas das acessibilidades aos empregos estão mais distantes entre si no resultado da calibração.

Apesar das altas correlações entre a situação observada e a simulação resultante do processo de calibração, o modelo não permitiu representar algumas áreas com predomínio de população de baixa renda nas proximidades do centro do município, região norte e nas imediações de bairros ricos. Observando a distribuição das acessibilidades por grupo de renda, nota-se que a dispersão das acessibilidades aos empregos da simulação resultante do processo de calibração é consideravelmente menor do que na situação observada. Isso 


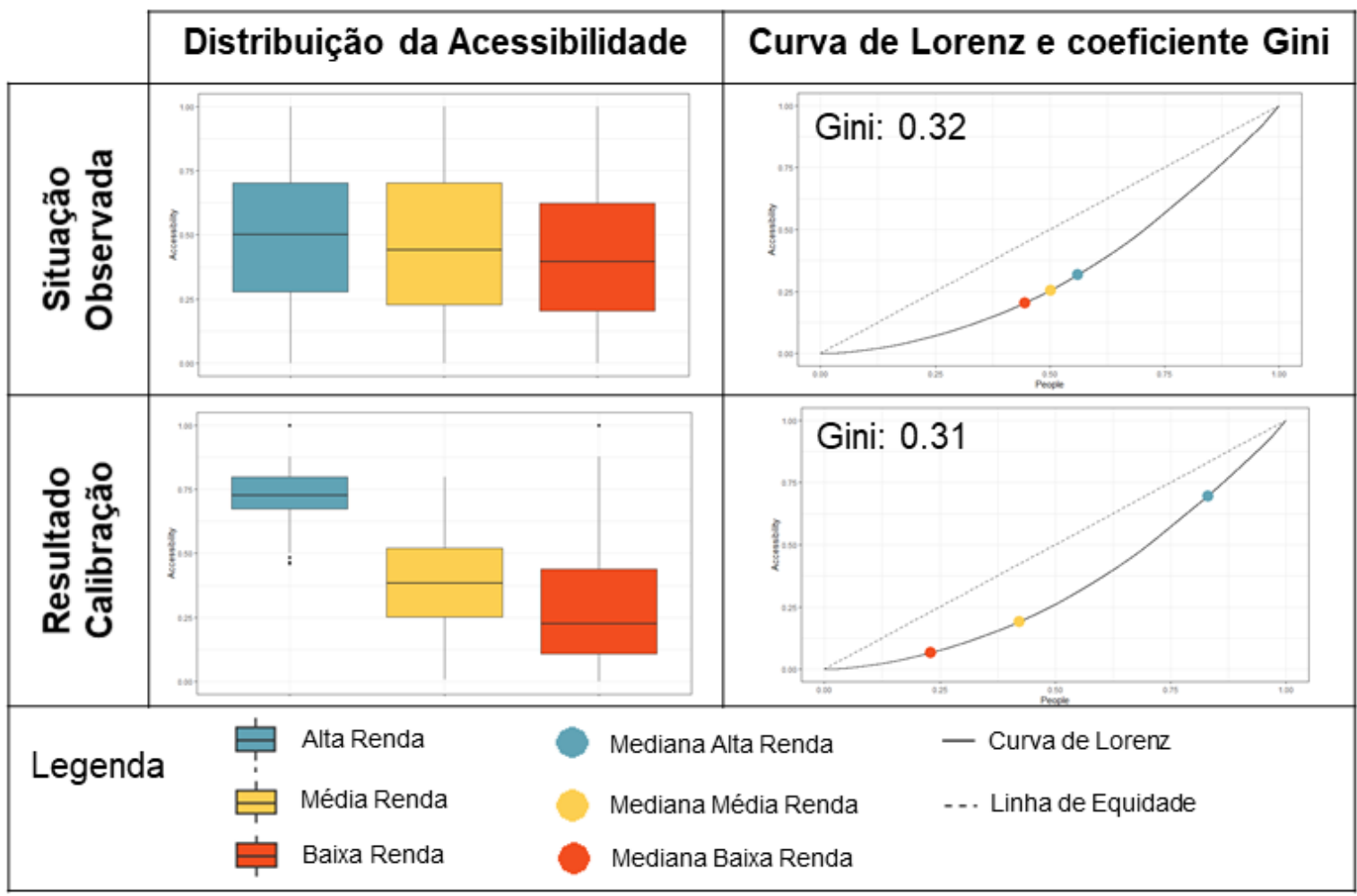

Figura 27 - Distribuição da acessibilidade aos empregos no modelo de Melbourne.

\begin{tabular}{|c|c|c|c|}
\hline & Grupo de Alta Renda & Grupo de Média Renda & Grupo de Baixa Renda \\
\hline 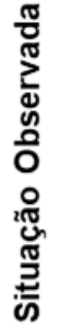 & \begin{tabular}{|l}
$\mathbb{E}_{300}^{400}$ \\
$\mathbb{E}_{200}^{300}$ \\
-250 \\
-200 \\
-150 \\
-100 \\
-100 \\
0
\end{tabular} & $\mathbb{E}_{500}$ & 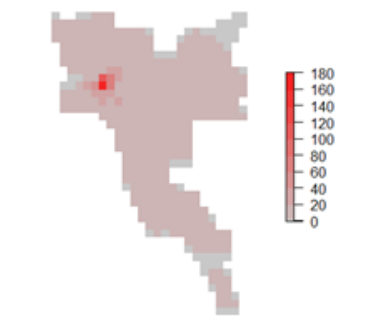 \\
\hline 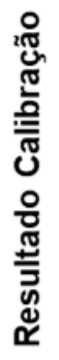 & 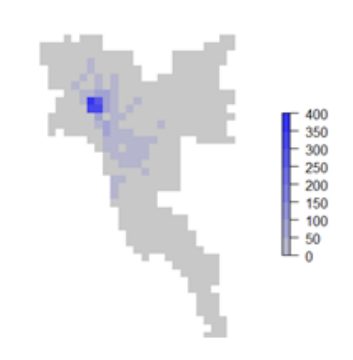 & 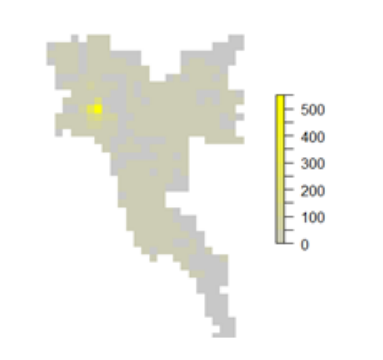 & 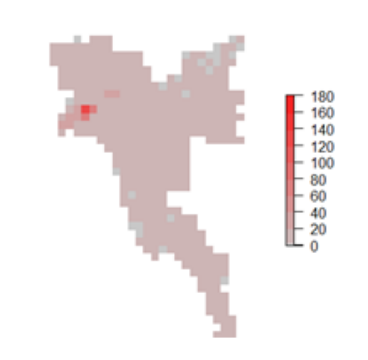 \\
\hline
\end{tabular}

Figura 28 - Distribuição dos grupos de renda em Melbourne.

se deve ao fato dos agentes na simulação precisarem se segregar mais do que na realidade para maximizarem a sua utilidade. Com isso, podemos observar que tanto as medianas da distribuição das acessibilidades quanto as medianas representadas nas curvas de Lorenz, estão mais distantes entre si do que as encontradas na situação observada. 


\subsubsection{Discussões e conclusões sobre o modelo de Melbourne}

O estudo de caso de Melbourne foi realizado com o objetivo de avaliar a robustez do modelo proposto em representar a realidade de uma região urbana localizada em um país desenvolvido. Como o objetivo é comparar uma área urbana no Brasil e outra em um país desenvolvido, a área selecionada da região metropolitana de Melbourne é compatível com o município de Curitiba em termos de área e número de habitantes.

Como esperado, a distribuição dos grupos de renda para Melbourne e Curitiba foram significativamente diferentes. Enquanto a população de Melbourne se enquadra majoritariamente no grupo de média renda (44\% da população), a população de Curitiba é majoritariamente pertencente ao grupo de baixa renda ( $50 \%$ da população). Além do grupo de média renda de Melbourne ser o grupo majoritário, o grupo de alta renda (27\% do total da população) também é proporcionalmente maior do que o de Curitiba (19\% do total da população). É importante ressaltar que não necessáriamente o grupo de alta renda de Melbourne e Curitiba apresentam rendimentos semelhantes, visto que o valor central de renda do cluster do grupo de alta renda de Melbourne é de AUD\$2.502,00 por semana, o que seria equivalente a aproximadamente $\operatorname{AUD} \$ 10.758,00$ por mês. Considerando que a média da cotação de $\operatorname{AUD} \$ 1,00$ para o ano de 2016, ano em que foram extraídos os dados de renda para o estudo de Melbourne, foi de aproximadamente $\mathrm{R} \$ 2,50$, obtemos um valor de aproximadamente $\mathrm{R} \$ 26.900,00$ por mês para o grupo de alta renda de Melbourne, o que é consideravelmente acima dos $\mathrm{R} \$ 5.342,00$ encontrados para o grupo de alta renda de Curitiba em 2010.

O estudo de caso de Melbourne também foi importante para avaliar efeitos geográficos específicos na capacidade do modelo em representar a localização residencial. Ao contrário de São Paulo e Curitiba, a região metropolitana de Melbourne se localiza na costa, sendo a baia de Port Phillip uma barreira natural que faz com que o centro de Melbourne não esteja localizado no centro geométrico da área de estudo. Essa configuração da área de estudo faz com que a acessibilidade aos empregos se distribuia de maneira distinta em relação a São Paulo e Curitiba.

O recorte selecionado da região metropolitana de Melbourne também permitiu investigar como o modelo se comporta quando o centro de negócios, onde se localizam grande parte dos empregos, não se localiza na região central da área de estudo. Como pode ser observado na Figura 25, a grande parte dos empregos se localizam na região oeste e noroeste da área de estudo.

Diferentemente do modelo de Curitiba, o modelo de Melbourne considerou o número total de famílias que recebem assistência social do governo para moradia, que foi modelado 
como habitações de interesse social. Conforme pode ser observado nas Figuras 25 e 26, existe um planejamento por parte do Estado para que as famílias que recebam assistência social para moradia se localizem perto das áreas com maior concentração de emprego.

Os resultados do modelo mostram que ele foi capaz de representar os principais padrões de localização residencial dos grupos de renda. O índice de Gini, curva de Lorenz e distribuição das acessibilidades aos empregos foram reconstituídos de forma aproximada.

Algumas limitações encontradas para o modelo podem estar relacionadas com particularidades da área de estudo. O fato de existirem políticas de habitação, que envolvem desde habitações de interesse social até o estímulo do mercado imobiliário para o grupo de alta renda no centro de negócios de Melbourne, fazem com que o modelo capte com menor acurácia a localização residencial dos grupos de renda. Além de políticas de habitação, o fato de apenas $9 \%$ das viagens na área metropolitana de Melbourne serem realizadas por transporte público, contra $72 \%$ através do transporte privado ${ }^{18}$, pode fazer com que as medidas de acessibilidade por transporte público não tenham a mesma importância como em Curitiba e São Paulo.

18 <https://transport.vic.gov.au/-/media/tfv-documents/vista/vista-2013-travel-in-metropolitan-melbourne-pdf. pdf $>$ Acesso em 18 de Abril de 2020. 


\section{Conclusões e Discussões}

O capítulo é dividido em três seções em que é apresentada uma síntese do trabalho (Seção 6.1), as conclusões, contribuições e limitações metodológicas (Seção 6.2) e sugestões para trabalhos futuros (Seção 6.3).

\subsection{Síntese do trabalho}

O presente trabalho teve como objetivo investigar os processos que levam às desigualdades de acessibilidade aos empregos considerando diferentes grupos sociais. Para investigar como são formadas as desigualdades, foi desenvolvido um modelo híbrido baseado em agentes e autômatos celulares. As variáveis utilizadas pelos agentes para maximizar a sua utilidade são acessibilidade aos empregos e status da vizinhança. Para avaliar a robustez do modelo, foram realizados quatro estudos de caso: um no município de São Paulo, que foi resultado do primeiro desenvolvimento completo do modelo ${ }^{1}$ e outros três estudos de caso. Os estudos de caso complementares ao modelo inicial foram propostos para testar a capacidade do modelo com a inclusão de dados empíricos com variação temporal e geográfica. Para a variação temporal foi explorado São Paulo comparando 2007 e 2017. Para a variação geográfica foram exploradas outras cidades de porte médio, em escala distinta da megacidade paulistana, sendo uma em mesmo contexto brasileiro, Curitiba, e outra em país desenvolvido, Melbourne.

O primeiro estudo de caso no município de São Paulo, mostrou as potencialidades do modelo para retratar a situação observada para o ano de 2007 utilizando dados socioocupacionais para estratificar a população. Além de permitir representar os macropadrões espaciais residenciais no município de São Paulo, foram simulados cenários com diferentes ofertas de empregos, transporte público e habitações de interesse social. A calibração do modelo revelou que a variável de status da vizinhança tem maior peso para os agentes do grupo de alto status do que para os agentes de outros grupos. O maior peso para a variável de status da vizinhança faz com que os agentes do grupo de alto status tendam a se concentrar, se isolando dos agentes dos demais grupos.

O segundo estudo de caso, no município de São Paulo, foi realizado para verificar se o modelo possui sensibilidade para captar alterações temporais. Para isso, foram utilizados 
os dados da pesquisa origem e destino do Metrô de 2007 e 2017 para gerar os agentes por grupo de renda e o ambiente de simulação com os atributos de oferta de habitação, empregos e transporte público. Foram encontradas diferentes distribuições de agentes por grupo de renda, que é resultado de alterações econômicas e demográficas no período de análise. O processo de calibração mostrou que, de 2007 para 2017, o grupo de alta renda passou a priorizar mais o status da vizinhança em detrimento à acessibilidade aos empregos. Já o grupo de média renda continuou considerando somente a acessibilidade aos empregos no processo de escolha residencial. Esses resultados mostram que o modelo foi capaz de captar uma pequena mudança na situação observada, que se traduziu em uma leve alteração nos parâmetros do modelo.

O estudo de caso de Curitiba foi realizado com o objetivo de testar como o modelo se adequaria a uma realidade distinta da de São Paulo e com uma área similar a zona central da região metropolitana de Melbourne. Da mesma forma que no estudo de caso anterior, os grupos foram estratificados de acordo com a renda e foi encontrada uma distribuição mais balanceada dos grupos de renda do que em São Paulo. A calibração do modelo de Curitiba mostrou que os agentes consideram pesos semelhantes aos de São Paulo no processo de escolha residencial. Os agentes do grupo de alta renda atribuem maior peso para o status da vizinhança do que a acessibilidade aos empregos e os agentes do grupo de média renda consideram mais importante a acessibilidade aos empregos.

O estudo de caso da zona central da região metropolitana de Melbourne teve como objetivo avaliar se o modelo permitiria representar uma área urbana localizada em um país desenvolvido e com área e população semelhantes ao município de Curitiba. A estratificação dos grupos de renda mostrou um cenário em que a maior parte da população se enquadra como grupo de média renda, o que é bastante distinto do que foi encontrado para Curitiba e São Paulo. Além da diferente distribuição dos grupos de renda, foram acrescentadas ao modelo habitações de interesse social de acordo com os dados de famílias contempladas com habitações providas pelo governo ou aluguel social. A calibração do modelo mostrou valores semelhantes aos encontrados para São Paulo e Curitiba, em que o grupo de alta renda considera o status da vizinhança mais importante do que a acessibilidade aos empregos, enquanto o grupo de média renda dá maior peso à acessibilidade aos empregos. O modelo de Melbourne foi o que apresentou menor correlação e similaridade espacial com a situação observada, mas permitiu representar os macropadrões espaciais de localização residencial. 


\subsection{Conclusões, contribuições e limitações metodológicas}

Conclui-se que a hipótese da pesquisa confirmou-se verdadeira, ou seja, que a redução das desigualdades de acessibilidade aos empregos depende da ação integrada de políticas de transporte e habitação. Os resultados dos estudos de caso mostraram que o modelo pode ser utilizado como uma ferramenta para apoio na tomada de decisão por permitir investigar potenciais impactos de políticas de públicas.

Embora simples, o modelo permitiu capturar os macropadrões espaciais de localização residencial para os grupos em análise em todos os estudos de caso. Algumas limitações do método devem ser discutidas. A representação de comunidades de baixa renda próximas a regiões de alta renda é uma delas. Para os estudos de caso de São Paulo e Curitiba essa limitação fica mais evidente, pois comunidades de baixa renda localizadas nas regiões centrais ou periféricas onde existem áreas de alta renda não foram captadas nas simulações dos modelos. Para retratar as comunidades de baixa renda, deveriam ser estudadas outras variáveis explicativas, porém a simplicidade do modelo, que considera apenas as variáveis de acessibilidade aos empregos e status da vizinhança, deve ser valorizada. A partir da inclusão de novas variáveis e pesos, a explicação do processo de escolha residencial se torna mais complexa, aumentando também a complexidade de comunicação e entendimento dos resultados.

Os estudos de caso permitiram observar que o modelo teve um comportamento diferente para Melbourne. O modelo de Melbourne foi o que apresentou menor correlação com a situação observada. Como pode ser observado na seção 5.4.1, Melbourne apresenta um planejamento territorial mais efetivo do que o encontrado nos município de São Paulo e Curitiba, evidenciado inclusive pela alta correlação entre oferta de empregos (Figura 25) e de habitações de interesse social (Figura 26). Como o modelo proposto não considera a influência de intervenções de planejamento urbano para além da oferta de habitações, transporte e emprego, não se espera que ele capte efeitos resultantes dessas intervenções na localização residencial. Trabalhos em desenvolvimento buscam alternativas em como incluir políticas de uso do solo como a revitalização em Melbourne de forma a ampliar a replicabilidade e adaptação do modelo a outros contextos.

O modelo proposto considera que existem diferentes prioridades na escolha residencial entre os agentes de acordo com seu grupo social. As prioridades na escolha residencial foram modeladas para retratar a diferença de poder financeiro e político entre os grupos sociais. Como o modelo retratou com maior fidedignidade a situação observada em São Paulo e Curitiba do que em Melbourne, questiona-se se as mesmas regras de prioridade se aplicam para estudos de caso em países desenvolvidos, que possuem menores desigualdades. 


\subsection{Sugestões para trabalhos futuros}

Como sugestões para trabalhos futuros, recomenda-se que sejam investigadas outras fontes de dados de entrada para o modelo, incluindo dados de fontes alternativas (por exemplo dados de redes sociais e dados imobiliários) e dados censitários e de pesquisas de origem e destino atualizados.

O modelo pode ser utilizado em projetos futuros para apoiar iniciativas que visem reduzir as desigualdades de acessibilidade aos empregos não só nas áreas já exploradas neste estudo, mas também em outras localidades. O modelo também pode ser empregado em iniciativas de geodesign para apoiar na tomada de decisão envolvendo localização residencial e desigualdades de acessibilidades.

Para trabalhos futuros, recomenda-se que seja investigado o processo de localização de empresas e que ele seja incluído como um submodelo. Ao adicionar o submodelo de localização de empresas, poderiam ser simuladas migrações de empregos de acordo com políticas públicas e a disputa entre os diferentes usos do solo. A inclusão desse submodelo também permitiria trabalhar com os dados de emprego de forma endógena ao modelo. 


\section{Referências}

ABS. Census QuickStats. 2016. Disponível em: < https://quickstats.censusdata.abs.gov. $\mathrm{au} /$ census_services/getproduct/census/2016/quickstat/2GMEL>.

ACHUTHAN, K.; TITHERIDGE, H.; MACKETT, R. L. Mapping accessibility differences for the whole journey and for socially excluded groups of people Mapping accessibility differences for the whole journey and for socially excluded groups of people. Journal of Maps, p. 220-229, 2010.

ALMEIDA, C. M. D. et al. GIS and remote sensing as tools for the simulation of urban land - use change. International Journal of Remote Sensing, v. 26, n. 4, p. 759-774, 2005.

ALONSO, W. Location and land use. Toward a general theory of land rent. [S.l.: s.n.], 1964 .

ANDRADE, N. de. Game Theory and Agent-Based Modelling for the Simulation of Spatial Phenomena. n. February, 2010. Disponível em: < http://urlib.net/8JMKD3MGP7W/ 38L4982>.

AXELROD, R. The complexity of cooperation: Agent-based models of competition and collaboration. [S.l.]: Princeton Univeersity Press, 1997.

AXELROD, R.; TESFATSION, L. Appendix A A Guide for Newcomers to Agent-Based Modeling in the Social Sciences. Handbook of Computational Economics, v. 2, n. Grant 0240852, p. 1647-1659, 2006. ISSN 15740021.

BABAKAN, A.; AlimohAmmADI, A. An Agent-Based Simulation of Residential Location Choice of Tenants in Tehran, Iran. Transactions in GIS, v. 20, n. 1, p. 101-125, 2 2016. ISSN 13611682. Disponível em: <http://doi.wiley.com/10.1111/tgis.12144>.

BABAKAN, A. S.; TALEAI, M. Impacts of transport development on residence choice of renter households: An agent-based evaluation. Habitat International, Elsevier Ltd, v. 49, p. 275-285, 2015. ISSN 01973975. Disponível em: <http: //dx.doi.org/10.1016/j.habitatint.2015.05.033>.

BARROS, J. Simulating Urban Dynamics in Latin American Cities. In: ATKINSON, P. et al. (Ed.). GeoDynamics. Boca Raton, FL: CRC Press, 2005. p. 313-328.

BARROS, J. Exploring urban dynamics in Latin American cities using an agent-based simulation approach. In: Agent-Based Models of Geographical Systems. Netherlands: Springer, 2012. p. 571-589.

BATTY, M. Accessibility: In Search of a Unified Theory. Environment and Planning B: Planning and Design, v. 36, n. 2, p. 191-194, 2009. ISSN 0265-8135.

BATTY, M. Urban modeling. International encyclopedia of human geography. Oxford: Elsevier, 2009. 
BEIGE, S.; AXHAUSEN, K. W. The dynamics of commuting over the life course: Swiss experiences. Transportation Research Part A: Policy and Practice, Elsevier Ltd, v. 104, p. 179-194, 2017. ISSN 09658564. Disponível em: < http: //dx.doi.org/10.1016/j.tra.2017.01.015>.

BENENSON, I. Agent-Based Modeling of Urban Residential Choice and Mobility. p. 67-95, 2004.

BENENSON, I.; OMER, I.; HATNA, E. Entity-based modeling of urban residential dynamics: The case of Yaffo, Tel Aviv. Environment and Planning B: Planning and Design, v. 29, n. 4, p. 491-512, 2002. ISSN 02658135.

BITTENCOURT, T. A. Transporte público urbano e desigualdades (em desenvolvimento). Tese (Doutorado) - Escola Politécnica - Universidade de São Paulo, 2020.

BLANCO, J. et al. Contested mobilities in the Latin American context. Journal of Transport Geography, v. 67, n. February, p. 73-75, 2018. ISSN 09666923.

BOERO, R.; SQUAZZONI, F. Does empirical embeddedness matter? Methodological issues on agent-based models for analytical social science. Jasss, v. 8, n. 4, p. 1-31, 2005. ISSN 14607425.

BONABEAU, E. Agent-based modeling: methods and techniques for simulating human systems. Proceedings of the National Academy of Sciences, v. 99, n. suppl. 3, p. 7280-7287, 2002. ISSN 0027-8424. Disponível em: < http://www.ncbi.nlm.nih.gov/ pubmed/12011407>.

BROWN, D. G. et al. Spatial process and data models: Toward integration of agent-based models and GIS. Journal of Geographical Systems, v. 7, n. 1, p. 25-47, 2005. ISSN 14355930 .

BROWN, D. G.; ROBINSON, D. T. Effects of heterogeneity in residential preferences on an agent-based model of urban sprawl. Ecology and Society, v. 11, n. 1, 2006. ISSN 17083087.

BURCHARDT, T.; GRAND, J. L.; PIACHAUD, D. Degrees of exclusion: developing a dynamic, multidimensional measure. [S.l.]: Oxford University Press, 2002.

CASS, N.; SHOVE, E.; URRY, J. Social exclusion, mobility and access. Sociological Review, v. 53, n. 3, p. 539-555, 2005. ISSN 00380261.

CASTLE, C. et al. Geocomputational methods and modeling. In: Geospatial Analysis: A comprehensive guide to principles, techniques and software tools. 6. ed. The Winchelsea Press, UK, 2018. cap. 8. Disponível em: < http://www.spatialanalysisonline.com/html/ index.html?geocomputational_methods_and_m.htm $>$.

CEBOLLADA, Mobility and labour market exclusion in the Barcelona Metropolitan Region. Elsevier Ltd, v. 17, p. 226-233, 2009.

CHURCH, A.; FROST, M.; SULLIVAN, K. Transport and social exclusion in London. Transport Policy, v. 7, n. 3, p. 195-205, 2000. ISSN 0967070X. 
CIOMMO, F. D. et al. Exploring the role of social capital influence variables on travel behaviour. Transportation Research Part A: Policy and Practice, Elsevier Ltd, v. 68, p. 4655, 2014. ISSN 09658564. Disponível em: < http://dx.doi.org/10.1016/j.tra.2014.08.018>.

COHEN, B. Urban growth in developing countries: A review of current trends and a caution regarding existing forecasts. World Development, v. 32, n. 1, p. 23-51, 2004. ISSN 0305750X.

CROOKS, A.; CASTLE, C.; BATTY, M. Key challenges in agent-based modelling for geo-spatial simulation. Computers, Environment and Urban Systems, Elsevier Ltd, v. 32, n. 6, p. 417-430, 2008. ISSN 01989715. Disponível em: <http://dx.doi.org/10.1016/j.compenvurbsys.2008.09.004>.

CURRIE, G. Quantifying spatial gaps in public transport supply based on social needs. Journal of Transport Geography, Elsevier Ltd, v. 18, n. 1, p. 31-41, 2010. ISSN 09666923. Disponível em: <http://dx.doi.org/10.1016/j.jtrangeo.2008.12.002>.

CURRIE, G.; DELBOSC, A. Modelling the social and psychological impacts of transport disadvantage. Transportation, v. 37, p. 953-966, 2010.

CURRIE, G.; DELBOSC, A. Exploring the trip chaining behaviour of public transport users in Melbourne. Transport Policy, Elsevier, v. 18, n. 1, p. 204-210, 2011. ISSN 0967070X. Disponível em: <http://dx.doi.org/10.1016/j.tranpol.2010.08.003>.

DALY, M.; SILVER, H. Social exclusion and social capital : A comparison and critique. p. $537-566,2008$.

DELMELLE, E. C.; CASAS, I. Evaluating the spatial equity of bus rapid transitbased accessibility patterns in a developing country: The case of Cali, Colombia. Transport Policy, Elsevier, v. 20, p. 36-46, 2012. ISSN 0967070X. Disponível em: $<$ http://dx.doi.org/10.1016/j.tranpol.2011.12.001>.

DfT. Guidance on Accessibility Planning in Local Transport Plans. London, 2005.

DIENER, E. Subjective well-being: The science of happiness and a proposal for a national index. American Psychologist, v. 55, n. 1, p. 34-43, 2000. ISSN 0003066X.

DONALDSON, R. Mass rapid rail development in South Africa' s metropolitan core : Towards a new urban form ? v. 23, p. 344-352, 2006.

EPSTEIN, J. M. Agent-based computational models and generative social science. Complexity, v. 4, n. 5, p. 41-60, 5 1999. ISSN 1076-2787. Disponível em: < http://doi.wiley.com/10.1002/\%28SICI\%291099-0526\%28199905/06\%294\%3A5\% 3C41\%3A\%3AAID-CPLX9\%3E3.0.CO\%3B2-F>.

ETTEMA, D. A multi-agent model of urban processes: Modelling relocation processes and price setting in housing markets. Computers, Environment and Urban Systems, Elsevier Ltd, v. 35, n. 1, p. 1-11, 2011. ISSN 01989715. Disponível em: <http://dx.doi.org/10.1016/j.compenvurbsys.2010.06.005>.

FEITOSA, F. F.; BAO, Q.; VLEK, P. L. G. Multi-agent simulator for urban segregation (MASUS): A tool to explore alternatives for promoting inclusive cities. Computers , Environment and Urban Systems, v. 35, p. 104-115, 2011. 
FOntAine, C. M.; ROUnSEVELL, M. D. A. An Agent-based approach to model future residential pressure on a regional landscape. Landscape Ecology, v. 24, n. 9, p. 1237-1254, 2009. ISSN 09212973.

FOX, H. World Bank urban transport strategy review - Mass Rapid Transit in Developing Countries. [S.l.], 2000. Disponível em: < http://www.worldbank.org/transport/utsr/ background_papers/uk_mass_transit_halcrow.pdf $>$.

FRAGONARD, B.; STROHL, H.; LEPRINCE, F. Cohésion sociale et prévention de l'exclusion: rapport de la comission. [S.l.], 1993.

FUJITA, M. Urban economic theory: land use and city size. [S.1.]: Cambridge university press, 1989.

GEURS, K. T.; WEE, B. van. Accessibility evaluation of land-use and transport strategies: review and research directions. Journal of Transport Geography, v. 12, n. 2, p. 127-140, 6 2004. ISSN 09666923. Disponível em: <https://doi.org/10.1016/j.jtrangeo.2003.10.005>.

GILBERT, N. Agent-based social simulation: dealing with complexity. p. 114, 2004. Disponível em: <http://www.agsm.edu.au/bobm/teaching/SimSS/ ABSS-dealingwithcomplexity-1-1.pdf $>$.

GINER, S.; ESPINOSA, E. L.; TORRES, C. Diccionario de sociología. [S.l.]: Alianza editorial, 1998.

GON, K. T.; ZEIGLER, B. P.; PRAEHOFER, H. Theory of modeling and simulation: integrating discrete event and continuous complex dynamic systems. [S.l.: s.n.], 2000.

GRIMM, V. et al. A standard protocol for describing individual-based and agent-based models. Ecological Modelling, v. 198, n. 1-2, p. 115-126, 2006. ISSN 03043800.

GUO, C.; BUCHMANN, C. M.; SCHWARZ, N. Linking urban sprawl and income segregation - Findings from a stylized agent-based model. Environment and Planning B: Urban Analytics and City Science, v. 46, n. 3, p. 469-489, 3 2019. ISSN 2399-8083. Disponível em: <https://doi.org/10.1177/2399808317719072>.

GUO, J. Y.; BHAT, C. R. Operationalizing the concept of neighborhood: Application to residential location choice analysis. Journal of Transport Geography, v. 15, n. 1, p. 31-45, 1 2007. ISSN 09666923. Disponível em: < https://linkinghub.elsevier.com/retrieve/pii/ S096669230500089X>.

HAGEN, A. Fuzzy set approach to assessing similarity of categorical maps. International Journal of Geographical Information Science, v. 17, n. 3, p. 235-249, 2003. ISSN 13658816.

HANSEN, W. G. Accessibility and Residential Growth. 1959.

HEPPENSTALL, A. J. J. et al. Agent-Based Models of Geographical Systems. [S.l.: s.n.], 2012. 1-759 p. ISSN 9789048189274 . ISBN 9789048189274.

HERNANDEZ, D. Uneven mobilities, uneven opportunities: Social distribution of public transport accessibility to jobs and education in Montevideo. Journal of Transport Geography, Elsevier, v. 67, n. August, p. 119-125, 2018. ISSN 09666923. Disponível em: <http://dx.doi.org/10.1016/j.jtrangeo.2017.08.017>. 
HERNANDEZ, D. O.; TITHERIDGE, H. Mobilities of the periphery: Informality, access and social exclusion in the urban fringe in Colombia. Journal of Transport Geography, Elsevier B.V., v. 55, p. 152-164, 2016. ISSN 09666923. Disponível em: $<$ http://dx.doi.org/10.1016/j.jtrangeo.2015.12.004>.

HODGSON, F. C.; TURNER, J. Participation not consumption: The need for new participatory practices to address transport and social exclusion. Transport Policy, v. 10, n. 4, p. 265-272, 2003. ISSN 0967070X.

IGLESIAS, C. A.; GARIJO, M.; GONZÁLEZ, J. C. A survey of agent-oriented methodologies. In: International Workshop on Agent Theories, Architectures, and Languages. Berlin, Heidelberg: Springer, 1998. p. 317-330.

INGRAM, D. R. The Concept of Accessibility : A Search for an Operational Form. Regional Studies, v. 5, n. 2, p. 101-107, 1971.

JARAMILlO, C.; LIZÁRRAGA, C.; GRINDLAY, A. L. Spatial disparity in transport social needs and public transport provision in Santiago de Cali (Colombia). Journal of Transport Geography, Elsevier Ltd, v. 24, p. 340-357, 2012. ISSN 09666923. Disponível em: $<$ http://dx.doi.org/10.1016/j.jtrangeo.2012.04.014>.

JORDAN, R.; BIRKIN, M.; EVANS, A. An agent-based model of residential mobility: Assessing the impacts of urban regeneration policy in the EASEL district. Computers, Environment and Urban Systems, v. 48, p. 49-63, 11 2014. ISSN 01989715. Disponível em: <https://linkinghub.elsevier.com/retrieve/pii/S0198971514000696>.

JUNIOR, A. A. R. Acessbilidade e mobilidade na estimativa de um índice de potencial de viagens utilizando redes neurais artificiais e sistemas de informações geográficas. Tese (Doutorado) — Escola de Engenharia de São Carlos, 2000.

KAMRUZZAMAN, M. et al. Measures of transport-related social exclusion: A critical review of the literature. Sustainability (Switzerland), v. 8, n. 7, p. 6-11, 2016. ISSN 20711050.

KELTON, W. D. Designing simulation experiments. In: Winter Simulation Conference Proceedings. Simulation-A Bridge to the Future. [S.l.: s.n.], 1999. p. 33-38.

KENYON, S.; LYONS, G.; RAFFERTY, J. Transport and social exclusion: Investigating the possibility of promoting inclusion through virtual mobility. Journal of Transport Geography, v. 10, n. 3, p. 207-219, 2002. ISSN 09666923.

KIM, J. H.; PAGLIARA, F.; PRESTON, J. The Intention to Move and Residential Location Choice Behaviour. Urban Studies, v. 42, n. 9, p. 1621-1636, 8 2005. ISSN 00420980. Disponível em: <http://journals.sagepub.com/doi/10.1080/00420980500185611>.

LEE, B. H. Y. et al. Reexamining the influence of work and nonwork accessibility on residential location choices with a microanalytic framework. Environment and Planning A, v. 42, n. 4, p. 913-930, 2010. ISSN 0308518X.

LEVITAS, R. et al. The Multi-dimensional Analysis of Social Exclusion. [S.l.], 2007.

LI, X.; LIU, X. Embedding sustainable development strategies in agent-based models for use as a planning tool. International Journal of Geographical Information Science, v. 22, n. 1, p. 21-45, 2008. ISSN 13658816. 
LIGMANN-ZIELINSKA, A.; JANKOWSKI, P. Agent-based models as laboratories for spatially explicit planning policies. Environment and Planning B: Planning and Design, v. 34, n. 2, p. 316-335, 2007. ISSN 02658135.

LITMAN, T. Evaluating Transportation Equity: Guidance for Incorporating Distributional Impacts in Transportation Planning. World Transport Policy \& Practice, v. 8, n. 2, p. 50-65, 2002. ISSN 01678116. Disponível em: <www.vtpi.org/equity.pdf >.

LOADER, C.; STANLEY, J. Growing bus patronage and addressing transport disadvantage-The Melbourne experience. Transport Policy, Elsevier, v. 16, n. 3, p. 106-114, 2009. ISSN 0967070X. Disponível em: <http://dx.doi.org/10.1016/j.tranpol.2009.02.001>.

LUCAS, K. Transport and social exclusion: Where are we now? Transport Policy, Elsevier, v. 20, p. 105-113, 2012. ISSN 0967070X. Disponível em: <http://dx.doi.org/10.1016/j.tranpol.2012.01.013>.

LUCAS, K.; GROSVENOR, T.; SIMPSON, R. Environment and equity concerns about transport. [S.l.], 2001.

LUCAS, K.; WEE, B. van; MAAT, K. A method to evaluate equitable accessibility: combining ethical theories and accessibility-based approaches. Transportation, Springer US, v. 43, n. 3, p. 473-490, 2016. ISSN 15729435. Disponível em: <http://dx.doi.org/10.1007/s11116-015-9585-2>.

MACAL, C. M.; NORTH, M. J. Tutorial on agent-based modelling and simulation. Journal of Simulation, v. 4, n. 3, p. 151-162, 2010. ISSN 17477778.

MACKETT, R. L.; ACHUTHAN, K.; TITHERIDGE, H. AMELIA : A tool to make transport policies more socially inclusive. Transport Policy, v. 15, n. 2008, p. 372-378, 2009.

MACY, M. W.; WILLER, R. From Factors to Factors: Computational Sociology and Agent-Based Modeling. Annual Review of Sociology, v. 28, n. 1, p. 143-166, 2002. ISSN 0360-0572.

MADANIPOUR, A.; CARS, G.; ALLEN, J. Social Exclusion in European Cities. [S.l.]: Jessica Kingsley, 1998.

MANSON, S. M. Validation and verification of multi-agent models for ecosystem management. Complexity and ecosystem managements : the theory and practice of multi-agent approaches., p. 63-74, 2003. ISSN 09218009. Disponível em: <http://hegis.umn.edu/pubs/Manson_2003_VandV_of_ABM.pdf $>$.

MARTÍNEZ, C. F. et al. Creating inequality in accessibility: The relationships between public transport and social housing policy in deprived areas of Santiago de Chile. Journal of Transport Geography, Elsevier, v. 67, n. July 2016, p. 102-109, 2018. ISSN 09666923. Disponível em: <http://dx.doi.org/10.1016/j.jtrangeo.2017.09.006>.

MEJIA-DORANTES, L.; LUCAS, K. Public transport investment and local regeneration: A comparison of London's Jubilee Line Extension and the Madrid Metrosur. Transport Policy, Elsevier, v. 35, p. 241-252, 2014. ISSN 0967070X. Disponível em: <http://dx.doi.org/10.1016/j.tranpol.2014.05.020>. 
METRÔ. Resultados finais da pesquisa origem e destino de 201\%. São Paulo, 2019. 134 p. Disponível em: <http://www.metro.sp.gov.br/pesquisa-od/arquivos/ EbookPesquisaOD2017_final_240719_versao_4.pdf $>$.

MIDGLEY, D.; MARKS, R.; KUNCHAMWAR, D. Building and assurance of agent-based models: An example and challenge to the field. Journal of Business Research, v. 60, n. 8, p. 884-893, 2007. ISSN 01482963.

MORENO-MONROY, A. I.; LOVELACE, R.; RAMOS, F. R. Public transport and school location impacts on educational inequalities: Insights from São Paulo. Journal of Transport Geography, Elsevier, v. 67, n. August 2017, p. 110-118, 2018. ISSN 09666923. Disponível em: <http://dx.doi.org/10.1016/j.jtrangeo.2017.08.012>.

NORTH, M. J.; MACAL, C. M. Managing business complexity: discovering strategic solutions with agent-based modeling and simulation. [S.l.]: Oxford University Press, 2007.

O'SUlLIVAN, D. Geographical information science: Agent-based models. Progress in Human Geography, v. 32, n. 4, p. 541-550, 2008. ISSN 03091325.

PÁEZ, A.; SCOTT, D. M.; MORENCY, C. Measuring accessibility: Positive and normative implementations of various accessibility indicators. Journal of Transport Geography, Elsevier Ltd, v. 25, p. 141-153, 2012. ISSN 09666923. Disponível em: $<$ http://dx.doi.org/10.1016/j.jtrangeo.2012.03.016>.

PAQUETTE, R. J.; ASHFORD, N. J.; WRIGHT, P. H. Transportation engineering; planning and design. [S.l.]: Ronald Press Co., 1972.

PEACE, R. SOCIAL EXCLUSION : A CONCEPT IN NEED OF DEFINITION ? n. 16, p. 17-36, 2001.

PEREIRA, R. H. et al. Distributional Effects of Transport Policies on Inequalities in Access to Opportunities in Rio De Janeiro. SSRN Electronic Journal, p. 1-39, 2017. ISSN 1556-5068. Disponível em: <https://www.ssrn.com/abstract=3040844>.

PRESTON, J.; RAJÉ, F. Accessibility, mobility and transport-related social exclusion. Journal of Transport Geography, v. 15, n. 3, p. 151-160, 2007. ISSN 09666923.

REVINGTON, N. Gentrification, transit, and land use: Moving beyond neoclassical theory. Geography Compass, v. 9, n. 3, p. 152-163, 2015. ISSN 17498198.

SANTOS, B. M. dos. As ZEIS e o acesso à cidade: o impacto das ZEIS na desigualdade da habitação por promoção privada em São Paulo (Mestrado). [S.l.: s.n.], 2020.

SCHELLING, T. C. Micromotives and Macrobehavior. New York: WW Norton, 1978.

SCHÖNFELDER, S.; AXHAUSEN, K. W. Activity spaces: Measures of social exclusion? Transport Policy, v. 10, n. 4, p. 273-286, 2003. ISSN 0967070X.

SENER, I. N.; PENDYALA, R. M.; BHAT, C. R. Accommodating spatial correlation across choice alternatives in discrete choice models: An application to modeling residential location choice behavior. Journal of Transport Geography, Elsevier Ltd, v. 19, n. 2, p. 294-303, 2011. ISSN 09666923. Disponível em: <http://dx.doi.org/10.1016/j.jtrangeo.2010.03.013>. 
SHAW, S. L.; XIN, X. Integrated land use and transportation interaction: A temporal GIS exploratory data analysis approach. Journal of Transport Geography, v. 11, n. 2, p. 103-115, 2003. ISSN 09666923.

SINCLAIR, R. Von Thünen and Urban Sprawl. p. 72-87, 1967.

SKLAR, E. Software Review: NetLogo , a Multi-agent Simulation Environment. Artificial life, v. 13, p. 303-311, 2007. ISSN 10645462.

SMITH, N. The new urban frontier: Gentrification and the revanchism city. [S.l.]: Psychology press, 1996.

Social Exclusion Unit. Preventing Social Exclusion: Cabinet Office London. [S.l.], 2001.

Social Exclusion Unit. Making the Connections: Final report on Transport and Social Exclusion. London, 2003.

SONDAHL, F.; TISUE, S.; WILENSKY, U. Breeding faster turtles: progress towards a Netlogo compiler. Proceedings of the Agent Directed Simulation Symposium, 2006.

STANLEY, J.; LUCAS, K. Social exclusion: What can public transport offer? Research in Transportation Economics, v. 22, n. 1, p. 36-40, 2008. ISSN 07398859.

STANLEY, J. K. J. R. J. K. J. R. et al. Mobility, social exclusion and wellbeing: Exploring the links. Transportation Research Part A: Policy and Practice, Elsevier Ltd, v. 45, n. 8, p. 789-801, 2011. ISSN 09658564. Disponível em: <http://dx.doi.org/10.1016/j.tra.2011.06.007>.

TESFATSION, L. Website on validation of ACE. 2007. Disponível em: < http: //www2.econ.iastate.edu/tesfatsi/empvalid.htm $>$.

THIELE, J. C.; GRIMM, V. NetLogo meets R: Linking agent-based models with a toolbox for their analysis. Environmental Modelling and Software, Elsevier Ltd, v. 25, n. 8, p. 972-974, 2010. ISSN 13648152. Disponível em: < http: //dx.doi.org/10.1016/j.envsoft.2010.02.008>.

THIELE, J. C.; KURTH, W.; GRIMM, V. Facilitating Parameter Estimation and Sensitivity Analysis of Agent-Based Models: A Cookbook Using NetLogo and R. Journal of Artificial Societies and Social Simulation, v. 17, n. 2014, 2014.

TRaC. Social Exclusion and the Provision of Public Transport. London, 2000.

VASCONCELLOS, E. A. de. Transport metabolism, social diversity and equity: The case of São Paulo, Brazil. Journal of Transport Geography, v. 13, n. 4, p. 329-339, 2005. ISSN 09666923.

VICKERMAN, R. W. Accessibility, Attraction, and Potential: A Review of Some Concepts and Their Use in Determining Mobility. Environment and Planning A: Economy and Space, v. 6, n. 6, p. 675-691, 1974. ISSN 0308-518X.

WACHS, M.; KUMAGAI, T. G. Physical Accessibility As a Social Indicator. Plan. Sci, v. 7, p. 437-456, 1973. Disponível em: <https: //ac-els-cdn-com.libproxy.uncg.edu/0038012173900414/1-s2.0-0038012173900414-main. pdf?_tid=05389158-5ea3-4176-b54e-d23dc8356b3b\&acdnat $=1552158770$ d362c43e1fda06201335c2d23dd7f27a> . 
WADDELL, P. UrbanSim: Modeling Urban Development for Land Use, Transportation, and Environmental Planning. Journal of the American Planning Association, v. 68, n. 3, p. 297-314, 9 2002. ISSN 0194-4363. Disponível em: < https: //doi.org/10.1080/01944360208976274>.

WADDELL, P. et al. Incorporating land use in metropolitan transportation planning. Transportation Research Part A: Policy and Practice, v. 41, n. 5, p. 382-410, 6 2007. ISSN 09658564. Disponível em: < https://linkinghub.elsevier.com/retrieve/pii/ S0965856406001170>.

WALKER, A.; WALKER, C. Britain divided: The growth of social exclusion in the $1980 \mathrm{~s}$ and 1990s. [S.l.]: Cpag London, 1997.

WEE, B. van; GEURS, K. T. Discussing equity and social exclusion in accessibility evaluations. European Journal of Transport and Infrastructure Research, v. 11, n. 4, p. 350-367, 2011. ISSN 1567-7141.

WELCH, T. F. Equity in transport: The distribution of transit access and connectivity among affordable housing units. Transport Policy, Elsevier, v. 30, p. 283-293, 2013. ISSN 0967070X. Disponível em: <http://dx.doi.org/10.1016/j.tranpol.2013.09.020>.

WERKER, C.; BRENNER, T. Empirical calibration of simulation models. 2004.

WILENSKY, U. Netlogo. Evanston, IL: [s.n.], 1999. Disponível em: < http: //ccl.northwestern.edu/netlogo $>$.

WILENSKY, U. Modeling nature's emergent patterns with multi-agent languages. Proceedings of EuroLogo, p. 1-16, 2001. Disponível em: <http://ccl.sesp.northwestern. edu/papers/2013/mnep9.pdf $>$.

WINDRUM, P.; FAGIOLO, G.; MONETA, A. Empirical validation of agent-based models: Alternatives and prospects. Jasss, v. 10, n. 2, 2007. ISSN 14607425.

WINGO, L. Transportation and Urban Land (Resources for the Future Inc., Washington, DC). 1961.

WISE, S.; CROOKS, A.; BATTY, M. Agent Based Modelling of Urban Systems. In: AL., M. N.-R. e. (Ed.). 1st Workshop on Agent based Modelling of Urban Systems (ABMUS 2016). Springer International Publishing AG, 2017. LNAI 10051, n. January, p. 129-148. ISBN 9783-319-51956-2. Disponível em: <http://link.springer.com/10.1007/978-3-319-51957-9>.

XIA, J. et al. A multi-dimensional view of transport-related social exclusion: A comparative study of Greater Perth and Sydney. Transportation Research Part A: Policy and Practice, Elsevier Ltd, v. 94, p. 205-221, 2016. ISSN 09658564. Disponível em: <http://dx.doi.org/10.1016/j.tra.2016.09.009>.

XIANG, X.; KENNEDY, R.; MADEY, G. Verification and Validation of Agent-based Scientific Simulation Models. Agent-Directed Simulation Conference, p. 47-55, 2005. Disponível em: <http://www.nd.edu/ nom/Papers/ADS019_Xiang.pdf > .

ZHOU, B. B.; KOCKELMAN, K. M. Microsimulation of Residential Land Development and Household Location Choices: Bidding for Land in Austin, Texas. Transportation Research Record: Journal of the Transportation Research Board, v. 2077, n. 1, p. 106-112, 12008. ISSN 0361-1981. Disponível em: <http://journals.sagepub.com/doi/10.3141/2077-14>. 
ZHUGE, C. et al. Agent-based joint model of residential location choice and real estate price for land use and transport model. Computers, Environment and Urban Systems, Elsevier Ltd, v. 57, p. 93-105, 2016. ISSN 01989715. Disponível em: <http://dx.doi.org/10.1016/j.compenvurbsys.2016.02.001>.

ZONDAG, B.; PIETERS, M. Influence of Accessibility on Residential Location Choice. Transportation Research Record: Journal of the Transportation Research Board, v. 1902, n. 1902, p. 63-70, 2005. ISSN 0361-1981. 


\section{A Protocolo ODD}

O protocolo ODD (Overview, Design Concepts and Details) tem como objetivo descrever modelos baseados em agentes e modelos baseados em indivíduos (GRIMM et al., 2006). O protocolo ODD é formado por 7 elementos que podem ser agrupados em 3 blocos (Tabela 3).

\begin{tabular}{|l|l|}
\hline Visão Geral & Propósito \\
& Variáveis de estado e escalas \\
& Visão de processo e escalonamento \\
\hline Conceitos do projeto & Conceitos do projeto \\
\hline Detalhes & $\begin{array}{l}\text { Inicialização } \\
\text { Entrada } \\
\end{array}$ \\
\hline
\end{tabular}

Tabela 3 - Estrutura do protocolo ODD (GRIMM et al., 2006).

\section{A.1 Propósito}

O propósito do modelo é investigar os processos de desigualdades de acessibilidade aos empregos dos diferentes grupos sociais. A partir da investigação, o modelo permitirá avaliar impactos potenciais de políticas públicas em transporte, habitação e emprego nas desigualdades de acessibilidade.

\section{A.2 Variáveis de estado e escalas}

As variáveis dos agentes e das células do ambiente de simulação são apresentadas nas Tabelas 4 e 5. Para os agentes, a escala de simplificação é de 100 ou 200 indivíduos por agente (a depender da área de estudo). As células do ambiente de simulação apresentam área de $1 \mathrm{Km}^{2}$ e a sua quantidade varia de acordo com a área de estudo. 


\begin{tabular}{|l|l|}
\hline Nome da Variável & Descrição \\
\hline Grupo social & O grupo social do agente (alto, médio ou baixo status). \\
\hline Modo de transporte & $\begin{array}{l}\text { Modo de transporte do agente (transporte público ou } \\
\text { transporte privado). }\end{array}$ \\
\hline Utilidade & Utilidade do agente (dado pela Eq.4.1). \\
\hline
\end{tabular}

Tabela 4 - Nome e descrição das variáveis dos agentes.

\begin{tabular}{|l|l|}
\hline Nome da Variável & Descrição \\
\hline Habitações & Número de habitações. \\
\hline $\begin{array}{l}\text { Habitações de interesse so- } \\
\text { cial }\end{array}$ & $\begin{array}{l}\text { Número de habitações de interesse social (exclusivas para } \\
\text { o grupo social de baixo status). }\end{array}$ \\
\hline Empregos & Número de empregos. \\
\hline $\begin{array}{l}\text { Acessibilidade aos empregos } \\
\text { pelo modo de transporte pú- } \\
\text { blico }\end{array}$ & $\begin{array}{l}\text { Número de empregos acessíveis no limite de tempo de } \\
\text { viagem estipulado por transporte público. }\end{array}$ \\
\hline $\begin{array}{l}\text { Acessibilidade aos empregos } \\
\text { pelo modo de transporte pri- } \\
\text { vado }\end{array}$ & $\begin{array}{l}\text { Número de empregos acessíveis no limite de tempo de } \\
\text { viagem estipulado por transporte privado. }\end{array}$ \\
\hline
\end{tabular}

Tabela 5 - Nome e descrição das variáveis das células do ambiente de simulação.

\section{A.3 Visão de processo e escalonamento}

A visão geral dos processos do modelo e o seu escalonamento são apresentados no diagrama da Figura 29.

\section{Seleção de Habitação}

No processo de seleção de habitação, os agentes insatisfeitos buscam por habitações em novas células. O percentual de agentes insatisfeitos é especificado na inicialização do modelo. A busca por novas habitações se dá de forma aleatória e contempla como opções qualquer uma das células do ambiente de simulação.

\section{Cálculo da Utilidade}

No processo de cálculo da utilidade, é comparada a utilidade original do agente (em sua célula de origem) com a nova utilidade do agente na célula selecionada aleatoriamente. 


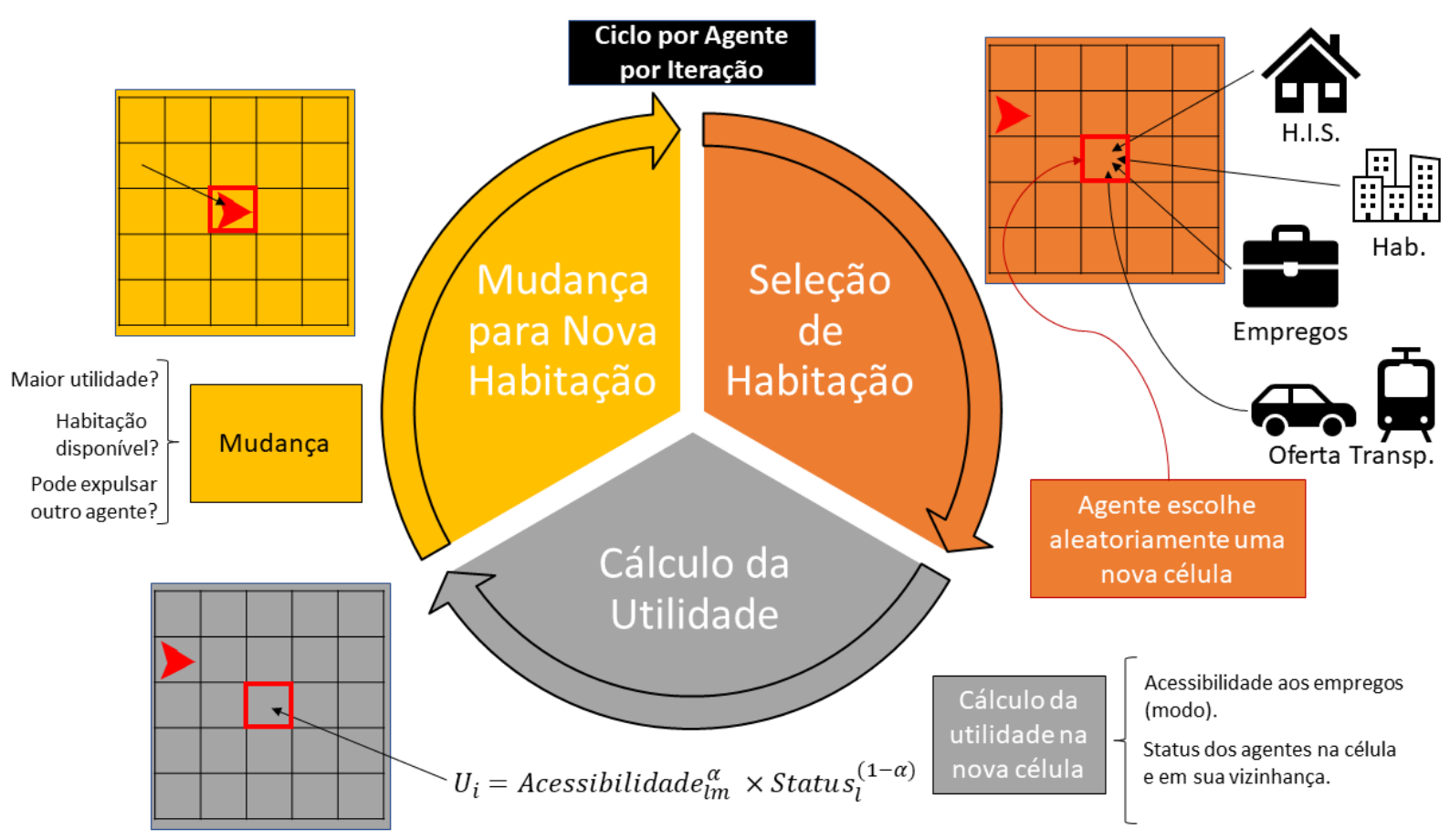

Figura 29 - Visão geral dos processos do modelo.

Para o cálculo da utilidade na nova célula, são considerados os atributos de acessibilidade aos empregos (que varia de acordo com o modo de transporte do agente) e de status da vizinhança Eq.(4.1), que são atributos associados as célula do ambiente de simulação.

\section{Mudança para Nova Habitação}

No processo de mudança para nova habitação, o agente se comporta da seguinte forma:

- O agente avalia se a sua utilidade é maior na nova célula ou na célula original.

- Se a utilidade na nova célula for menor, o agente permanece na célula original.

- Se a utilidade na nova célula for maior, o agente verifica se existe alguma habitação disponível.

- Se houver uma habitação disponível, o agente se move para a habitação da nova célula.

- Se não houver uma habitação disponível, o agente verifica se há algum outro agente com menor prioridade do que a sua (agentes de status alto podem expulsar agentes de status médio ou baixo e agentes de status médio pode expulsar agentes de status baixo). 
- Se o agente encontrar outro agente de menor prioridade na nova célula, ele o expulsa e se muda para a habitação na nova célula.

- Se o agente não encontrar outro agente de menor prioridade na nova célula, o agente retorna para sua célula original.

\section{A.4 Conceitos do projeto}

\section{Emergência}

O modelo foi criado para explorar a emergência dos padrões de acessibilidade aos empregos por grupos sociais. Os padrões de acessibilidade aos empregos emergem como consequência das interações entre os agentes e as células do ambiente de simulação.

\section{Objetivos}

Em um nível individual, os agentes possuem como objetivo maximizar as suas utilidades. Para isso, os agentes se mudam para novas habitações em células aleatoriamente selecionadas do ambiente de simulação. A utilidade final é obtida quando os agentes maximizam suas utilidades e, por isso, param de se movimentar.

\section{Interação}

As interações entre os agentes ocorrem na disputa por habitações e nas análises de vizinhança. Na disputa por habitações, agentes podem expulsar outros, serem expulsos, ou serem inibidos de se mudar pela presença de outros. Nas análises de vizinhança, os agentes contabilizam a presença de outros agentes de grupos sociais distintos para compor a sua utilidade em uma célula específica.

\section{Coletivos}

Os agentes são agrupados em 3 grupos sociais (alto, médio e baixo status). Cada grupo social apresenta uma prioridade de alocação, sendo o grupo de alto status o que apresenta maior prioridade, seguido pelos grupos de médio e baixo status. Os agentes de baixo status podem se alocar em habitações exclusivas, que são as habitações de interesse social.

\section{Observação}

As observações incluem gráficos contendo Curvas de Lorenz das acessibilidades aos 
empregos, histogramas da distribuição das acessibilidades aos empregos e o índice Gini, que indica a desigualdade de acessibilidade aos empregos considerando os grupos sociais analisados. Os resultados também são obtidos exportando um arquivo em formato texto contendo o identificador de cada um dos agentes, suas acessibilidades aos empregos, status da vizinhança, utilidades e células alocadas.

\section{A.5 Inicialização}

$\mathrm{Na}$ inicialização do modelo, são criadas as células do ambiente de simulação, definidos o nível de insatisfação dos agentes e a estratégia de comparação de utilidade, criados os agentes e alocados aleatoriamente no ambiente de simulação.

As células do ambiente de simulação são criadas através dos dados de entrada. Os atributos de habitação, habitação de interesse social, empregos e acessibilidades aos empregos são criados de maneira exógena ao modelo e variam de acordo com o cenário a ser simulado.

O nível de insatisfação dos agentes é um parâmetro utilizado para tornar o processo de realocação dos agentes mais ou menos acentuado na simulação. O parâmetro varia de 0 a 100 e define o percentual de agentes que buscarão novas moradias. O nível de insatisfação é atribuído aleatoriamente aos agentes na inicialização do modelo. Atribuída a insatisfação aos agentes, são selecionados os agentes com insatisfação maior ou igual ao parâmetro adotado na simulação para que eles busquem novas habitações.

A estratégia de comparação de utilidade é usada para definir se os agentes compararão suas utilidades com agentes do mesmo ou diferentes grupos sociais. De acordo com o parâmetro adotado, os agentes se tornam mais ou menos exigentes em relação ao local de moradia. Por exemplo, a estratégia de comparação de utilidade entre diferentes grupos diminui o nível de exigência dos agentes do grupo 1 (alto status), pois suas utilidades são comparadas as dos agentes dos grupos 2 (médio status) e 3 (baixo status). Para agentes do grupo social 3, o efeito é inverso, pois sua utilidade é comparada com o todos os demais agentes, incluindo aqueles com maior prioridade que, consequentemente, possuem maior utilidade. Por outro lado, quando a estratégia de comparação de utilidade é entre agentes do mesmo grupo social, o grupo social 1 se torna mais exigente, pois suas utilidades são comparadas com agentes do mesmo grupo, que possuem a mais alta prioridade de realocação. Pelo mesmo motivo, agentes do grupo social 3 se tornam menos exigentes.

Em seguida são criados os agentes. O número de agentes na simulação e a pro- 
porção por grupo social são definidos com base na caracterização socio-ocupacional ou socioeconômica da área de estudo e no fator de simplificação adotado (no estudo de caso de São Paulo foi adotado um fator de simplificação de 200, ou seja, um agente representa 200 indivíduos). A proporção de viagens com motivo de trabalho foi definida através de dados da pesquisa origem e destino e atribuída aos agentes de acordo com o grupo social. Os agentes são alocados aleatoriamente no ambiente de simulação.

\section{A.6 Entradas}

As entradas do modelo são formadas por dois arquivos. O primeiro arquivo (em formato .asc) contém as células do ambiente de simulação e seus identificadores únicos. O segundo arquivo (em formato texto) contém os atributos das variáveis das células do ambiente de simulação (habitações, habitações de interesse social, empregos, acessibilidade aos empregos por transporte público e privado). O arquivo contendo os atributos das variáveis das células de simulação se relacionam com as células através do identificador único.

Os atributos de habitação e empregos foram atribuídos as células do ambiente de simulação interseccionando-as com as zonas de tráfego (São Paulo), com os setores censitários (Curitiba) ou com as áreas estatísticas (Melbourne). Através da densidade de habitantes e de empregos de cada zona de tráfego, setor censitário ou área estatística, foram atribuídos os números totais de habitações e empregos em cada célula. O atributo de habitação de interesse social é atribuído manualmente as células de interesse.

Os atributos de acessibilidade aos empregos por transporte público foram calculados utilizando os centróides das células de $1 \mathrm{Km}^{2}$ como pontos de origem e de destino para gerar as matrizes de tempo de viagem através do Open Trip Planner (OTP). Os atributos de acessibilidade por transporte privado (apenas para o estudo de caso de São Paulo) foram calculados utilizando uma matriz de tempos de viagem por subzona de tráfego. Calculados os tempos de viagem, foi utilizada a acessibilidade cumulativa (Eq. 5.1) para calcular o número de empregos acessiveis por transporte público e transporte privado a partir de cada célula do ambiente de simulação. 


\section{A.7 Submodelos}

Submodelo ambiente: O submodelo ambiente é composto por uma grade de células com três atributos constantes representando o uso do solo: emprego, habitação e oferta de transporte. Os atributos de oferta de empregos e de transporte são utilizados no cálculo da acessibilidade por transporte público e privado, que se mantêm constantes ao longo da simulação. A oferta de habitação é utilizada no cálculo do status da vizinhança, que é dinâmico, pois é influenciado diretamente pela alocação dos agentes.

A acessibilidade aos empregos é um componente exógeno ao modelo, sendo o usuário livre para escolher a medida que melhor caracteriza a área de interesse.

O status da vizinhança é um componente endógeno ao modelo, representando a atratividade da célula com base na localização residencial dos agentes de cada grupo social. Cada agente possui um atributo de status que varia de 1 a 3 , de acordo com seu grupo social. O status da vizinhança de uma célula é calculado a partir da média dos status dos agentes alocados na célula e em sua vizinhança de Moore ${ }^{1}$.

Tanto a acessibilidade aos empregos quanto o status da vizinhança são normalizados para o cálculo da utilidade dos agentes.

Submodelo Trabalhadores: O submodelo trabalhadores foi criado para simular a dinâmica de localização da população trabalhadora. O submodelo é estratificado em níveis micro e macro.

No nível micro, temos os agentes com seus atributos e o algoritmo de escolha residencial. Os agentes são caracterizados por três atributos: grupo social; modo de transporte; e utilidade.

O atributo de grupo social é utilizado para definir o grupo social do agente. O grupo social 1 representa o grupo de alto status, o grupo 2 de médio status e o grupo 3 de baixo status. O modelo foi concebido para representar diferentes realidades considerando as bases de dados disponíveis, logo, variáveis de renda ou demais variáveis podem ser utilizadas como proxy para os grupos sociais.

Os grupos sociais são diferenciadas de acordo com suas prioridades no processo de escolha residencial. Conforme proposto por Guo, Buchmann e Schwarz (2019), a prioridade é modelada para representar o poder político e financeiro dos grupos sociais mais altos em transformar e ocupar locais de acordo com seus interesses. Agentes do grupo social 1 têm

\footnotetext{
1 A vizinhança de Moore é formada pela célula de referência e suas oito células vizinhas.
} 
prioridade sobre agentes do grupo social 2 e 3, enquanto agentes do grupo social 2 têm prioridade sobre agentes do grupo social 3.

O atributo de modo de transporte é usado para definir se o agente utilizará transporte público ou privado. O atributo de modo de transporte é designado de acordo com a divisão modal de cada grupo social. Uma vez designado, o agente considerará a acessibilidade aos empregos correspondentes ao modo de transporte para o cálculo da acessibilidade.

O objetivo de cada agente é maximizar sua função de utilidade, que leva em consideração a acessibilidade aos empregos e o status da vizinhança. O parâmetro de acessibilidade aos empregos foi inspirado no trabalho clássico de Fujita (1989) em escolha residencial, em que uma família leva em consideração três variáveis: acessibilidade, espaço e ambiente. O parâmetro de status da vizinhança é baseado no trabalho pioneiro de Schelling (1978) e trabalhos mais recentes de Benenson, Omer e Hatna (2002), Barros (2005) e Feitosa, Bao e Vlek (2011) sobre segregação residencial e a relevância da composição populacional em processos de escolha residencial.

Este trabalho adotou a função de utilidade (Eq.(A.1)), que considera a literatura supramencionada e procura capturar os conceitos mais importantes em uma função simples:

$$
U_{i}=\text { acessibilidade }_{l m}^{\alpha} \times \operatorname{status}_{l}^{(1-\alpha)}
$$

Na Eq.(A.1), $U_{i}$ é a utilidade do indivíduo $i$, acessibilidade é a acessibilidade aos empregos normalizada da célula $l$ onde o agente se localiza e de acordo com o seu modo de transporte $m$, status é o status da vizinhança normalizado na célula $l$ e $\alpha$ é o peso dado aos parâmetros. O conjunto de alternativas dos indivíduos é formado pelo número de residências, que varia de acordo com a área de estudo.

O parâmetro de peso $(\alpha)$, é utilizado para ponderar a acessibilidade aos empregos e o status da vizinhança na função de utilidade. O parâmetro $\alpha$ varia entre 0 e 1 , sendo que 0 representa peso total para o status da vizinhança e 1 peso total para acessibilidade aos empregos. Através do parâmetro $\alpha$, é possível simular diferentes comportamentos dos agentes e, dessa forma, calibrar o modelo para diferentes realidades.

No nível micro está o algoritmo de localização residencial. O algoritmo seleciona uma célula aleatória e avalia se a utilidade do agente aumentará na nova célula. Uma vez encontrada uma célula com maior utilidade, é avaliado se existe disponibilidade de habitação. Se sim, o agente se move para a nova célula deixando a sua célula anterior com 
uma habitação vaga. Caso seja identificada uma célula de maior utilidade, porém sem habitação disponível, é avaliado se existe algum agente com menor prioridade para ser expulso.

O agente expulso realiza uma escolha aleatória no ambiente para se realocar em uma célula de maior utilidade. Se não houver células de maior utilidade, o agente será alocado em uma célula com utilidade igual ou menor que a sua célula anterior, desde que haja disponibilidade de habitação.

No algoritmo de localização residencial, o nivel de insatisfação dos agentes e a estratégia de comparação das utilidades são configuradas (inicialização do modelo). Ambos os parâmetros são intrinsecamente relacionados ao dinamismo do modelo e foram inspirados pela satisfação individual e geral de Guo, Buchmann e Schwarz (2019).

No nível macro está a população, que apresenta atributos sociodemográficos como a população total, proporção de agentes em cada grupo social e prioridades de realocação. Através desses atributos, os agentes são criados para representar características sociodemográficas específicas da área de interesse.

Definidos os parâmetros e atributos, inicia-se a etapa de processamento. Na etapa de processamento, ocorrem as buscas aleatórias dos agentes insatisfeitos por habitações em novas células. A ordem dos agentes para as buscas de novas habitações é aleatória e o modelo completa uma iteração quando todos os agentes insatisfeitos da simulação fazem a busca por novas habitações. São realizadas diversas iterações ao longo das simulação até que as utilidades dos agentes sejam maximizadas e eles não consigam mais se mover para habitações com maior utilidade. Quando os agentes não conseguem mais se realocar, a acessibilidade aos empregos por grupo social é analisada.

A Figura 3 mostra o procedimento do modelo, incluíndo: (1) os dados de entrada e configurações dos agentes e ambiente; (2) A inicialização das células e agentes, com seu nível de insatisfação, estratégia de comparação de utilidade e alocação inicial aleatória dos agentes; (3) o procedimento de simulação; e (4) as saídas das simulações. 